Historic, Archive Document

Do not assume content reflects current scientific knowledge, policies, or practices. 



\title{
A STUDY OF THE BIOLOGY AND TAXONOMY OF GENUS BRUCHIDIUS (COLEOPTERA : BRUCHIDAE) FROM INDIA
}

\section{FINAL TECHNICAL REPORT (1974-1979)}

\author{
G. L. ARORA \\ Principal Investigator
}

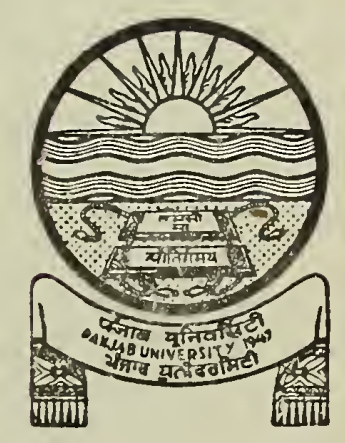

U. S. PL. 480 Research Project A7-ENT-103 DEPARTMENT OF ZOOLOGY

Panjab University, Chandigarh 
Arst Boolplene
(I-61)

\section{NATIONAL}

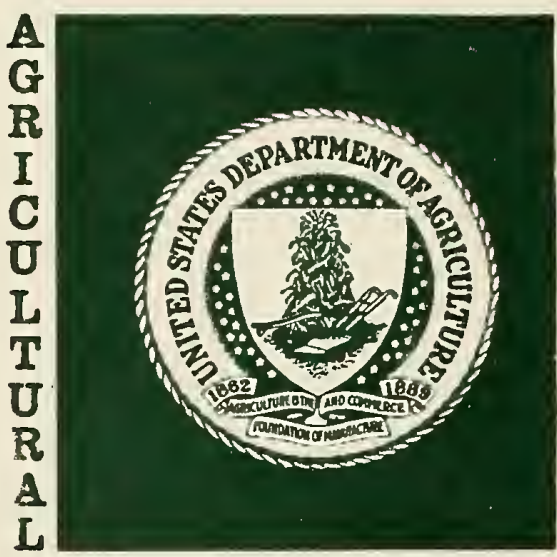

LIBRARY

USDA National Agricultural Librem

NAL Building

10301 Baltimore Blvd.

Beltsville, MD 20705.2351 


\title{
A STUDY OF THE BIOLOGY AND TAXONOMY OF GENUS BRUCHIDIUS (COLEOPTERA : BRUCHIDAE) FROM INDIA
}

\section{FINAL TECHNICAL REPORT (1974-1979)}

\author{
G. L. ARORA \\ Principal Investigator
}
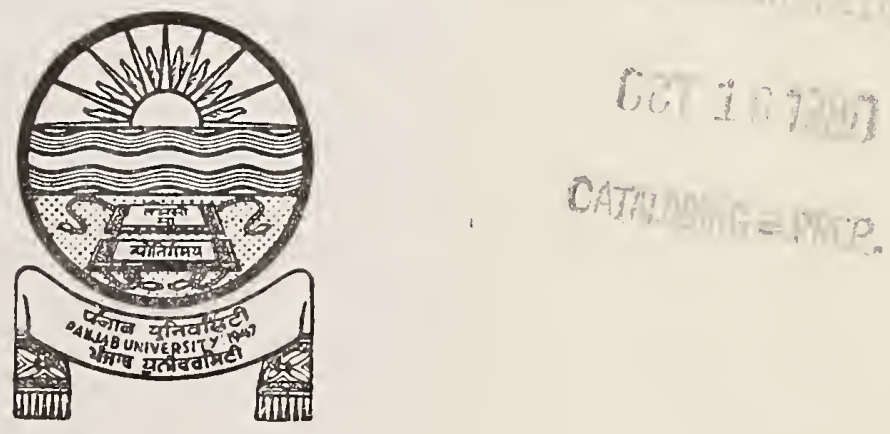

USDA, National Agricultural Library NAL Blidg 10301 Baltimore Blvd Beltsville, MD 20705-2351

U. S. PL. 480 Research Project A7-ENT-103 DEPARTMENT OF ZOOLOGY

Panjab University, Chandigarh

Price : Rs. 80 



\section{FINAL TECHNICAL REPORT}

(1974-1979)

Project Title :

Name of Principal Investigator :

Name and address of reporting Institution:

Grant No. :

Project No. :
"A study of the Biology and Taxonomy of Genus Bruchidius (Coleoptera: Bruchidae) from India”.

Prof. (Dr.) G. L. Arora

Department of Zoology, Panjab University Chandigarh-160014, India.

FG-IN-499

A7-ENT-103 


\section{CONTENTS}

\section{PAGE}

SUMMARY

DETAILED REPORT

. 1

.. 2

\section{INTRODUCTION}

.. 2

List of species, host plants \& localities Table I

. 2

Table II showing Sexual Dimorphism in species

.. 5

INCIDENCE AND DISTRIBUTION

.. 8

Table III showing incidence and distribution of species of Bruchidius

.. 9

Map showing distribution of New species of Bruchidius

. 11

TAXONOMY

. 12

Family Bruchidae

. 12

Sub-family Bruchinae

. 12

Genus Bruchidius

.. 12

KEY TO SPECIES OF BRUCHIDIUS

. 12

Additional information about already known species of Bruchidius

.. 17

Detailed description of New Species of Genus Bruchidius

.. 20

BIOLOGY OF SOME SPECIES OF BRUCHIDIUS

.. 63

Biology \& Life-history of B. pygomaculatus Arora

.. 63

Biology \& Life-history of $B$. mimosae Arora

. 69

Biology \& Life-history of $B$. angustifrons Schilsky

. 71

Biology \& Life-history of $B$. tephrosiae Arora

. . 74

Table showing comparative Biology

.. 78

DISCUSSION AND CONCLUSIONS

.. 82

ACKNOWLEDGMENTS

. 82

PHOTOS I-XXI

.. 83

REFERENCES

.. 95

PUBLICATIONS

.. 96 


\section{SUMMARY}

Forty-four species of the genus Bruchidius have so far been collected from the different States in India during the period from May 1, 1974 to September 30, 1979 that the present project was in progress. Of these there are 21 species which appear to be new whereas the remaining 23 species have already been described.

A list with the names of the species, their host-plants and the localities from where they have been collected is given, indicating the host-plant specificity and the transitional host-plants. A table showing Sexual Dimorphism in the species is appended.

The Incidence and Distribution of the species in the different States of India show their populations to be dense, medium or rare based on their numbers. A map of India showing the incidence and distribution of the new species of Bruchidius is included.

Information in regard to Additional host-plants and Additionallocalities is added only in the cases of already known species, whereas detailed descriptions are given in the cases of new species. A new key to the species of Bruchidius has been prepared.

The biology and life-histories of 4 common species of Bruchidius viz. B. pygomaculotus Arora, B. mimosae Arora, B. angustifrons Schilsky and B. tephrosiae Arora have been dealt with in detail, followed by a Table showing their comparative biology. 


\section{DETAILED REPORT}

\section{INTRODUCTION}

The genus Bruchidius Schilsky, which belongs to the family Bruchidae of the Order Coleoptera, forms a group of seed feeding beetles including a large number of dissimilar species, many of which are neither properly identified nor adequately described in India due to a paucity of relevent literature. These bruchids attack and destroy the seeds and pods of some wild forest plants, and the edible, medicinal and ornamental legumes. They are also responsible to a degree and contribute to the suppression of the growth and multiplication of the noxious weedy plants with the seeds of which they are associated. The economic importance of these bruchids, thus, needs to be fully explored. A detailed investigation of the species from India will surely provide a basis for a revisional study covering a greater part of the Old World Bruchidae. The results of t'a tıxononic rejearches including the collection, incidence and identification of species together with their host-plants, and the biological studies involving the behaviour of some common species of the group during their life-histories and the association of some with the seeds and pods of the noxious weedy plants will contribute a valuable agricultural information for the benefit of workers in India and the U.S. which can profitably be used in devising adequate control measures for the pests as well as the weeds associated with our crops.

As many as forty-four species of Bruchidius have been collected from the various States of India during the period from May 1, 1974 to September, 1979 of which 21 species appear to be new. The following Table I shows the list of species along with their host-plants and the localities from where they have been collected:-

Table I
S. No. Name of species
Host plants
Localities

\section{Bruchidius obscurus Arora Capris decidua (Foresk) (leaves) \& grass}

2. B. vulgaris Arora
3. B. compositus Arora
4. B. minutus $(\mathrm{F})$
5. B. aureus Arora

Tagetes petula (Flowers), Eschscholtzia californica (flowers), Shorea robusta Gaerin (leaves), Alisycarpus monilifer (weed), Lantana indica (flowers).
Lauraea nudicaulis (Flowers)
Acacia modesta Wall
Albizzia lebbek Benth

Uttar Pradesh; Chandigarh; Himachal Pradesh; Jammu \& Kashmir; Rajasthan; Goa and Karnatka.

Chandigarh, Uttar Pradesh, Bihar, Orissa, Andhra Pradesh, Karnatka, Goa \& Maharasthra; Punjab, Haryana, Assam, Tamil Nadu, West Bengal, Himachal Pradesh, Jammu \& Kashmir, Sikkim, Manipur, Rajasthan, Gujarat, Madhya Pradesh.

Chandigarh.

Chandigarh; Madhya Pradesh: Rajasthan, Gujarat, Maharashtra.

Chandigarh, Himachal Pradesh, Uttar Pradesh; Punjab, Haryana, Bihar, West Bengal, Maharashtra, Karnatka, Kerala, Rajasthan \& Tamil Nadu. 
S. No. Name of species

6. B. albizziae Arora

\section{Bruchidius pygomaculatus Arora}

8. B. multilineolatus Arora

9. B. saundersi (Jek)

10. B. sahlbergi Schilsky

11. B. mimosae Arora

12. Bruchidius urbanus (Sharp)

13. B. tephrosiae Arora

14. B. flavovirens Arora

15. B. cassiae Arora

16. B. dimorphous Arora

17. B. maculipygus (Champ.)

18. B. lineolatus Arora
Host plants

Albizzia lebbek Benth Albizzia procera (Roxb) Benth Acacia catechu Willd.

Albizzia lebbek Benth Albizzia procera (Roxb) Benth Acacia modesta Wall Acacia catechu Willd

Albizzia lebbek Benth

Albizzia lebbek Benth Albizzia sp.

Acacia farnesiana Willd.

Mimosa rubicaulis Lamk.
Localities

Chandigarh, Punjab; Jammu \& Kashmir, Uttar Pradesh, Rajasthan; Haryana, Andhra Pradesh.

Chandigarh, Punjab, Haryana, Himachal Pradesh, Jammu \& Kashmir, Uttar Pradesh, Rajasthan, Maharashtra, Orissa, Karnatka, Tamil Nadu; Bihar, Andhra Pradesh; Gujarat, Madhya Pradesh \& Kerala.

Chandigarh, Punjab, Bihar, Tamil Nadu; Himachal Pradesh, Uttar Pradesh, West Bengal, Maharashtra, Karnatka; Haryana \& Madhya Pradesh.

Chandigarh, Punjab, Haryana, Himachal Pradesh; Uttar Pradesh, Karnatka; Rajasthan, Bihar, West Bengal and Tamil Nadu.

Chandigarh, Manipur; Haryana and Uttar Pradesh.

Chandigarh, Uttar Pradesh, Bihar, Karnatka; Himachal Pradesh, Orissa; Punjab.

Albizzia procera (Roxb) Benth Himachal Pradesh; Assam, West Bengal, Andhra Pradesh.

Tephrosia purpurea (Linn) Pers.

Chandigarh, Jammu \& Kashmir, Uttar Pradesh, West Bengal, Orissa, Andhra Pradesh, Tamil Nadu, Kerala, Karnatka, Maharashtra, Madhya Pradesh, Gujarat, Rajasthan, Punjab, Haryana, Goa; Himachal Pradesh, Bihar and Assam.

Albizzia procera (Roxb) Benth. Himachal Pradesh; Uttar Pradesh, Bihar, Assam, West Bengal \& Rajasthan.

Cassia tora L.

Himachal Pradesh, Uttar Pradesh, West Bengal; Jammu \& Kashmir, Assam, Manipur; Punjab, Sikkim, Nagaland, Andhra Pradesh, Maharashtra.

Acacia pennata Willd.

Himachal Pradesh; Uttar Pradesh, Karnatka.

Himachal Pradesh, Maharashtra; Uttar Pradesh, Karnatka; Bihar and Tamil Nadu.

Albizzia procera (Roxb) Benth Himachal Pradesh. 
S. No. Name of species

Host plants

Localities

19. B. angustifrons Szhilsky Sesbania sesban (L.)

20. B. nigricans Arora

not known

21. B. solanensis Arora

Albizzia sp.

22. B. andrewesi (Pic.)

23. B. schilskyi Arora

24. B. orientale sp. nov.

Ref. No. 52

25. B. blemeris sp. nov.

(Ref. No. 54)

Acacia auriculiformis Cunn.

Albizzia lebbek Benth

Acacia modesta Wall.

Acacia catechu Willd.

Grass

Grass

26. B. endotubercularis

sp. nov. (Ref. No. 55)

27. B. variegata sp. nov.

(Ref. No. 56)

28. B. mathaii sp. nov.

(Ref. No. 57)

29. B. amarae sp. nov.

(Ref. No. 58)

30. B. bangalorensis sp. nov. Acacia sp.

(Ref. No. 59)

31. B. eupatoricus sp. nov.

(Ref. No. 60)

grass \& Eupatorium sp.

(flowers)

32. B. brunnetashii sp. nov. grass \& Wild (flowers)

(Ref. No. 61)

33. B. siwalikus $\mathrm{sp}$. nov.

(Ref. No. 62)

Grass

Albizzia sp.

Albizzia sp.

Albizzia sp.

Albizzia amara

Chandigarh; Delhi, Rajasthan, Maharashtra, Tamil Nadu, Uttar Pradesh, Assam, West Bengal, Gujarat and Andhra Pradesh.

Chandigarh.

Himachal Pradesh.

Haryana; Uttar Pradesh and Rajasthan. Uttar Pradesh: Punjab.

Chandigarh, Himachal Pradesh, Assam, Manipur.

Uttar Pradesh, Andhra Pradesh, Chandigarh, Punjab, Jammu \& Kashmir, Himachal Pradesh, Sikkim, West Bengal \& Rajasthan.

Karnatka, Tamil Nadu.

Karnatka.

Kerala.

Karnatka \& Kerala.

Karnatka.

Gujarat, Maharashtra, Karnatka.

Tamil Nadu.

Maharashtra; Himachal Pradesh, Uttar Pradesh, Gujarat, Madhya Pradesh. Bihar \& Orissa.

Orissa.

Desmodium pulchellum Benth Orissa; Himachal Pradesh; Tamil Nadu.

35. B. desmodei sp. nov. (Rsf. No. 64)

36. B. dorsivalvia sp. nov. Grass (Ref. No.65)

37. B. punctoterminalis sp. nov. Grass (Ref. No. 66)

Maharashtra; Andhra Pradesh, West Bengal \& Bihar.

Jammu \& Kashmir. 


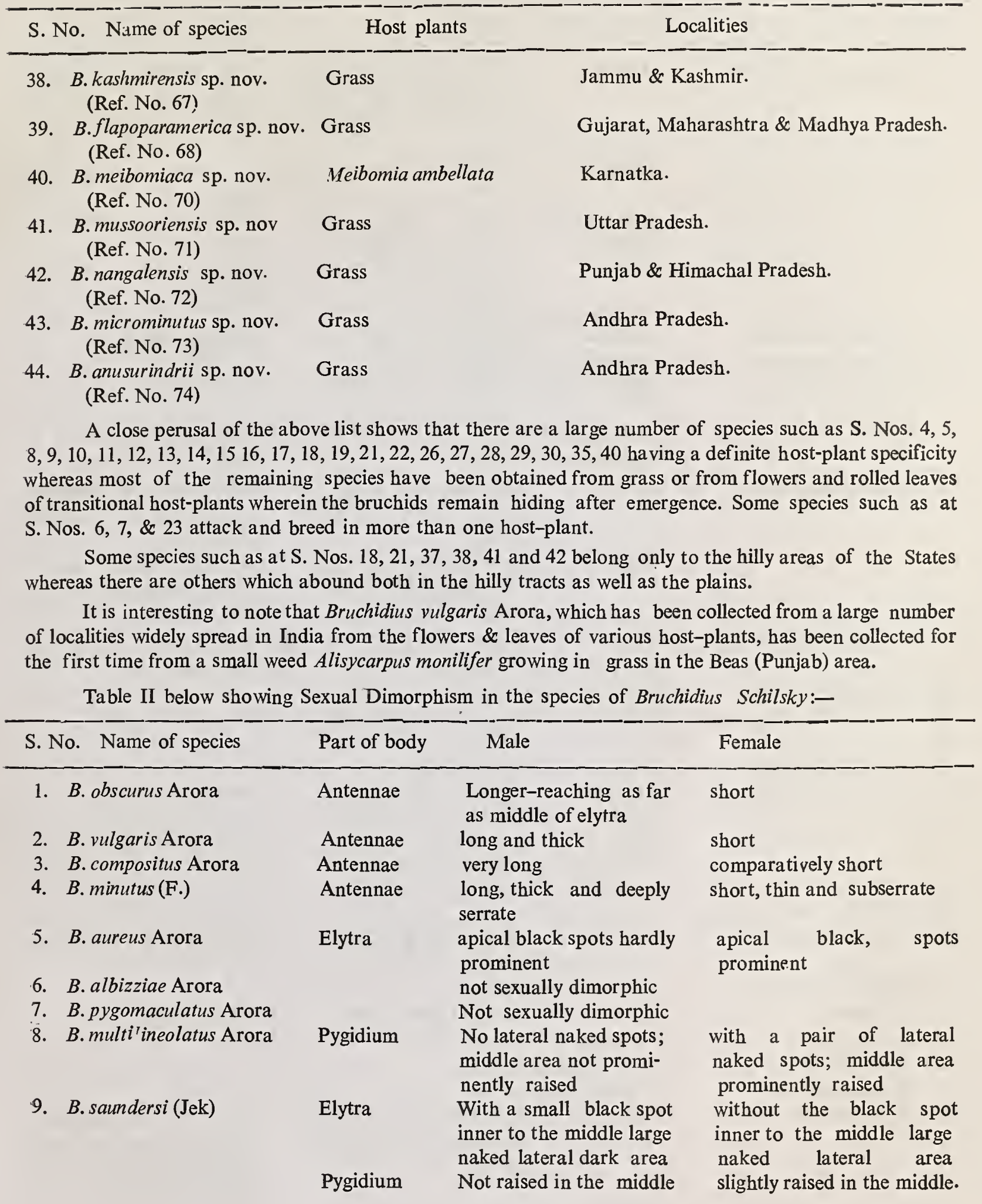




S. No. Name of specie
10. B. sahlbergi Schilsk

11. B. mimosae Arora
12. B. urbanus (Sharp)
13. B. tephrosiae Arora
14. B. flavovirens Arora
15. B. cassiae Arora

16. B. dimorphous Arora

17. B. maculipygus (Champ)

18. B. lineolatus Arora

19. B. angustifrons Schilsky

20. B. nigricans Arora

21. B. solanensis Arora

22. B. andrewesi (Pic)

23. Bruchidius schilskyi Arora

24. B. orientale sp. nov.

25. B. blemeris sp. nov.

26. B. endotubercularis sp. nov

27. B. variegata sp. nov.

28. B. mathaii sp. nov.

29. B. amarae sp. nov.

30. B. bangalorensis sp. nov.
Part of body Male

Elytra

pygidium

Abdomenal sternite last pygidium

Not Sexually dimorphic

Antennae longer and serrate

Not sexually dimorphic

Pygidium Vertical, its apex bent forward.

Last abdomi- short and notched in nal sternite middle

Elytra

Pygidium brown all over, covered uniformly with golden setae brown in male, covered uniformly with golden setae

Pygidium lateral areas of dull white setae

Not Sexually dimorphic

Antennae longer and deeply serrate

No dimorphism

Pygidium broader than long

Pygidium more pointed apically

Last narrow \& slightly

abdominal notched in middle sternite

Not sexually dimorphic

Antennae longer; segs. 1-4 cylindrical

No Sexual dimorphism

Antennae slightly longer in male

No sexual dimorphism

No sexual dimorphism

No sexual dimorphism

Pronotum brown \& covered uniformly with pale yellow setae
Female

with a large common median and a pair of lateral, naked dark brown spots.

sub-vertical and less pointed apically

broad and not notched in middle

apex slightly inclined forward

short and subserrate

\section{Sub-vertical}

broad and not notched in middle.

apices black \& surface covered with pale-white and golden setae.

blackish in female with a circular naked patch at the apex.

lateral areas of shining white setae.

short and sub-serrate

longer than broad less pointed apically broad and not notched in middle

shorter; segs. 1-3 cylindrical

slightly shorter

dark brown with punctate surface and a pair of dark patches one on either side of median line. 


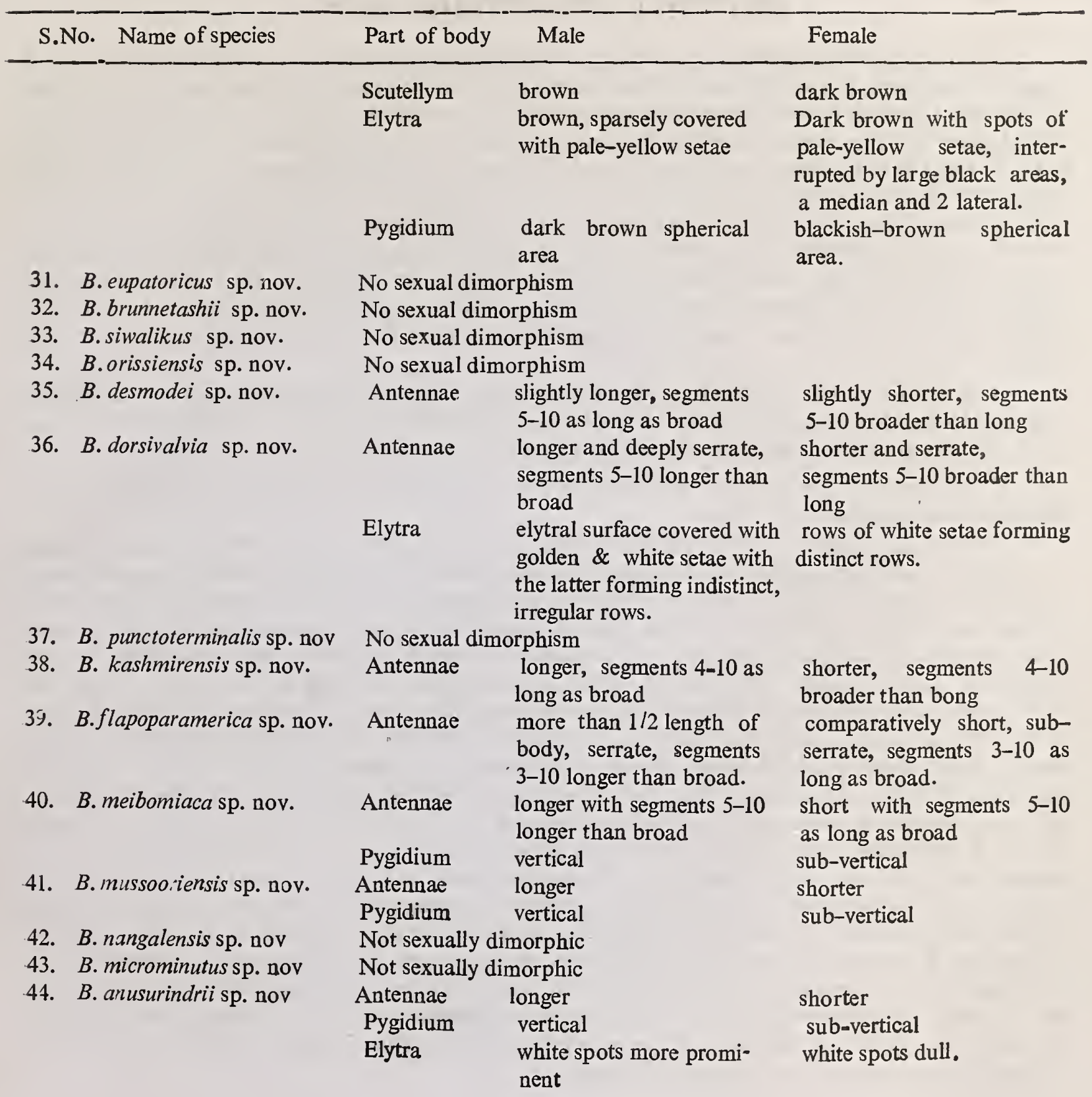




\section{INCIDENCE AND DISTRIBUTION}

Several Survey-cum-collection tours were undertaken, frequent short tours to different areas in and around Chandigarh, Punjab, Haryana \& Himachal Pradesh; and long trips to the near and far flung States of India such as the one to Uttar Pradesh covering Dehradun, Ranikhet and Haridwar areas during December, 74 to March, 1975; to Assam, Nagaland, Manipur, Meghalaya, Siliguri and Darjeeling areas during ApriI to Sept., 1975; to Tamil Nadu, Pondicherry, Kerala, Karnatka, Goa, part of Bombay and Rajasthan during August 1975 to March, 1976; to Himachal Pradesh and Uttar Pradesh areas during April, 1976 to September, 1976; to Jammu, Orissa, West Bengal, Bihar and part of Uttar Pradesh areas during October, 1976 to March, 1977; to Jammu and Kashmir \& Simla Hills areas during April to September, 1977; to Morni Hills (Haryana), Gujarat, Maharashtra and Madhya Pradesh areas during October, 1977 to March, 1978; to Hissar and Jind (Haryana), Dehradun, Chakrata \& Mussoorie (U. P.) and other neighbouring areas during April to September, 1978; and to Sikkim, Siliguri, Bhutan border and Andhra Pradesh areas during October, 1978 to. September, 1979.

The species at various localities form a dense population in a State when the number of individuals. collected exceeds 25 whereas the population is a medium one when the number of individuals falls between 10 and 25 , the population being rare when the numbers fall below 10 .

The Table III at pp $9 \& 10$ gives the incidence and distribution of the species of Bruchidius in the different States of India :-

Of all the species in Table III B.tephrosiae Arora is the most dominant with a dense population in 13 States, a medium population in 3 States and a rare population in another 3 States. B. pygomaculatus Arora stands second in order of dominance with a dense population in 11 States, a medium population in 2 States and a rare population in an another 3 States, whereas $B$. vulgaris Arora is a close third in order of dominance with a dense population in 8 States, a medium population in 5 States and a rare population in 7 States. The next in order of dominance are $B$. aureus Arora spread out in 12 States; B. multilineolat us Arora and B. cassiae Arora spread out in 11 States; B. saundersi (Jek), $B$. angustifrons Schilsky and $B$. blemeris sp. nov. spread out in 9 States each; B. albizziae Arora, B. mimosae Arora, and $B$. siwalikus sp. nov. spread out over 7 States each; $B$. obscurus Arora, $B$. flavovirens Arora, $B$. maculipygus (Champ.) spread over 7 States each; B. minutus (F.) spread over 5 States; $B$. sahlbergi Schilsky, $B$. urbanus (Sharp), B. orientale sp. nov., $B$. dorsivalvia sp. nov. spread over 4 States each; $B$, desmode $i$ sp. nov. $B$. dimorphous Arora, $B$. andrewesi (Pic), $B$. eupatoricus sp. nov. and $B$. flapoparamerica sp. nov. spread over 3 States each; $B$. schilskyi Arora, $B$. endotubercularis sp. nov., $B$. amarae sp. nov and $B$. nangalensis sp. nov. spread over 2 States each only; and the remaining species restricted to a single State each viz., B. compositus Arora to Chandigarh; B. lineolatus Arora to Himachal Pradesh; $B$. nigricans Arora to Chandigarh; B. solanensis Arora to Himachal Pradesh; $B$. variegata sp. nov. to Rajasthan; B. mathaii sp. nov. to Kerala; $B$. bangalorensis sp. nov. to Karnataka; $B$. brunnetashii sp. nov to Tamil Nadu; $B$. orissiensis sp. nov. to Orissa; $B$. punctoterminalis sp. nov. and B. kashmirensis sp. nov. to Jammu and Kashmir; $B$. meibomiaca sp. nov. to Karnatka; $B$. mussooriensis sp.nov. to Uttar Pradesh; and B. microminutus sp. nov. and $B$. anusurindrii sp. nov. to Andhra Pradesh. 
Arora : Biology and Taxonomy of Bruchidius
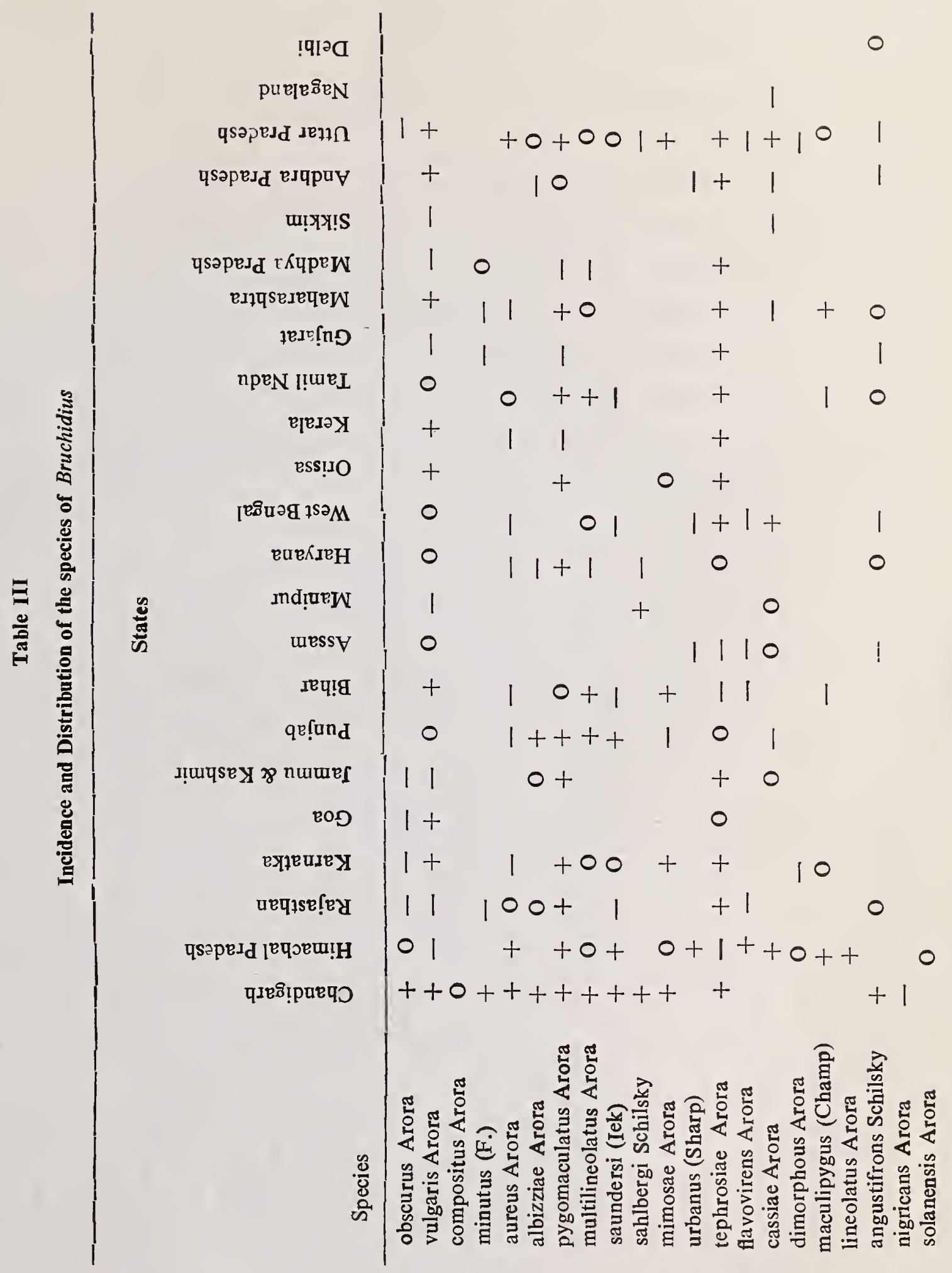
Final Technical Report 1974-79

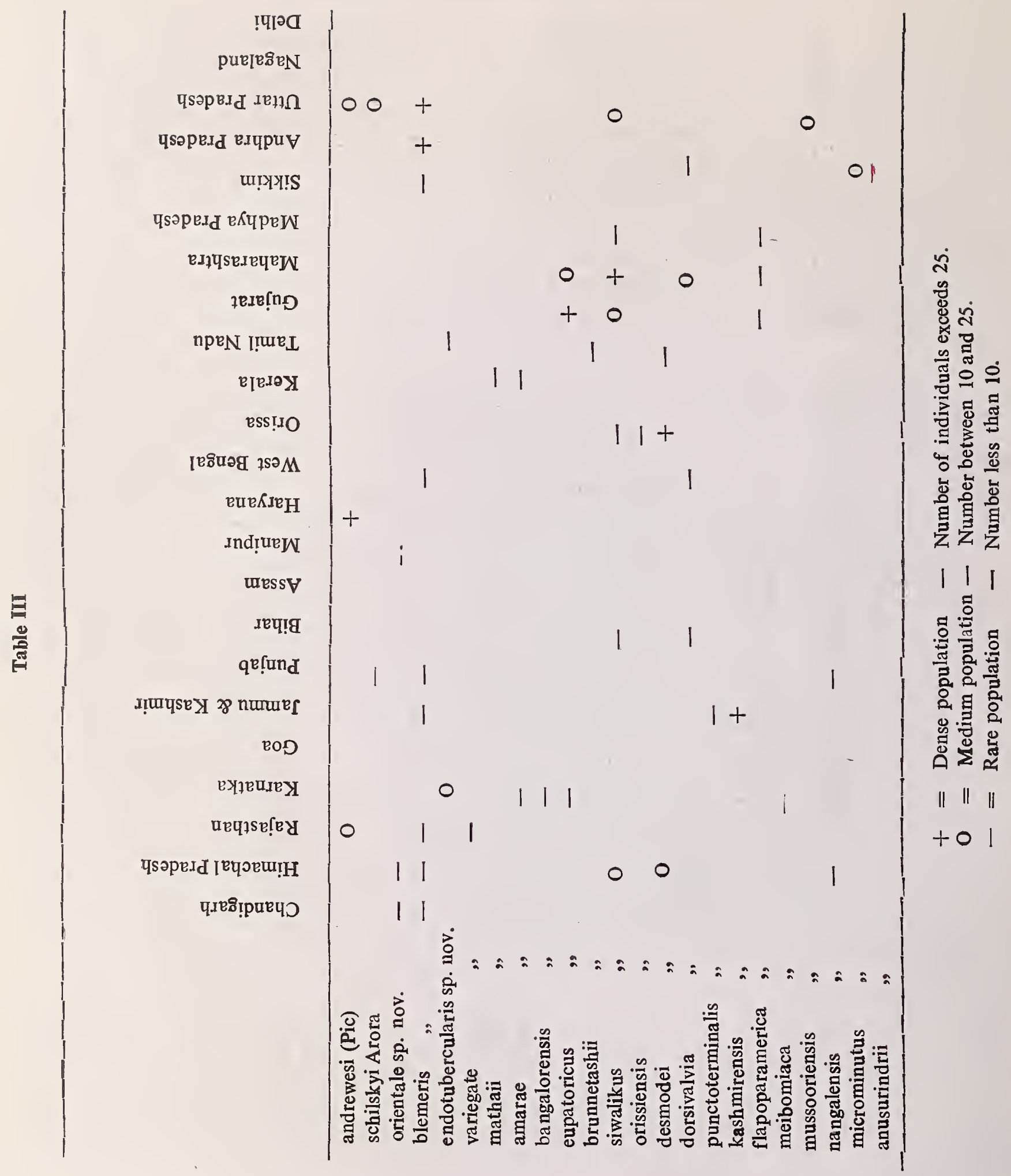




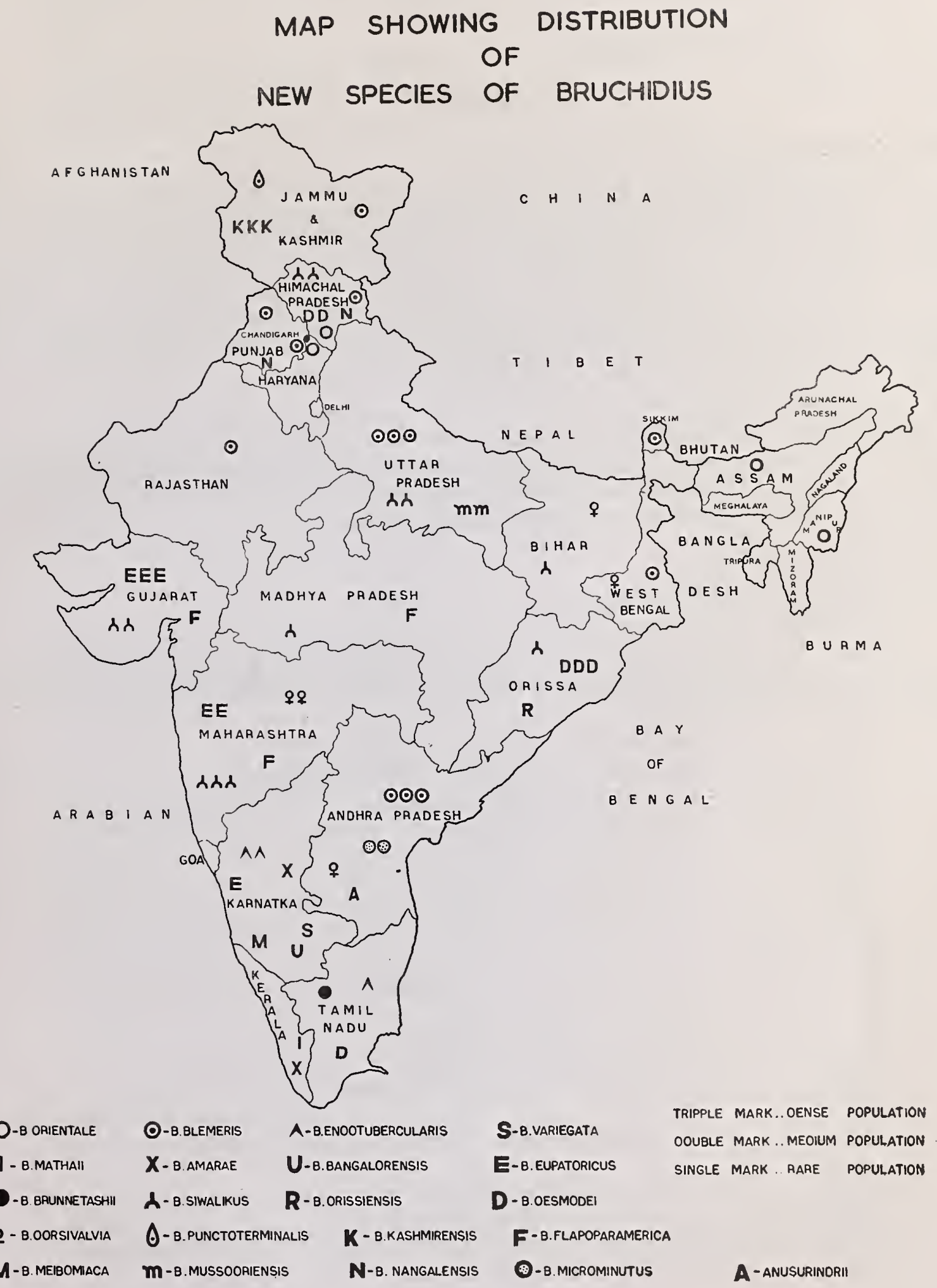




\section{TAXONOMY}

\section{FAMILY BRUCHIDAE}

The family Bruchidae belongs to the superfamily Chrysomeloidea which comprises medium-sized beetles having pseudotetramerous tarsi, the fourth tarsomere being covered by the bilobed third tarsomere. The head is small and usually somewhat retracted into prothorax. Their mouth-parts are directed forwards and downwards. The eyes are emarginate anteriorly. The antennae are 11-segmented, serrate to pectinate. The prothorax is oval, bell-shaped, conical or trapezoidal. The elytra generally leave the pyqidium uncovered. The hind legs are usually much longer and thicker than the fore and the middle legs; the hind femora are flat and thickened, unicarinate or bicarinate below with or without preapical spines or the single carina may be with a comb-like row of spines.

\section{SUBFAMILY BRUCHINAE}

Hind femora moderately thickened, ventrally flat or canaliculated with one or both edges carinate, carinae with or without pre-apical spines but without a comb-like row of spines. Hind tibiae straight or slightly arched; striae on the elytra partly abbreviated and not reaching apex. Hind tibiae without movable spurs; antennae serrate to pectinate and scutellum quadrangular.

Genus Bruchidius Schilsky

Bruchidius Schilsky, 1905 Kauf Eur.

\section{1 : 8. Type species : B. quinqueguttatus}

Pronotum sub-conical; hind fernur canaliculate below with a minute preapical tooth on the inner carina ventrally, not accompanied by smaller teeth; univoltine species attacking the green pods of wild forest, medicinal and ornamental plants.

\section{KBY TO THE SPECIES OF BRUCHIDIUS SCHILSKY}

1. Antennae long, surpassing the base of pronotum; eyes greatly bulging $\quad \ldots \quad 2$

Antennae short, not surpassing the base of pronotum; eyes flat or moderately bulging .. 23

2. Small sized insects, less than $2.5 \mathrm{~mm}$; ground colour black; host-plants generally obscure, collected from flowers, leaves or grass, or associated with some transitory host-plant

Medium sized insects, more than $2.5 \mathrm{~mm}$, going up to about $5 \mathrm{~mm}$; ground color variable; collected from host-plants or from transitional host-plants wherein they hide after emergence

3. Elytra with varying number of tubercles at the bases of certain striae Elytra without basal strial tubercles

4. Elytra each with a tubercle at the base of 4 th stria Elytra with a tubercle each at the bases of 3 rd and 4th striae

5. Endophallus with 3 endophallic plates; parameres fused at base to $1 / 3$ length .. B. orientale sp. nov. (Ref. No. 52) Endophallus with 2 endophallic plates; parameres variously fused at base but not as above

Scutellum squarish; parameres fused almost to tips (tips free), each bearing 10 parameral setae; endophallic tubercles short and blunt Scutellum longer than broad; parameres fused to less than $1 / 3$ length, each bearing less than 10 parameral setae; endophallic tubercles sharply pointed 
7. Parameres fused at base to $1 / 6$ length, each with a conical flap \& bearing 4 parameral setae; endophallus with a prominent dorsal valve

.. B. flapo, aramerica sp. nov. (Ref. No. 68)

Parameres fused at base to 1/4 length, each rounded and bearing 5-6 parameral setae;

endophallus without a dorsal valve

.. compositus Arora

8. Pronotum with a raised pre-scutellar area; phallus wth a dorsal valve $\quad \ldots \quad 9$

Pronotum without a raised prescutellar area; phallus without a dorsal valve $\quad$.. 11

9. Antennae yellowish with a prominent terminal black segment; scutellum rectangular; endophallus with 2 endophallic plates; dorsal valve beak-shaped or vase-shaped _. 10 Antennae testaceous to light brown but without a terminal black segment; scutellum squarish; endophallus with 4 endophallic plates; dorsal valve double trough-shaped

.. B.nangalensis sp. nov. (Ref. No. 72)

10. Scutellum broader than long; elytra with golden setae; parameres fused at base to about $1 / 3$ total length but less than $1 / 2$ length; dorsal valve beak-shaped

.. B. orissiensis sp. nov. (Ref. No. 63)

[Scutellum longer than broad; elytra with elongated spots of yellowish-white and brown setae and some dark areas; parameres fused at base to more than 1.2 length; dorsal valve vase-shaped

.. B. punctoterminalis sp. nov. (Ref. No. 66)

11. Antennae unicolourous; scutellum longer than broad: elytra with elongated spots and some dark areas

Antennae with 4 basal segments light testaceous, rest black; scutellum broader than long; elytra covered uniformly with sparse pubescence

.. B. mussooriensis sp. nov. (Ref. No. 71)

12. Antennae brown; parameres with $1 / 6$ basal fusion and each bearing 8 parameral setae; endophallus-with 3 endophallic plates .. B. kashmirensis sp. nov. (Ref. No. 67)

Antennae light testaceous; parameres with $2 / 3$ basal fusion, each carrying 6 parameral setae; endophallus with 2 prominent, lateral longitudinal rows of sclerotized platelets

B. meibomiaca sp. nov. (Ref. No. 70)

13. Antennae with a few basal segments light colored and rest black; endophallus with 2 or 4 endophallic plates

Antennae unicolorous; endophallus with 3 endophallic plates

14. Antennae with 4 basal segments light colored, rest black; elytra with white setose spots intermingled with spots of pale or golden setae

Antennae with 3 basal segments colored differently from the rest black segments; elytra uniformly covered with pale white or yellow setae

15. Scutellum squarish; parameres fused at base for more than $1 / 2$ total length, each bearing 9-10 parameral setae; dorsal valve absent

.. minutus (F.)

Scutellum longer than broad; parameres fused at base for less than $1 / 2$ total length, each carrying upto 8 parameral setae; dorsal valve present

16. Parameres fused at base to $1 / 5$ total length, each slightly broadened terminally and bearing 5 long parameral setae; endophallus with 2 endophallic plates and profusely studded with sharp, pointed tubercles; dorsal valve quadrangular and apically bifid .. B. dorsivalvia sp. nov. (Ref. No. 65)

Parameres fused at base to $1 / 4$ total length; each conical terminally and bearing 7-8 parameral setae; endophallus with 4 endophallic plates and numerous blunt tubercles; dorsal valve of two wine-glass-shaped plates 
17. Antennae with segments 1-3 light testaceous, rest black; elytral surface covered with whitish setae; scutellum broader than long; parameres fused at base to $1 / 2$ total length .. vulgaris Arora Antennae with basal 3 segments brown, rest black; elytral surface covered with yellow setae; scutellum longer than broad; parameres fused at base to less than $1 / 2$ total length . B. blemeris sp. nov.

(Ref. No. 54)

18. Scutellum squarish; elytra with pale setae \& spots of white setae intermingled with dark areas; parameres dlstally distended and flattened, each carrying 4 parameral setae

.. B. siwalikus sp. nov.

(Ref. No. 62)

Scutellum rectangular; elytra with golden setae and without dark areas; parameres truncated or notched distally, each carrying more than 4 parameral setae

19. Scutellum broader than long; parameres fused at base to more than $1 / 2$ total length; truncated distally and each carrying 5 parameral setae; endophallus with 2 rows of flattened disc-shaped tubercles; hasal endophallic plate small; exophallic valve short and conical .. B. desmodei sp. nov.

Scutellum longer than broad; parameres fused at base to less than $1 / 2$ total length, (Ref. No. 64) notched distally and each carrying 7 parameral setaes; endophallus with strong \& sharply-pointed tubercles: basal endophalic plate elongated, bifid anteriorly and trifid posteriorly; exophallic valve a long cone .. B anusurindrii sp. nov.

(Ref. No. 74)

20. Scutellum longer than broad; antennae with segments $1-4$ cylindrical and 5-10 broader than long; elytra with variable arrangement of basal strial tubercles; saccus smooth and without apical tubercles

Scutellum squarish; antennae with segments $1-3$ cylindrical and 4-10 as broad as long; elytra with a tuberculate area at the base of 4th stria; endophallus with apical tubercles on the saccus .. B, eupatoricus sp. nov.

(Ref No. 60)

21. Elytra each with long spots of pale-white setae intermingled with dark areas, a bituberculate area at the bases of 3 rd and 4th striae; endophallus with 4 endophallic plates (3rd horn-like); exophallic valve truncated; parameres fused at base to $2 / 3$ total length.

\section{.. cassiae Arora}

Elytra covered with pale-white, yellow or golden setae but without dark areas; and with a variable number of basal strial tubercles; endophallus with 3 endophallic plates; exophallic valve variable but not truncated; parameres fused differently at base

22. Antennae light testaceous; elytra with pale-white and yellow setae, each bearing 3 strial tubercles at the bases of 2 nd, 3 rd and 4 th striae; hind tibia with short apical denticles; endophallus mallet-shaped; parameres fused at base to $1 / 3$ total length; exophallic valve flat and triangular . . angustifrons Schilsky

Antennae dark testaceous margined with black; elytra covered with thickly set white and golden setae and 2 strial tubercles at the bases of 3 rd and 4th striae; hind tibia with a strong apical process; endophallus tubular; parameres fused at base to $4 / 5$ total length; exophallic valve an elongated cone .. tephrosiae Arora

23. Eyes flattened 
24. Forms dimorphic, male elytra covered uniformly with golden setae; female elytra with palewhite and golden setae intermingled with small dark areas at the apices; female pygidium with a large medio-distal oval dark area; antennae yellowish, margined with black; scutellum squarish; parameres arched, truncate distally; phallus bilobed distally in each half dimorphous Arora

Sexes similar; pygidium without a large dark area; antennae testaceous; scutellum broader than long; parameres almost rounded distally; phallus not bilobed distally . . 25

25. Frons carinate; antennal segments 1-4 cylindrical, 5-10 broader than long; elytra uniformly covered with pale white setae and without dark areas; parameres fused at base to $1 / 5$ length; phallus with saccus more or less triangular; exophallic valve conical mimosae Arora

Frons without carina; antennal segments 1-5 cylindrical and 6-10 broader than long; elytra covered with pale-yellow setae and with a dark postero-median, a pair of dark apical and a pair of irregular, dark humeral areas; parameres fused to $1 / 4$ basal length; saccus oblong; exophallic valve broadly rounded _.. B. mathaii sp. nov. (Ref. No. 57)

26. Endophallus with small chitinized plates in addition to tubercles $\quad . .27$ Endophallus without chitinized plates but with tubercles only $\quad . .28$

27. Elytra marked with prominent white and black setose spots and each with a strial tubercle at the bases of 2 nd, 3rd and 4th striae; endophallic plates elongated . . sahlbergi Schilsky Elytra clothed with white setae and a strial tubercle each at the bases of 3rd \& 4th striae: endophallic plates bifid and converging towards the middle andrewesi (Pic.)

28. Body, antennae and legs entirely black . 29 Body, antennae and legs variously colored but not completely black

.. 31

29. Pronotum covered uniformly with pale-white setae; scutellum slightly longer than broad; frons carinate; elytra without basal strial tubercles and covered uniformly with pale-white setae; parameres finger-shaped, each carrying 2 extra long setae in addition to several short setae; no lateral sclerotizations on exophallic rim; exophallic valve elongated cone .. nigricans Arora

Pronotum with a dark median area or narrow lateral areas with spots: scutellum broader than long; frons non-carinate; elytra each with 2 strial tubercles at the bases of 3rd \& 4th striae and with a pattern of dark areas; parameres flattened distally, each bearing small setae only; a pair of lateral scterotizations on exophallic rim; exophallic valve broadly conical

30. Pronotum with an anterior large median, dark area; elytra with a median saddleshaped area clothed with silky-white setae and 3 pairs of lateral, naked, spherical black areas; parameres fused at base to $1 / 3$ length; pygidium with a pair of lateral black spots

... saundersi (Jek)

Pronotum without the median dark area but with a pair of narrow, black lateral streaks, bearing a pair of white spots; elytra with a large saddle-shaped area bearing spots of silvery-white setae and a pair of small triangular, medio-lateral black spots and a narrow transverse dark apical area; parameres fused at base to $1 / 2$ length; pygidium with 2 pairs of black, lateral spots

.. solanensis Arora

31. Frons carinate; parameres fused at base from $1 / 4$ to $1 / 3$ total length $\quad .32$ Frons without carina; parameres fused at base to less than $1 / 4$ length

32. Elytra without a pattern of spots and dark areas but uniformly covered with unicolorous setae 
33. Ground colour testaceous; elytra covered with golden-yellow setae ; no lateral sclerotizations on exophallic rim; exophallic valve truncated .. albizziae Arora Ground colour blackish brown; elytra covered with fennel-colored setae; a pair of lateral sclerotizations on exophallic rim; exophallic valve broadly conical

.. flavovirens Arora

34. Elytral pattern with prominent elongated spots .. 35

Elytral pattern variable but without elongated spots

.. 37

35. Scutellum squarish; pygidium with a large, median dark-brown, shining,-spoon-shaped area maculipygus (Champ)

Scutellum broader than long; pygidium without a spoon-shaped area

36. Ground colour of elytra dark brown with elongated spots of white setae in the middle, flanked by continuous dark areas; pygidium brown, laterally covered with small rows of white setae and a median longitudinal band of white setae separating two large dark spots; medium-sized species 2.97 to $4.29 \mathrm{~mm}$ in length .. lineolatus Arora Ground colour of elytra light-brown with elongated spots of white, dark-brown and reddish-yellow setae; pygidium dirty-white with a faint median line of white setae; large-sized species 4.68 to $6.83 \mathrm{~mm}$ in length .. multiineolatus

Arora

37. Elytra with a broad medium saddle-shaped area of white setae with 2 pairs of narrow streaks of white setae forming 3 pairs of lateral black areas; pronotum with a pair of prominent antero-median black areas separted by a forward prologation of its median callus; pygidum covered by thickly set golden setae all over except a pair of small laterally placed black spots

Elytra without the saddle-shaped area; pronotum without the antero-median black areas; pygidum either lacking the small lateral black spots or with more than one pair of dark spots

Elytra light brown, covered all over with golden setae except a large, prominent, darkbrown, oval apical spot on each; pygidium covered only with golden setae; exophallic rim with a pair of lateral sclerotizations .. aureus Arora Elytra dark-brown with a pattern of dark spots and setae; pygidium bearing more than one pair of dark spots; exophallic rim without lateral sclerotizations

39. Elytra with a distinct median, flask-shaped, dark-brown area and two pairs of dark marignal spots in the posterior half; pygidium with 2 pairs of distinct dark-brown lateral spots schilskyi Arora Elytra without the median flask-shaped area but each possessing a postero lateralcum-apical dark area; pygidium with 3 pairs of lateral spots pygomaculatus Arora

40. Elytra with a pattern of setose spots and dark areas; pygidium with prominent dark areas; endophallus terminally distended

Elytra without a pattern and pygidium without dark areas; endophallus tubular

41. Sexes similar; pygidium with paired dark spots

Sexes dimorphic with elytra uniformly covered with pale-yellow setae in male and a pattern of dark-brown lateral areas, a median dark area and several transverse, irregular rows of white spots in female; pygidium with a single large dark spot.. B. bangalorensis sp.nov.

42. Elytra with elongated spots of golden-yellow and white setae, and a large dark(Ref. No. 59) brown apical spot on each; pygidium with a pair of large kidney-shaped dark areas, separated by a median white band .. B. endotubercularis sp. nov. (Ref. No. 55) Elytra covered with dirty-white setae, intermingled with several, rectangular black spots, and a pair each of irregular antero-lateral and postero-lateral dark patches; pygidium with 2 pairs of prominent lateral black spots 
43. Scutellum broader than long; elytra light-brown with fennel-colored setae; parameres fused to $1 / 5$ basal length and bearing 14-15 long setae on the rounded tip; endophallus tuberculate and without basal sclerotized ring; exophallic valve conical with prominent sensory bodies

Scutellum squarish; elytra dark-brown with pale white setae; parameres fused slightly at base to $1 / 7$ length and bearing 18-20 parameral setae on a spoon-shaped tip; endophallus studded with sclerotized tubercles and a strong ring at base; exophallic valve dome-shaped without sensory bodies

.. B. brunnetashil sp. nov. (Ref. No. 61)

\section{ADDITIONAL INFORMATION ABOUT THE FOLLOWING ALREADY KNOWN SPECIES OF BRUCHIDIUS SCHILSKY}

1. Bruchidius obscurus Arora

Arora, G. L. 1977, Bruchidae of North-west India

Oriental Insects, Suppl. 7, p. 48.

Additional host: also collected from grass (transitory' host).

Additional localities : Chandigarh; Himachal Pradesh; Jammu and Kashmir, Rajasthan, Goa and Karnatka.

2. Bruchidius vulgarus Arora

Arora, G. L. 1977,' Bruchidae of North-west India.

Oriental Insects, Suppl. 7, p. 45.

Additional hosts : Alisycarpus monilifer (weed), Lantana indica (flowers).

Additional localities : Bihar, Orissa, Andhra' Pradesh, Karnatka, Goa and Ma harashtra; Punjab, Haryana, Assam, Tamil Nadu, West Bengal; Himachal Pradesh, Jammu \& Kashmir, Sikkim, Manipur, Rajasthan, Gujarat and Madhya Pradesh.

3. Bruchidius compositus Arora

Arora, G. L. 1977. Bruchidae of North-west India,

Oriental Insects, Suppl. 7, p. 43.

4. Bruchidius minutlis (F.)

Bruchus minuts Fabricius, 1801, Systema Eleutheratorum, 2, Hiliae: 401; Gyll., 1833, in Schonh., Gen, Cure., I : 56.

Arora, G. L. 1977. Bruchidae of North-west India.

Oriental Insects, Suppl. 7, p. 44.

Additional localities : Madhya Pradesh; Gujarat, : Maharashtra.

5. Bruchidius aureus Arora

Arora, G. L. 1977. Bruchidae of North-west India.

Orinetal Insects, Suppl. 7, p. 60.

Additional localities : Rajasthan, Tamil Nadu; Bihar, West Bengal, Maharashtra, Karnatka and Kerala.

6. Bruchidius albizziae Arora

Arora, G. L., $1977 . \quad$ Bruchidae of North-west India.

Oriental Insects, Suppl. 7, p. 55.

Additional localities: Andhra Pradesh.

7. Bruchidius pygomaculatus Arora

Arora, G. L. 1977. Bruchidae of North-west India.

Oriental Insects, Suppl. 7, p. 62.

Additional localities: Chandigarh, Maharashtra, Orissa, Karnatka, Tamil Nadu, Bihar, Andhra

Pradesh, Gujarat, Madhya Pradesh and Kerala. 
8. B. multilineolatus Arora

Arora, G. L., 1977. Bruchidae of North West India.

Oriental Insects, Suppl. 7, p. 58.

Adlitional localities: Chandigarh, Bihar, Tamil Nadu, West Bengal, Maharashtra, Karnatka, Madhya Pradesh.

9. Bruchidius saundersi (Jek)

Bruchus saundersi Jekel, 1855, Ins. Saund.. 1:6; Shomar 1863, Bull. Soc. Ent. Egypte 47:174. Arora, G. L. 1977. Bruchidae of North-west India.

Oriental Insects, Suppl. 7, p. 51.

Additional localities : Chandigarh, Karnatka, Rajasthan, Bihar, West Bengal and Tamil Nadu.

10. Bruchidius sahlbergi Schilsky

Bruchidius sahlbergi Sbhilsky, 1905, Kaf. Eur., 41, Nurnberg: 94; Shomar, 1963, Bull, Soc. Ent. Egypte, $47: 173$.

Arora, G. L., 1977. Bruchidae of North-west India.

Oriental Insects,' Suppl. 7, p. 49.

Additional localities: Manipur.

11. Bruchidius mimosae Arora

Arora, G. L., 1977. Bruchidae of North-west India.

Oriental Insects, Suppl. 7, p. 54.

Additional localities : Chandigarh, Bihar, Karnatka, Orissa.

12. Bruchidius urbanus (Sharp)

Bruchus urbanus Sharp, 1886 Ann. Mag. Nat. Hist., 17 (5) : 35

Arora, G. L., 1977. Bruchidae of North-west India.

Oriental Insects, Supl. 7, p. 59.

Additional localities : Assam, West Bengal, Andhra Pradesh.

13. Bruchidius tephrosiae Arora

Arora, G. L. 1977. Bruchidae of North-west India.

Oriental Insects, Suppl. 7, p. 47.

Additional localities : Chandigarh, Jammu \& Kashmir, West Bengal, Orissa, Andhra Pradesh, Tamil Nadu, Kerala, Karnatka, Maharashtra, Madhya Pradesh, Gujarat, Punjab, Haryana, Goa, Himachal Pradesh, Bihar and Assam.

14. Bruchidius flavovirens Arora

Arora, G. L. 1977. Bruchidae of North-west India.

Oriental Insects, Suppl. 7, p. 56.

Additional localities : Uttar Pradesh, Bihar, Assam, West Bengal, Rajasthan.

15. Bruchidius cassiae Arora

Arora, G. L. 1977. Bruchidae of North-west India.

Oriental Insects, Suppl. 7, p. 46.

Additional localities: Himachal Pradesh, West Bengal, Jammu \& Kashmir, Assam, Manipur, Punjab, Sikkim, Nagaland, Andhra Pradesh \& Maharashtra.

16. Bruchidius dimorphous Arora

Arora, G. L. 1977. Bruchidae of North-west India.

Oriental Insects, Suppl. 7, p. 53.

Additional localities: Karnatka.

17. Bruchidius maculipygus (Champ.)

Bruchus maculipygus Champion, 1919, Ent. Mon. Mag., 55 : 244-245

Arora, G. L. 1977. Bruchidae of North-west India.

Oriental Insects, Suppl. 7, p. 57.

Additional localities : Maharashtra; Karnatka, Bihar \& Tamil Nadu. 
18. Bruchidius lineolatus Arora

Arora, G. L., 1977, Bruchidae of North West India.

Oriental Insects, Suppl. 7, p. 57.

It belongs to the hilly areas of Himachal Pradesh.

19. Bruchidius angustifrons Schilsky

Bruchidius angustifrons, Schilsky, 1905, Kaf. Eur., 41, Nurnberg : 52; Shomar, 1963, Bull.

Soc. Ent. Egypte, $47: 160$.

Arora, G. L. 1977. Bruchidae of North-west India.

Oriental Insects, Suppl. 7, p. 47.

Additional localities : Rajasthan, Maharashtra, Tamil Nadu, Assam, West Bengal, Gujarat and Andhra Pradesh.

20. Bruchidius nigricans Arora

Arora, G. L. 1977. Bruchidae of North-west India.

Oriental Insects, suppl. 7, p. 50.

Host not known. It is a rare species from Chandigarh.

21. Bruchidius solanensis Arora

Arora, G. L. 1977. Bruchidae of North West India.

Oriental Insects, Suppl. 7, p. 52.

It is a species from area from Solan to Salogra in Himachal Pradesh with a medium population.

22. Bruchidius andrewesi (Pic.)

Bruchus andrewesi Pic, 1932, Ann. Mag. Nat. Hist. London, 10(9) : 330.

Arora, G. L. 1977. Bruchidae of North-west India.

Oriental Insects, Supp1. 7, p. 50.

The host-plant is a weed.

23. 'Bruchidius schilskyi Arora

Arora, G. L. 1977. Bruchidae of North-west India.

Oriental Insects, Suppl. 7, p. 61.

It has a medium population in Uttar Pradesh and a rare population in Punjab. 


\title{
DETAILED DESCRIPTIONS OF NEW SPECIES OF GENUS BRUCHIDIUS
}

\author{
BRUCHIDIUS ORIENTALE sp. nov.
}

\author{
(Ref. No. 52) PHOTO I
}

(P1 1, figs. 1-9)

Head black; frons carinate, its surface beset with dull white setae; eyes emarginate, protruding, canthus narrow and shallow, its surface covered with dull white setae; antennae testaceous, surpassing base of pronotum, subserrate, longer in the male with segments 1-4 cylindrical, segments 5-10 broader than long and segment 11 conical, female with segments 1-3 cylindrical, segments 4-10 broader than long and segment 11 conical.

Pronotum sub-conical, black, its surface minutely pitted and covered with dull white setae, with a posterior median spot of pale white setae in front of the scutellum.

Scutellum black, slightly longer than broad, its surface bearing white setae. Elytra black, together longer than broad, with a tubercle at the base of 4th stria, its surface marked with irregular, transverse rows of elongated spots of white setae. Fore and middle legs testaceous with tips of tarsi and claws black; hind legs entirely black; hind femur bicarinate below, inner carina with a small preapical tooth; hind tibia apically produced into a pair of prominent spines internally and 2 small spines externally. Pygidium black, longer than broad, vertical in both sexes, clothed with dull white setae.

Phallus $1.158 \mathrm{~mm}$ long; parameres fused at base to $1 / 3$ total length, sclerotized along its outer margin, broadened at apex and carrying 8 slender setae; endophallus elongated and broadened at saccus region with 2 toothed plates near its apex and a narrow toothed plate at its base, and rows of sharp tubercles along endophallus; exophallic valve greatly elongated cone; a pair of lateral sclerotizations at exophallic rim.

Size small- length male 1.95 to $2.00 \mathrm{~mm}$ length female 1.90 to $2.00 \mathrm{~mm}$

Localities- Assam, Manipur, Chandigarh and Himachal Pradesh; from grass (a transitory host). Holotype $M$, allotype $F$, INDIA : MANIPUR, v, 1975, collected from grass. Paratypes $2 M M$, with the same data asholotype. Paratypes $4 M M, 2 F F$, ASSAM, v, 1975. Paratypes $3 M M, 3 F F$, CHANDIGARH; ix, 1975. Paratypes $M$, HIMACHAL PRADESH, Hamirpur, vi, 1976. Paratype $M$, HIMACHAL PRADESH: Sunder Nagar, vii, 1976. Deposited in Zoology Museum (Project Section), Panjab University, Chandigarh.

Salient features- 1. Elytra with a tubercle at the base of 4th stria.

2. Endophallus with 3 endophallic plates.

3. Parameres fused at base to $1 / 3$ total length - (a new combination).

Remarks- With antennae long and surpassing base of pronotum, greatly bulging eyes, size less than $2.50 \mathrm{~mm}$, black ground colour, obsecure host-plant (collected from grass and flowers), and with an elytral strial tubercle at the base of 4 th stria, this species is allied to $B$. obscurus Arora, $B$. flapoparamerica sp. nov. (Ref. No. 68) and $B$. compositus Arora. It, however, differs from the three species in having 3 endophallic plates ( 2 endophallic plates in the others) and parameres fused at base to $1 / 3$ total length (parameres fused almost to tips in $B$. obsscurus, and to less than $1 / 3$ length in the other two). 
PLATE 1
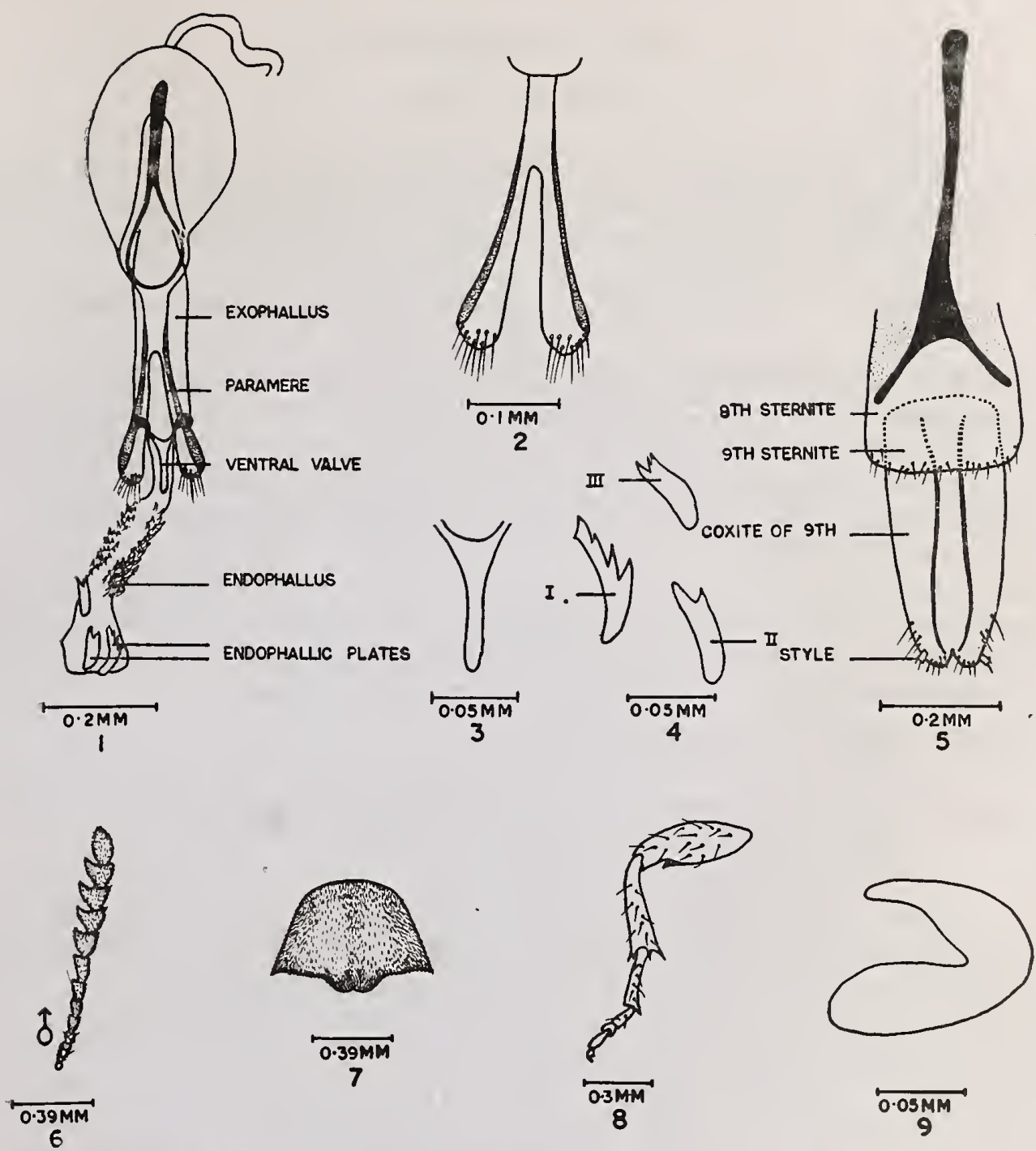

Bruchidius orientale sp. nov.

Figs. 1. Phallus; 2. Parameres; 3 . Exophallic valve; 4. Endophallic plates; 5. Female genitalia; 6. Antenna; 7. Pronotum; 8. Hind leg; 9. Spermatheca. 


\title{
BRUCHIDIUS BLEMERIS sp. nov.
}

\author{
(Ref. No. 54) PHOTO II
}

\author{
(P1. 2, figs. 10-18)
}

Head black; frons strongly carinate, its surface beset with pale yellow setae; eyes emarginate and greatly protruding, canthus deep and broad, its surface covered with pale yellow setae. Antennae long, a little ov er half the length of the body, sub-serrate with 3 basal segments dark-brown, rest of the segments black.

Prontoum black, sub-conical, its surface minutely pitted and uniformly covered with pale yellow setae.

Scutellum quadrangular, slightly longer than broad, its surface bearing pale yellow setae. Elytra black, together longer than broad, without any basal strial tubercles, its surface sparsely covered with pale yellow setae. Fore tibiae, tarsi and apices of femora testaceous, bases of femora black. Middle tibiae and tarsi testaceous, femora black; hind legs completely black; hind femur bicarinate below, inner carina with a short pre-apical tooth. Pygidium black, longer than broad, sub-vertical in both sexes, its surface covered with pale yellow setae.

Phallus $1.070 \mathrm{~mm}$ long; parameres fused at bases to less than $1 / 2$ total length, sclerotized along its outer margin, each having a rounded tip and carrying 5 small setae; endophallus densely studded with weakly sclerotized tuberrcles all over with a pair of short toothed plates in its middle; exophallic valve roughly pentagonal; exhphallic rim with a pair of lateral sclerotizations.

Size small— length male $1.80 \mathrm{~mm}$ to $2.00 \mathrm{~mm}$ length female 1.90 to $2.00 \mathrm{~mm}$

Localitics- Dehradun, Chandigarh, Punjab, Udhampur, Sikkim, Rajasthan, Himachal Pradesh, Andhra Pradesh, West Bengal.

Collected from grass (transitory host).

Holotype $M$, allotype $F$, INDIA, UTTAR PRADESH : Dehradun, iii, 1975 collected from grass. Paratypes $3 M M, 2 F F$, with same data as hototype. Paratype $1 M$, HIMACHAL PRADESH : Jwalamukhi, vi, 1976, collected from Lantana indica. Paratypes, $2 M M, 1 F$, HIMACHAL PRADESH: Kangra, vi, 1976. Paratype $1 F$, RAJASTHAN : Udaipur vi, 1976. Paratypes 2 MM, JAMMU \& KASHMIR: Jammu, xi, 1976. Paratypes $5 M M, 1 F$, JAMMU \& KASHMIR, Udhampur, viii, 1977. Paratypes $22 M M, 13 F F$, UTTAR PRADERH : Dehradun, v, 1978. Paratypes $5 M M, 2 F F$, CHANDIGARH, vi, 1978. Paratype $1 F$, PUNJAB : Chattbir Zoo, ix, 1978. Paratypes $3 \mathrm{MM}, 1 \mathrm{~F}$, PUNJAB ; Nangal, xi, 1978. Paratypes $1 \mathrm{M}, 2 \mathrm{FF}$, SIKKIM : Gangtok, x, 1978. Paratypes $1 \mathrm{M}, 2 \mathrm{FF}$, SIKKIM : Rangpa, x, 1978. Paratype $1 \mathrm{M}$, WEST BENGAL; Hasimara, x, 1978. Paratype $1 M$, ANDHRA PRADESH, Nalgonda, xii, 1978. Paratypes 35 MM, $18 F F$, ANDHRA PRADESH, Warangal, xii,. 1978. Paratypes $18 M M, 10 F$, ANDHRA PRADESH : Khamam, xii, 1978. Paratypes $5 M M, 4 F F$, ANDHRA PRADESH : Vijaywada, xii, 1978. Paratypes $20 M M$, $12 F F$, ANDHRA PRADESH : Eluru, xii, 1978. Paratypes $4 M M, 2 F F$, ANDHRA PRADESH : Anakapalli, xii, 1978, Paratypes $16 M M, 10 F F$, ANDHRA PRADESH : Kakinada, xii, 1978. Paratypes 12 $M M, 8 F$, ANDHRA PRADESH; Anantapur, i, 1979. Paratypes $2 M M, 8 F F$, ANDHRA PRADESH, Hydrabad, i, 1979. Deposited in Zoology Museum (Project section), Panjab University, Chandigarh.

Salient features- 1. Elytra without basal strial tubercles and elytral surface covered uniformly with pale yellow setae;

2. Antennae with 3 basal segments dark brown and rest black;

3. Endophallus with 2 endophallic plates;

4. Parameres fused at base to less than $1 / 2$ total length (New combination)

Remarks: With long antennae, surpassing the base of pronotum; greatly bulging eyes; size less than 
PLATE 2
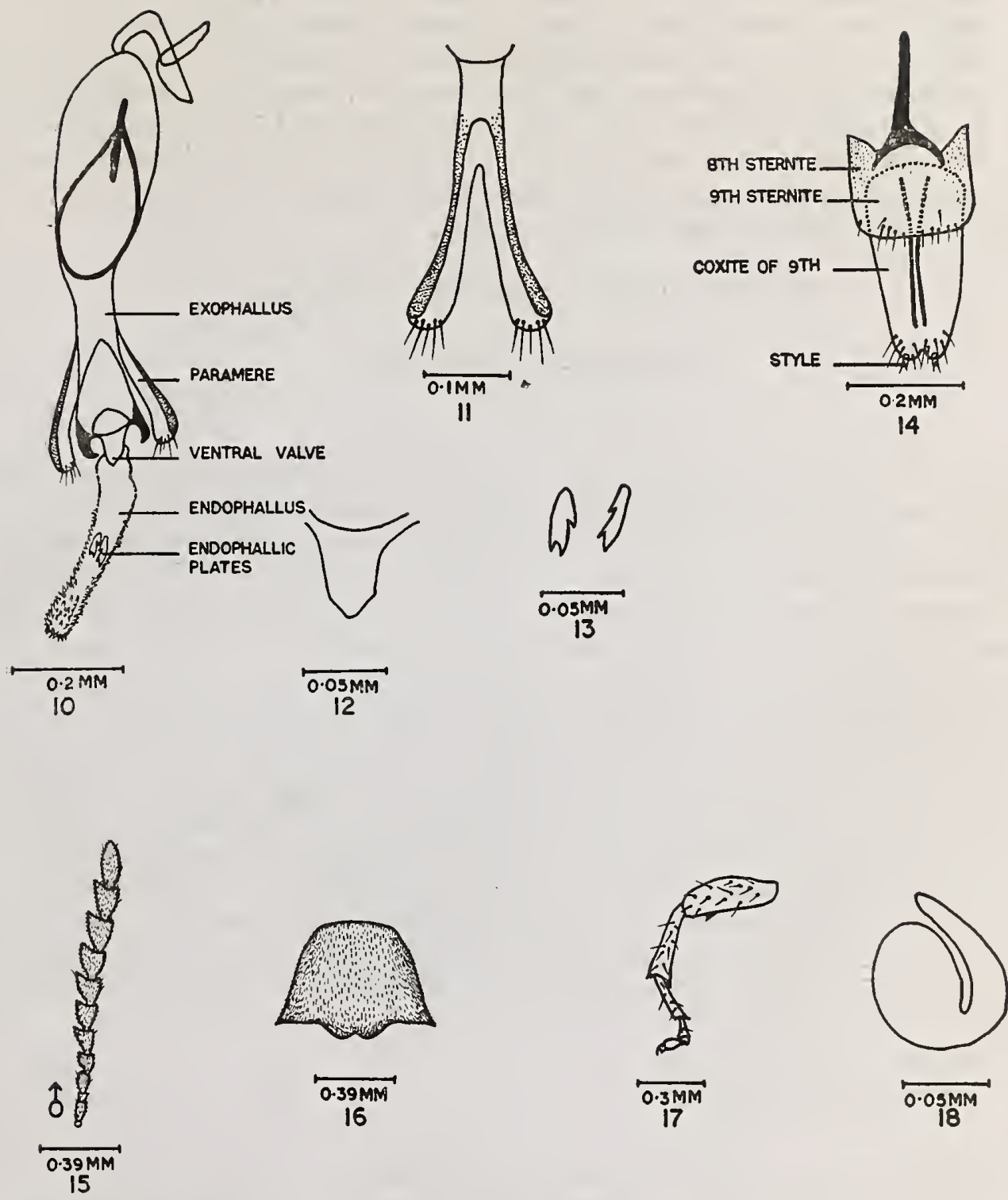

Bruchidius blemeris sp. nov.

Figs. 10. Pha!lus; 11. Parameres; 12. Exophallic valve; 13. Endophallic plates; 14. Female genitalia; 15. Antenna; 16. Pronotum; 17. Hind leg; 18. Spermatheca. 
$2.50 \mathrm{~mm}$; black ground colour; host plant obsecure, collected from grass, and without basal strial tubercles on the elytra, this species is closely allied to $B$. vulgaris Arora. It, however, differs from the latter in having 3 basal segments of antennae dark brown and rest black (antennae with 3 basal segments light testaceous in $B$. vulagris), in elytra covered with pale yellow setae (elytra covered with dull whitish setae in $B$. vulgaris), in scutellum longer than broad (scutellum broader than long in $B$. vulgaris), and in parameres fused at base to much less than 1/2 total length (parameres fused at base to $1 / 2$ total length in $B$. vulagaris).

The species has been named after the pale yellow setae covering the various parts of the body including the pronotum, scutellum, elytra and the pygidium.

BRUCHIDIUS ENDOTUBERCULARIS sp. nov.

\section{(Ref. No. 55) PHOTO III}

$$
\text { (Pl. } 3 \text { figs. 19-26) }
$$

Head dark brown, broader at posterior end; frons not carinate, area between and behind the eyes slightly raised, its surface minutely punctate and covered with scattered golden yellow setae; eyes moderately bulging, emarginate, canthus slightly shallow and small, its surface covered with golden yellow setae. Antennae testaceous, short and not surpassing base of pronotum, slightly longer in male than in female, sub-serrate, segments 1-5 longer than broad, segments 6-10 as long as broad, segment 11 oblong cone.

Pronotum dark brown, sub conical, its surface pitted and covered uniformly with golden yellow setae.

Scutellum quadrangular, broader than long, beset with golden yellow setae. Elytra dark brown, almost quadrangular, slightly longer than broad, its surface covered with golden yellow setae with small elongated spots of white setae, each elytron having a large dark brown apical spot and a common tuberculate area at the bases of 3 rd and 4th striae. Fore and middle legs testaceous with black claws; hind legs brown, hind femur bicarinate below, inner carina with a short-preapical tooth, preceded by a small serrulation before the middle. Pygidium dark brown, sub-vertical in both sexes, covered with golden setae, with a pair of dark brown kidney-shaped areas separated by a median band of white setae. Phallus $1.179 \mathrm{~mm}$. long; parameres fused at their bases upto about $1 / 4$ of their total length, with rounded tips, each carrying long 11-12 setae; endophallus inverted-shaped, its surface uniformly beset with small sharp tubercles and a sclerotized ring; a pair of lateral sclerotizations on the exophallic rim; exophallic valve broadly conical with an indented margin.

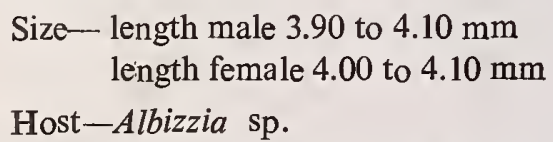

Localities-Hessan (Karnatka), Maduari and Madras (Tamil Nadu).

Hototype $M$, INDIA, TAMIL NADU : Maduari, ii 1976, collected from Albizzia sp. (family Leguminosae) Allotype F, INDIA: KARNATKA; Hessan forest, ii, 1976, collected from Albizzia sp. Paratypes 2 MM, with same data as holotype. Paratypes $2 M M, 2 F F$, with the same data as allotype. Paratypes $4 M M$, 3 FF, KARNATKA; after emergence from pods of Allbizia sp. brought from Hessan forest during iv, 1976. Deposited in Zoology Museum (Project section), Panjab University, Chandigarh.

Salient features : 1. Antennae short, not surpassing base of pronotum;

2. Eyes moderately bulging;

3. Endophallus with tubercles only;

4. Frons without carina;

5. Elytra with a pattern of spots and dark areas;

6. Pygidium with dark areas. 


\section{PLATE 3}

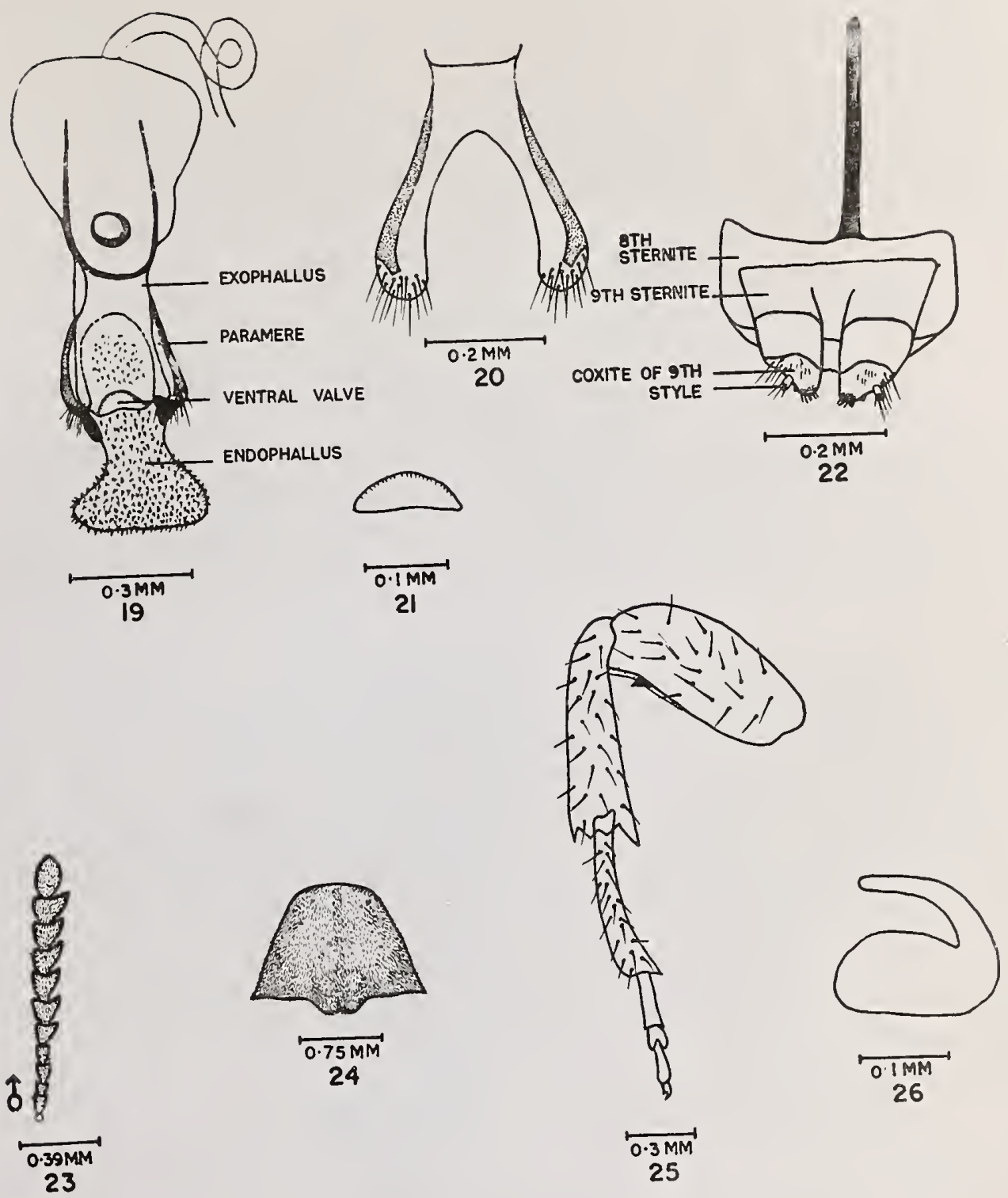

Bruchidius endotubercularis $\mathrm{sp}$. nov.

Figs. 19. Phallus; 20. Parameres; 21. Exophallic valve; 22. Female genitalia; 23. Antenna; 24. Pronotum; 25. Hind leg; 26. Spermatheca. 
Remarks: With short antennae; moderately bulging eyes; endophallus with tubercles only; body, antennae, and legs variously colored (not completely black) and parameres fused to less than $1 / 4$ length at base; elytra with setose spots and dark areas; pygidium with dark areas and forms with similar sexes, the present species is allied to $B$. variegate sp. nov. (Ref. No. 56). It, however, differs from the latter in having elytra with elongated spots of golden yellow and white setae and dark brown apical spot on each (elytra with dirty white setae intermingled with several rectangular black spots, and anterolateral and posterolateral irregular dark patches in $B$. variegata) and pygidium with a pair of dark kidney-shaped areas, separated by a median band (pygidium with 2 pairs of lateral, dark spots in B. variegata).

\section{BRUCHIDIUS VARIEGATA sp. nov.}

\section{(Ref. No. 56) PHOTO IV}

\section{(P1. 4 figs. 27-32)}

Head fuscus (brownish black), broader and raised at posterior end; frons without carina, its surface covered with pale yellow pubescence; eyes widely separated, bulging, emarginate, canthus narrow and shallow, its surface densely covered with pale yellow setae. Antennae brownish subserrate, short and not surpassing base of pronotum, segments 1-4 cylindrical, segments 5-10 broad and segment 11 conical.

Pronotum dark brown, sub-conical, broader than long, its surface covered with thickly set dirtywhite setae.

Scutellum black, quadrangular, broader than long, posteriorly bifid, its surface covered with dirty white sitae. Elytra dark brown with an antero-lateral dark area on each elytron, the two elytra together longer than broad, not covering the last two abdominal tergites with a pair of tubercles at the bases of 3rd and 4th striae, the elytral surface covered with white setae interrupted with rectangular black spots and irregular, antero-lateral and posterolateral dark patches. Fore and middle legs testaceous with terminal tarsi black; hind legs dark brown, hind femur bicarinate below, inner carina with a small preapical tooth. Pygfidium dark brown, sub-oblique in both sexes, much longer than broad, its surface covered with whitish setae leaving two pairs of lateral, elongated naked spots, one behind the other. Phallus $0.808 \mathrm{~mm}$. long; parameres fused at their bases upto $1 / 7$ of their total length, sclerotized along their outer borders, flattened and spoon-shaped at their ends, each carrying 11-12 setae; endophallus enlarged and globular, covered with weakly sclerotized tubercles and a sclerotized ring behind ; exophallic valve dome-shaped; without lateral sclerotizations on exophallic rim.

$$
\begin{aligned}
\text { Size large }- & \text { length male }: 4.50-5.00 \mathrm{~mm} \\
& \text { length female }: 4.20-4.50 \mathrm{~mm} .
\end{aligned}
$$

Host : Albizzia sp.

Localities : Bangalore, Mysore, Hessan forest (Karnatka)

Holotype M, INDIA, KARNATKA : Bangalore; i, 1976, collected from Albizzia sp. (Family Leguminosae). Allotype $F$, KARNATKA : Mysore, i, 1976. Paratype $1 M$, KARNATKA : Bangalore, from pods of Albizzia sp. at emergence ii, 1976. Paratype $1 \mathrm{~F}$, KARNATKA; Hessan forest from pods of host plant at emergence, iii, 1976. Deposited in Zoology Museum (Project Section), Panjab University, Chandigarh.

Remarks : The present species $B$. variegata sp. nov. (Ref. No. 56) is allied to B. endotubercularis sp. nov. (Ref. No. 55) and has been compared and discussed under the latter species. 


\section{PLATE 4}
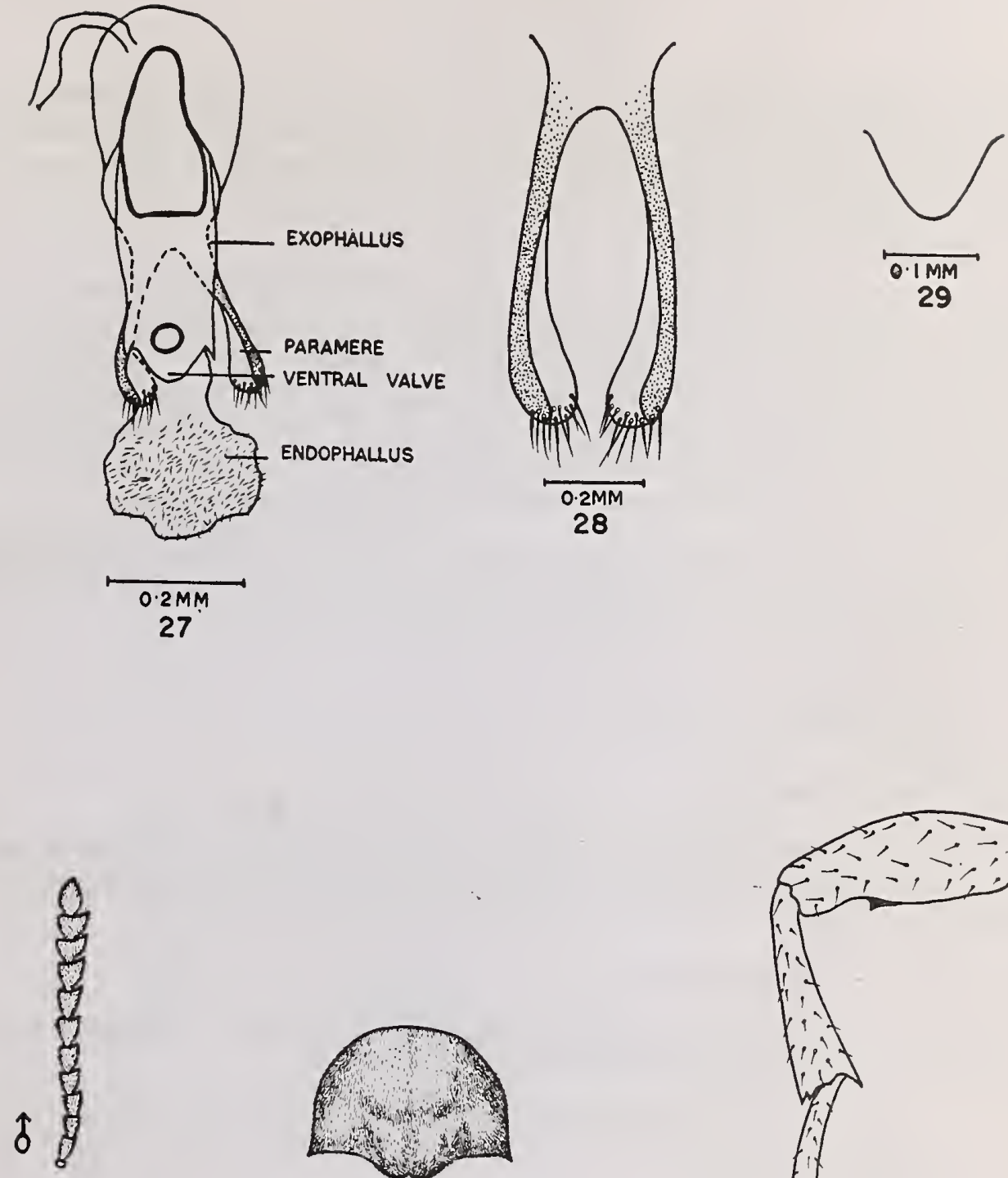

$0.39 \mathrm{MM}$

30

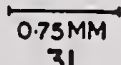

31

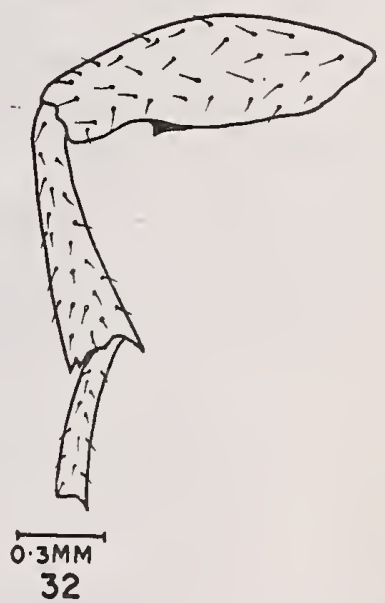

Bruchidius variegata sp. nov.

Figs. 27. Phallus; 28. Parameres; 29. Exophallic valve; 30. Antenna; 31. Pronotum; 32. Hind leg. 
BRUCHIDIUS MATHAII sp. nov. (Ref. No. 57) Photo V

\section{(Pl. 5 figs 33-38)}

Head dark brown, broader at posterior end; frons without carina, area between and behind eyes raised and fairly punctured, its surface covered with pale white setae; eyes small and dorsally flattened, emarginate, canthus extremely small, narrow and shallow, its surface beset with golden pubescence. Antennae short, testaceous and subserrate, not surpassing base of pronotum, segments 1-5 cylindrical, segments 6-10 broader than long, segment 11 conical.

Pronotum dark borwn, sub-conical, broader at base, its surface pitted and covered with white and pale yellow setae. Elytra dark brown, together longer than broad, covering anterior part of pygidium, each elytron with a pair of tubercles at the bases of 3rd and 4th striae, its surface covered with unicolours pale-yellow setae, a pair of dark apical patches and a postero-median dark area without setae. Fore and middle legs testaceous with apices of tarsi and claws black; hind femur bicarinate below, inner carina bearing a pointed, preapical tooth preceded by a small serrulation. Pygidium dark brown, longer than broad, oblique in both sexes, its surface covered with unicolorous pale-yellow setae.

Phallus $1.356 \mathrm{~mm}$ long; parameres fused at bases upto about $1 / 4$ length, broadly rounded tips, each carrying 16-18 setae; endophallus globular, beset with small tubercles only; a pair of lateral sclerotizations on the exophallic rim; exophallic valve broadly rounded at apex.

$$
\begin{aligned}
& \text { Size large-length male-4.00 mm } \\
& \text { len gth female-4.10 mm } \\
& \text { Host-Albizzia } \mathrm{sp} . \\
& \text { Locality-Trichur forest, Kerala. }
\end{aligned}
$$

Holotype M, allotype F, INDIA: KERALA; Triohur, i, 1976, collected from Albizzia sp. (family Legumi nosae). Paratype $M$, with the same date as holotype. Deposited in Zoology Museum (Project Section), Panjab University, Chandigarh.

Salient features : 1. Frons without carina;

2. Antennae short, not surpassing base of pronotum; segments 1-5 cylindrical, segments $6-10$ broader than long;

3. Elytra with pale yellow setae and postero-median, apical and humeral dark areas;

4. Eyes flattened;

5. Parameres fused at bases to $1 / 4$ total length;

Named after the great Scientist Prof. (Dr.) G. Mathai from Trichur.

Remarks : With short antennae, not surpassing base of pronotum; flat eyes; sexes similar; pygidium without a dark area; scutellum broader than long; parameres rounded distally and phallus not bilobed, the present species is closely related to B. mimosae Arora. It, however, differs from the latter in having frons without carina (frons carinate in $B$. mimosae), in having elytra covered with pale-yellow setae, and a dark postero-median, a pair of dark apical and a pair of dark humeral areas (elytra in $B$. mimosae uniformly covered with pale-white setae but without dark areas), in having oblong saccus (saccus triangular in $B$. mimosae), and in having exophallic valve broadly rounded (exhophalic valve coniccal in B. mimosae). 


\section{PLATE 5}
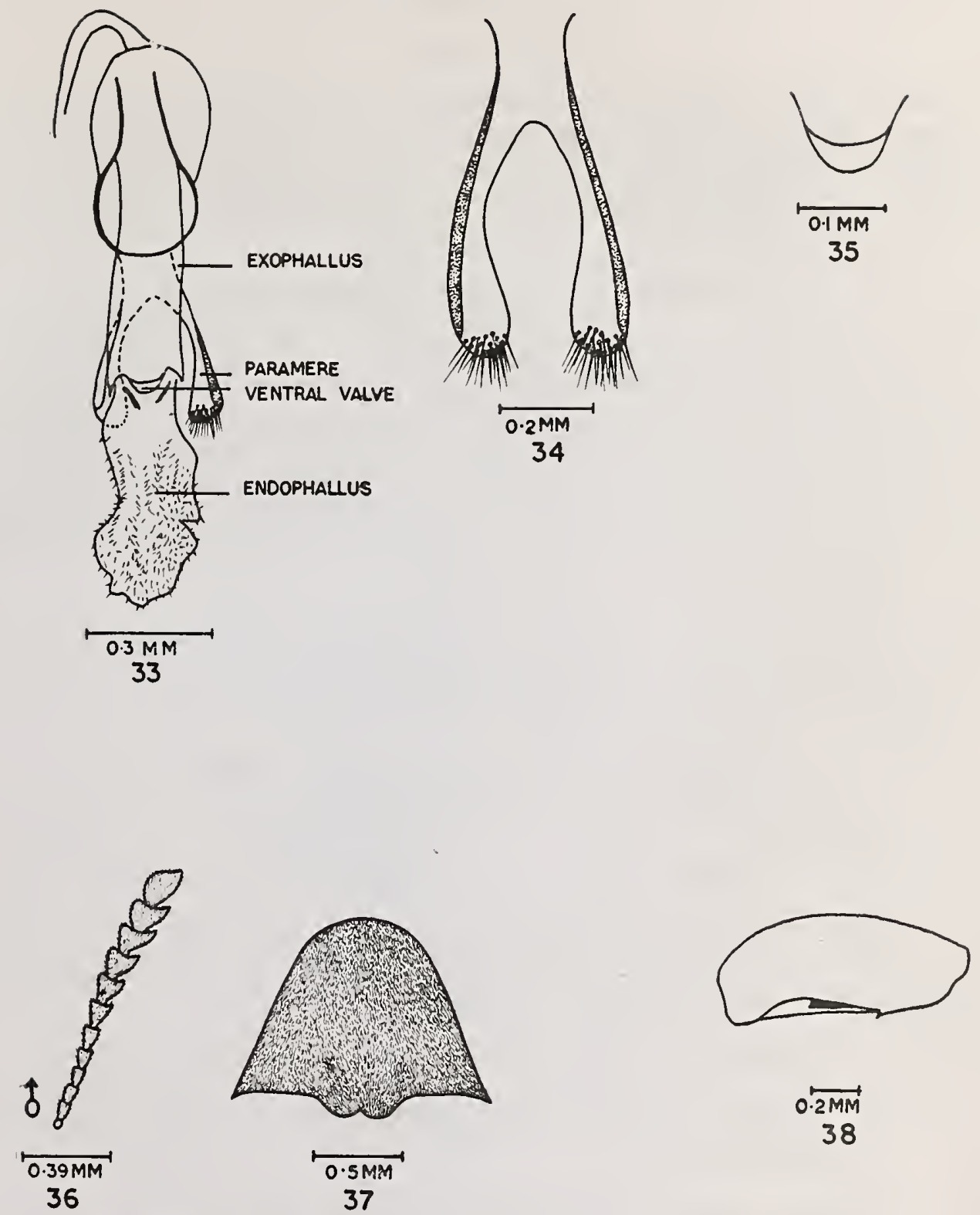

38

Bruchidius mathaii sp. nov.

Figs. 33. Phallus; 34. Parameres; 35. Exophallic valve; 36. Antenna; 37. Pronotum; 38. Hind femur. 


\title{
BRUCHIDIUS AMARAE sp. nov.
}

\author{
(Ref. No. 58) Photo VI
}

(Pl. 6 figs. 39-46)

Head dark brown, broader at posterior end; frons without carina, area between and behind the eyes raised, its surface covered with pale yellow setae; eyes small, moderately bulging, emarginate, canthus very small, narrow and shallow, its surface beset with pale-yellow setae. Antennae testaceous, sub-serrate, short and not surpassing base of pronotum, segments 1-4 cylindrical, segments 5-10 broader than long, segment 11 conical.

Pronotum dark brown, sub-conical, its surface pitted and uniformly covered with unicolorous fennelcolored setae.

Scutellum dark brown, broader than long, bifid posteriorly, its surface covered with fennel-colored setae. Elytra dark brown, together longer than broad, covering the anterior part of pygidium, its surface uniformly covered with fennel-colored setae, each elytron with a pair of tubercles at the bases of 3rd and 4th stria. Fore and middle legs testaceous with apices of tarsi and claws black; hind femur bicarinate below with inner carina bearing a pointed preapical tooth; hind tibia produced apically into two prominent spines internally and two small spines externally. Pygidium dark brown, oblique in both sexes, longer than broad, its surface covered with fennel-colored setae.

Phallus $0.934 \mathrm{~mm}$. long; parameres fused at bases to $1 / 5$ of their total length, ends flattened, spoonshaped, each carrying 14-15 long setae; endophallus weakly tuberculate and without lateral sclerotizations. at exophallic rim; exophallic valve a cone with sensory bodies at its tip.

Size moderate : length male 3.60 to $3.90 \mathrm{~mm}$

length female $3.50 \mathrm{~mm}$ to $3.80 \mathrm{~mm}$

Host : Albizzia amara

Localities-Bangalore, Trichur forest.

Holotype $M$, allotype F, INDIA; KARNATKA : Bangalore, iii, 1976, collected from Albizzia amara (family Leguminosae). Paratypes $1 M, 1 F$, KERALA ; Trichur forest iii, 1976. Deposited in Zoology Museum (Project Section), Panjab University, Chandigarh.

Salient features:- 1 . fennel-colored setae covering pronotum, elytra and pygidium;

2. Parameres fused at base to $1 / 5$ total length and bearing 14-15 setae on rounded tips;

3. Antennae testaceous;

4. Body, scutellum, pronotum and elytra dark brown;

Named after its host-plant.

Remarks : With antennae short, not surpassing base of pronotum; eyes moderately bulging; endophallus. tubular with tubercles only; body, antennae and legs not completely black; frons without carina; parameres. fused at base to less than $1 / 4$ length; elytra without a pattern and pygidium without dark areas, the present species is related to B.brunnetashii sp. nov. (Ref. No.61). It, however, differs from the latter in having scutellum broader than long (squarish in the other), in having light brown elytra with fennel-colored setae (elytra dark brown with pale white setae in B.brunnetashii), in having endophallus without sclerotized ring (endophallus 
PLATE 6

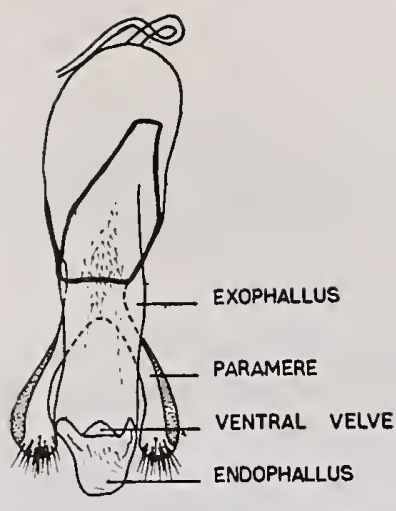

$0.3 \mathrm{MM}$

39

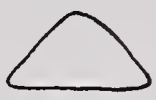

$\longdiv { 0 . 2 M M }$

41
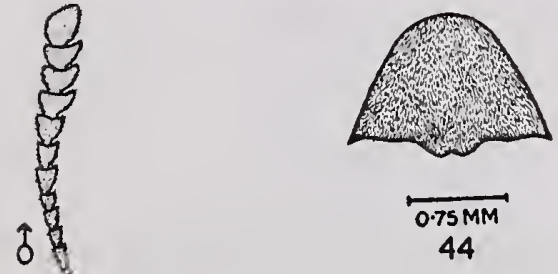

$0.39 \mathrm{MM}$

43

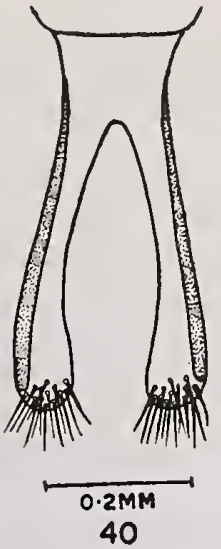

40
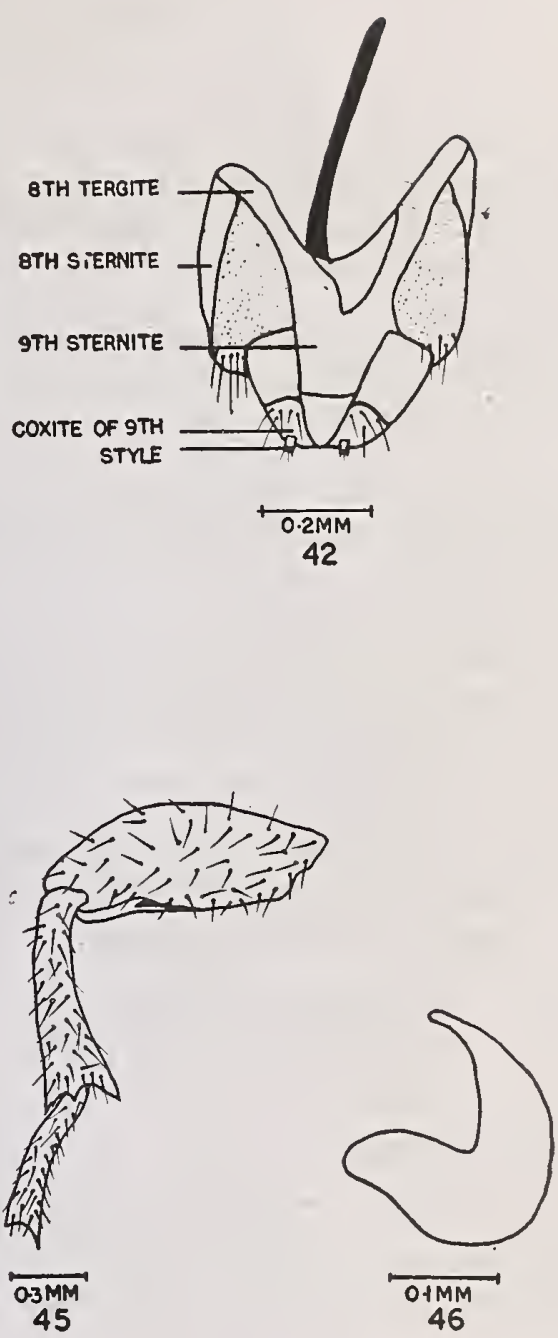

Bruchidius amarae sp. nov.

Figs. 39. Phallus; 40. Parameres; 41. Exophallic valve; 42. Female genitalia; 43. Antenna; 44. Pronotum; 45. Hind leg; 46. Spermatheca. 
in B.brunnetashii with a sclerotized ring), and exophallic valve conical with sensory bodies at tip (exophallic valve dome-shaped, without sensory bodies in the other).

\section{BRUCHIDIUS BANGALORENSIS sp. nov.}

(Ref. No. 59) Photos VII A \& B

(Pl. 7 figs. 47-54)

Head black, broader at posterior end; frons without carina, finely pitted, its surface covered with paleyellow setae; eyes moderately bulging, emarginate, canthus narrow and shallow, its surface beset with pale yellow setae. Antennae testaceous, sub-serrate, short and not surpassing base of pronotum, segments. $1-4$ cylindrical, segments $5-10$ broader than long, segment 11 conical.

Pronotum brown in male and uniformly covered with pale-yellow setae, dark brown in female, subconical, its surface punctate, covered with pale-yellow setae which are more aggregated at the median basal lobe, and a pair of dark patches, one on either side of the median line.

Scutellum brown in male, dark brown in female, broader than long, bifid posteriorly, its surface, beset with pale-yellow setae. Elytra brown in male and dark brown in female, together longer than broad, with a pair of tubercles at the bases of 3rd and 4th striae on each elytron, elytral surface sparsely covered with pale-yellow setae in male, a few spots of pale-yellow setae interrupted by large black areas in female. Fore and middle legs testaceous with apices of tarsi and claws black; hind legs dark brown with apices of tarsi and claws black; hind femur bicarinate below, inner carina with a pre-apical tooth, preceded by two small serrulations. Pygidium sub-vertical in both sexes, with a large spherical dark brown area in middle in male, blackish brown area in female, bounded by a rim of golden setae in both sexes.

Phallus $1.170 \mathrm{~mm}$. long; parameres fused at bases for $1 / 5$ of their total length, flattened into spoonshaped tips, each carrying 18-20 long setae; endophallus vase-shaped, having divergent ribs of sharp conical denticles; exophallic valve nipple-shaped.

Size : length male 4.50 to $4.60 \mathrm{~mm}$ length female $4.60-4.80 \mathrm{~mm}$

Host : Acacia sp.

Locality-Bangalore

Holotype $M$, allotype $F$, INDIA : KARNATKA : Bangalore, iii, 1976, collected from Acacia sp. (family Leguminosoe). Paratype $1 M$ with same data as holotype. Deposited in Zoology Museum (Project section), Panjab University, Chandigarh.

Salient features : 1. Frons without carina;

2. Forms dimorphic with elytra in male covered uniformly with pale-white setae, and a pattern of dark-brown lateral areas, a median dark area and several transverse irregular rows of white spots in female;

3. Pygidium with a large dark spherical spot;

Remarks :

4. Endophallus disteneded terminally.

With short antennae, not surpassing base of pronotum; eyes moderately bulging; endophallus with tubercles only; body, antennae and legs not completely black; frons without carina and endophallus distended terminally, the present species is allied to B. endotubercularis sp. nov. (Ref. No. 55) and B. variegata sp. nov. (Ref. No. 56). It, however, differs from them in having dimorphic sexes (sexes similar in the other two species), in having elytra, covered uniformly with pale-yellow setae in male, and a pattern of 


\section{PLATE 7}
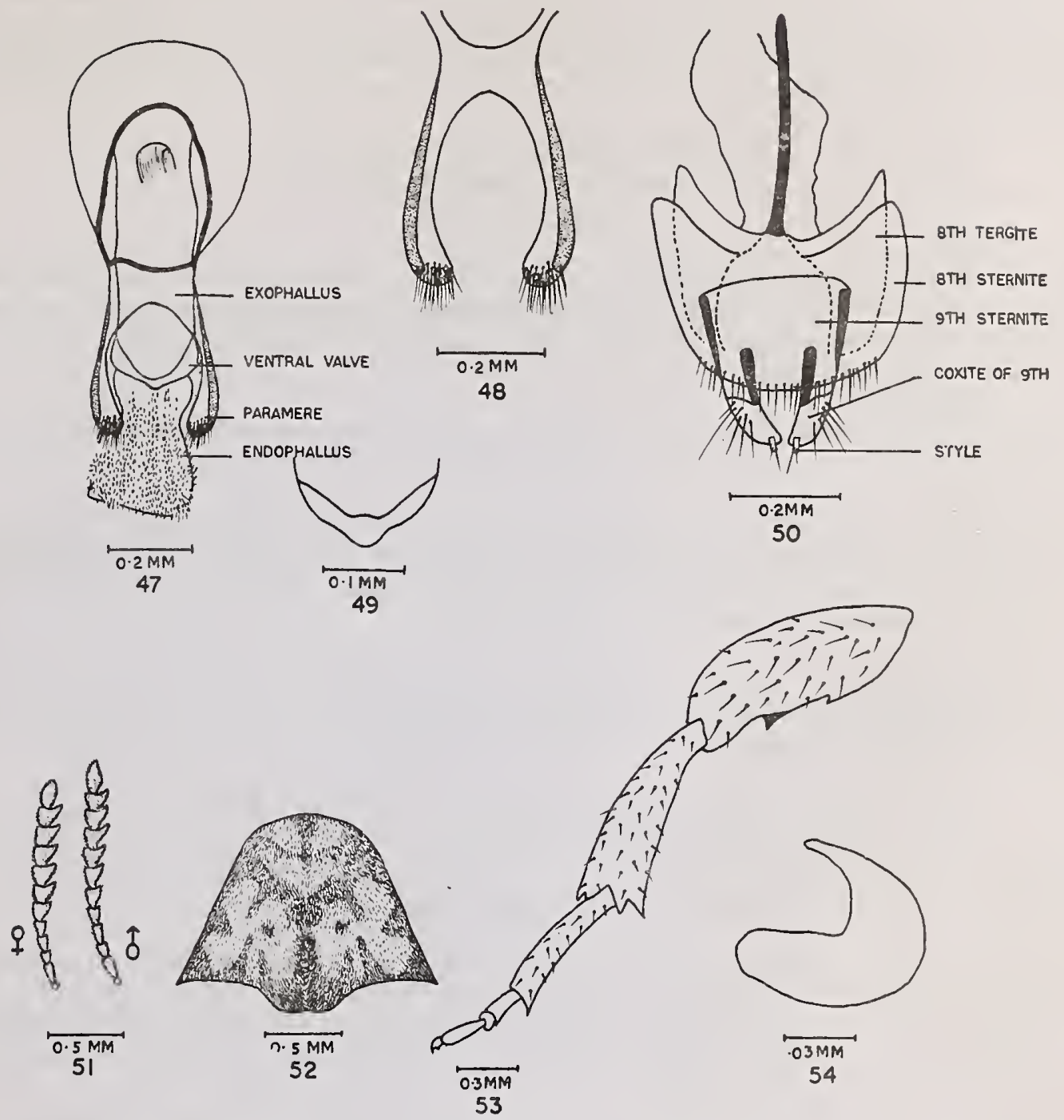

Bruchidius bangalorensis sp. nov.

Figs. 47. Phallus; 48. Parameres; 49. Exophallic valve; 50, Female genitalia; 51. Antennae; 52. Pronotum; 53. Hind leg; 54. Spermatheca. 
dark brown lateral areas, a median dark area and several rows of small white spots in female, (elongated spots of golden-yellow and white setae and a dark brown elytral apical spots in B. sp.nov. Ref. No. 55 . and dirty-white setae, intermingled with several black spots in $B$. sp.nov.-Ref. No. 56 with anterolateral and postero-lateral dark patches) $\mathrm{r}$ r d $\mathrm{jr}$ having a large spherical dark spot on pygidium (pygidium with a pair of lateral kidney-shaped spots in $B$. sp.nov.-Ref. No. 55, and two pairs of lateral spots in $B$. sp. nov. Ref. No. 56)

\section{BRUCHIDIUS EUPATORICUS sp. nov.}

(Ref. No. 60) PHOTO VIII

(Pl. 8 figs. 55-62)

Head black, brołder at posterior end; frons without carina, its surface covered with pale setae; eyes bulging, emarginate, canthus broad and shallow, its surface covered with pale golden setae. Antennae long, testaceous, sub-serrate, surpassing the base of pronotum, segments 1-3 cylindrical, segments 4-10 as broad as long with black marginations.

Pronotum dark brown, sub-conical, broader than long at base, its surface pitted and covered with white and pale setae.

Scutellum dark brown, squarish, its surface covered with pale setae; elytre with a basal, strial tuberculate area at the base of 4th stria. Fore and middle legs testaceous with apical part of tarsi black; hind femur bicarinate below, its inner carina with a small preapical tooth. Pygidium dark 'brown, longer than broad, vertical, its surface covered with pale white setae.

Phallus $1.281 \mathrm{~mm}$. long; parameres fused at bases to $3 / 5$ of their total length, each, tip rounded and carrying 6-8 setae; endophallus provided with 3 toothed plates and two rows of tubercles in addition to apical tub rrcles on saccus; exophallic valve pointed and conical.

Size moderate : length of male $3.00 \mathrm{~mm}$

length of female : $2.80-2.90 \mathrm{~mm}$

Hosts : Grass and Eupatorium sp.

Localities : Hessan Forest; Gujarat and Maharashtra.

Holotype $M$, allotype $F$, INDIA : KARNATKA; Hessan forest, i, 1976, colleoted from Eupatorium sp. Paratypes 4 MM, GUJARAT; Ahmadabad, i, 1978. Paratypes $14 M M, 5 F F$, GUJARAT; Junagarh, i, 1978, collected from grass in wheat field. Paratype $M$, MAHARASHTRA; Bombay, i, 1978. Paratypes 5 MM, 5 FF, MAHARASHTRA, Poona, i, 1978. Deposited in Zoology Museum (Project Section), Panjab University, Chandigarh.

Saliont features

1. Scutellum squarish;

2. Antennae with segments 1-3 cylindrical and segments $4-10$ as long as broad;

3. Elytra with a tuberculate area at base of 4th stria.

4. Endophallus with 3 endophallic plates and saccus with apical tubercles.

Remarks :

With antennae long and surpassing base of pronotum; greatly bulging eyes; size more than 2.50 $\mathrm{mm}$ in length; ground colour dark brown, (not black), the species is allied to B. cassiae Arora, B. angustifrons Schilsky and B. tephrosiae Arora. It, however, differs from them in having a squarish scutellum (scutellum longer than broad in the others), in having a tuberculate strial area at the base of 4th sstria (a bituberculate area at the bases of 3rd and 4th striae in B. cassiue; 3 strial basal tubercles at the bases of 2nd, $3 \mathrm{rd}$ and 4 th striae in B. angustifrons), and endophallus with apical tubercles on the saccus (apical 
PLATE 8
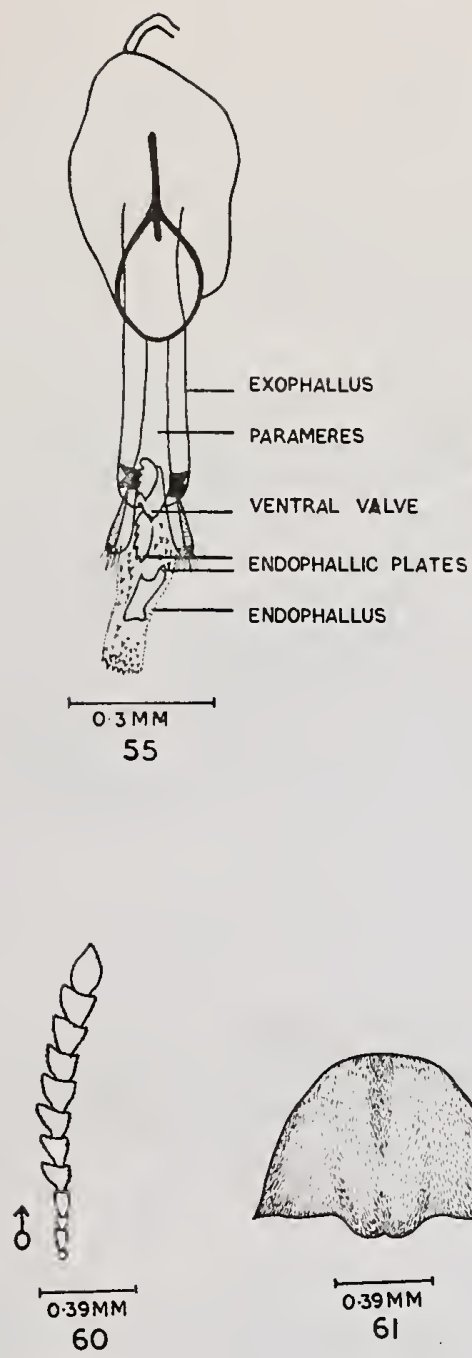
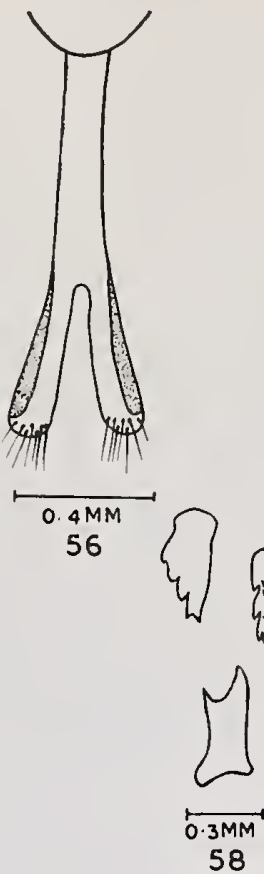
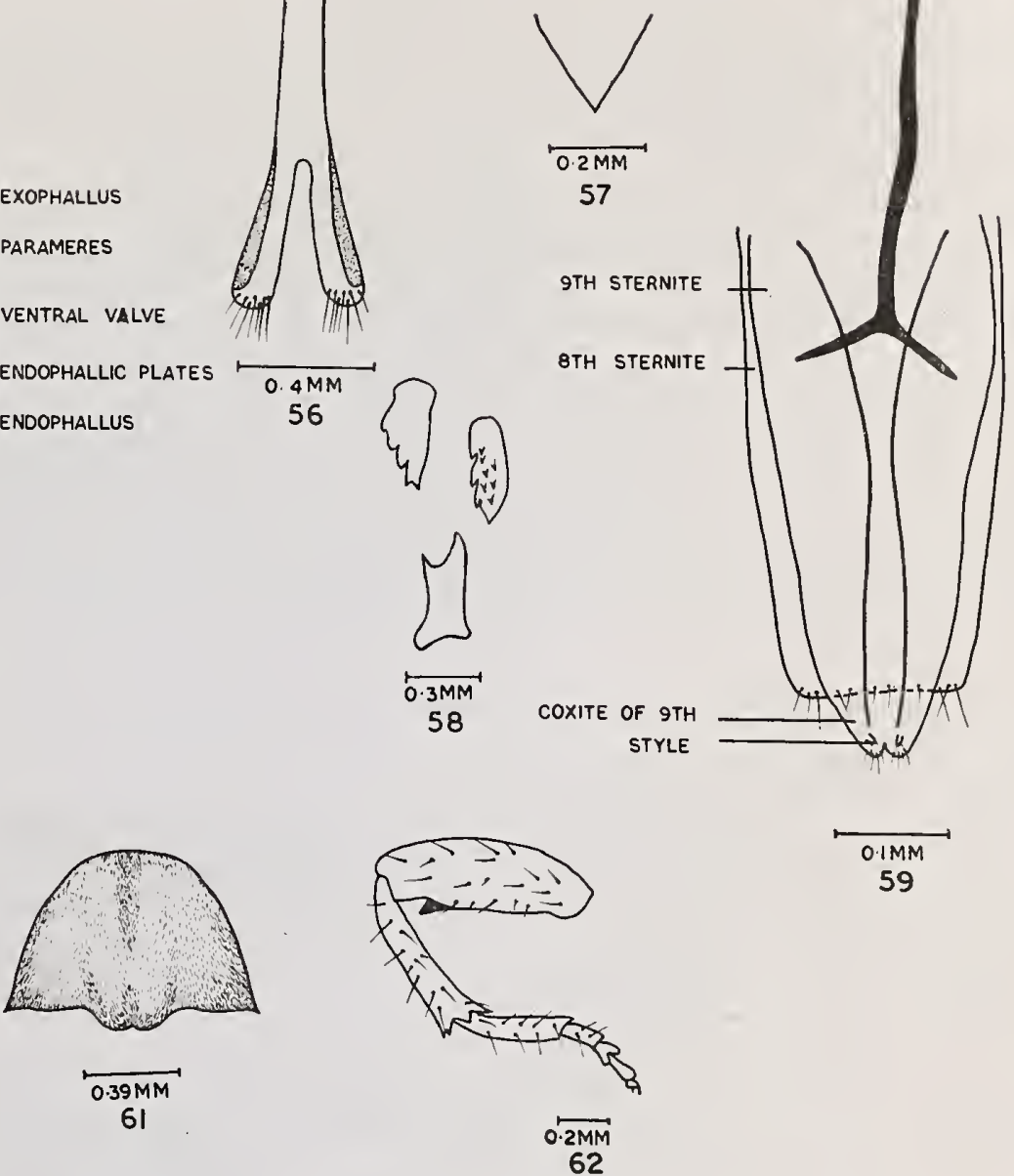

$0.1 \mathrm{MM}$

59

Bruchidius eupatoricus sp. nov.

Figs. 55. Phallus; 56. Parameres; 57. Exophallic valve; 58. Endophallic plates; 59. Female genitalia; 60. Antenna; 61. Pronotum; 62. Hind leg. 
tubsrcles absent in the other two).

The species is named after host plant Eupatorium sp.

BRUCHIDIUS BRUNNETASHII sp. nov.

(Ref. No. 61) PHOTO IX

(Pl. 9 figs. 63-68)

Head dark brown, broad posteriorly; frons without carina, with median area raised; its surface covered with pale-yellow setae; eyes slightly bulging, emarginate, canthus narrow to long, its surface covered with pale-yellow setae. Antennae brown, short and not surpassing base of pronotum, sub-serrate, segments 1-4 cylindrical, segnents 5-10 broader than long, 11th segment conical.

Pronotum dark brown, sub-conical, nearly as long as broad, its surface pitted and uniformly covered with pale-yellow setae. Scutellum dark brown, squarish, apically bifid, its surface covered with pale yellow setae. Elytra dark brown, longer than broad, covering anterior part of pygidium, with a common tuberculate area bearing a pair of tubercles almost fused at the bases of 3rd and 4th striae, the elytral surface covered uniformly with pale-yellow setae. Fore and middle legs testaceous with tarsi and claws black; hind femur bicarinate below, inner carina with a small blunt pre-apical tooth. Pygidium dark brown, subvertical, longer than broad. its surface covered with unicolorous pale-yellow setae.

Phallus $0.926 \mathrm{~mm}$. long; parameres fused slightly at bases to $1 / 7$ of their total length, well sclerotized, spoon-shaped tips, each carrying 18-20 long setae; endophallus short, thick and tubular. its surface studded with weakly sclerotized tubercles and a ring at base; exophalic valve dome-shaped; no lateral sclerotizations on exophallic rim.

Size moderate. length male $3.50-3.80 \mathrm{~mm}$

Host : from flowers and grass

Locality : Maduari forest (Tamil Nadu)

Holotype $M$, INDIA : TAMIL NADU; Maduari forest, xii, 1975, collected from flowers and grass. Paratypes $3 M M$ with the same data as holotype. Deposited in Zoology Museum (Project Section), Panjab University, Chandigarh.

Salient features: 1. Scutellum squarish:

2. Antennae brown;

3. Elytra dark brown with pale-white setae;

4. parameres fused slightly at base to $1 / 7$ total length; with $18-20$ parameral setae on spoon-shaped tip;

5. Endophallus short and tubular with sclerotized tubercles and a ring;

6. Exophallic valve dome-shaped without sensory bodies.

\section{Remarks :}

With short antennae, not surpassing base of pronotum; eyes slightly bulging; endophallus with tubercles only; body, antennae and legs differently colored but not completely black; frons without carina; elytra uniformly covered with setae and pygidium without dark areas, and a tubular endophallus, the present species is allied to B. amarae sp. nov. (Ref. No. 56). It, however, differs from the latter in having squarish scutellum (Scutellum broader than long in $B$. amarae), in having dark brown elytra with pale white setae (light brown elytra with fennel-colored setae in B. amarae), in having parameres fused at base to $1 / 7$ total length and bearing 18-20 parameral setae (parameres fused to $1 / 5$ basal length and bearing 14-15 parameral setae in B.amarae), in having endophallus with a strong ring in addition to tubercles (without a ring in $B$.amarae) and in having a dome-shaped exophallic valve without sensory bodies on tip (exophallic valve conical in $B$. amarae with sensory bodies on tip. 


\section{PLATE 9}
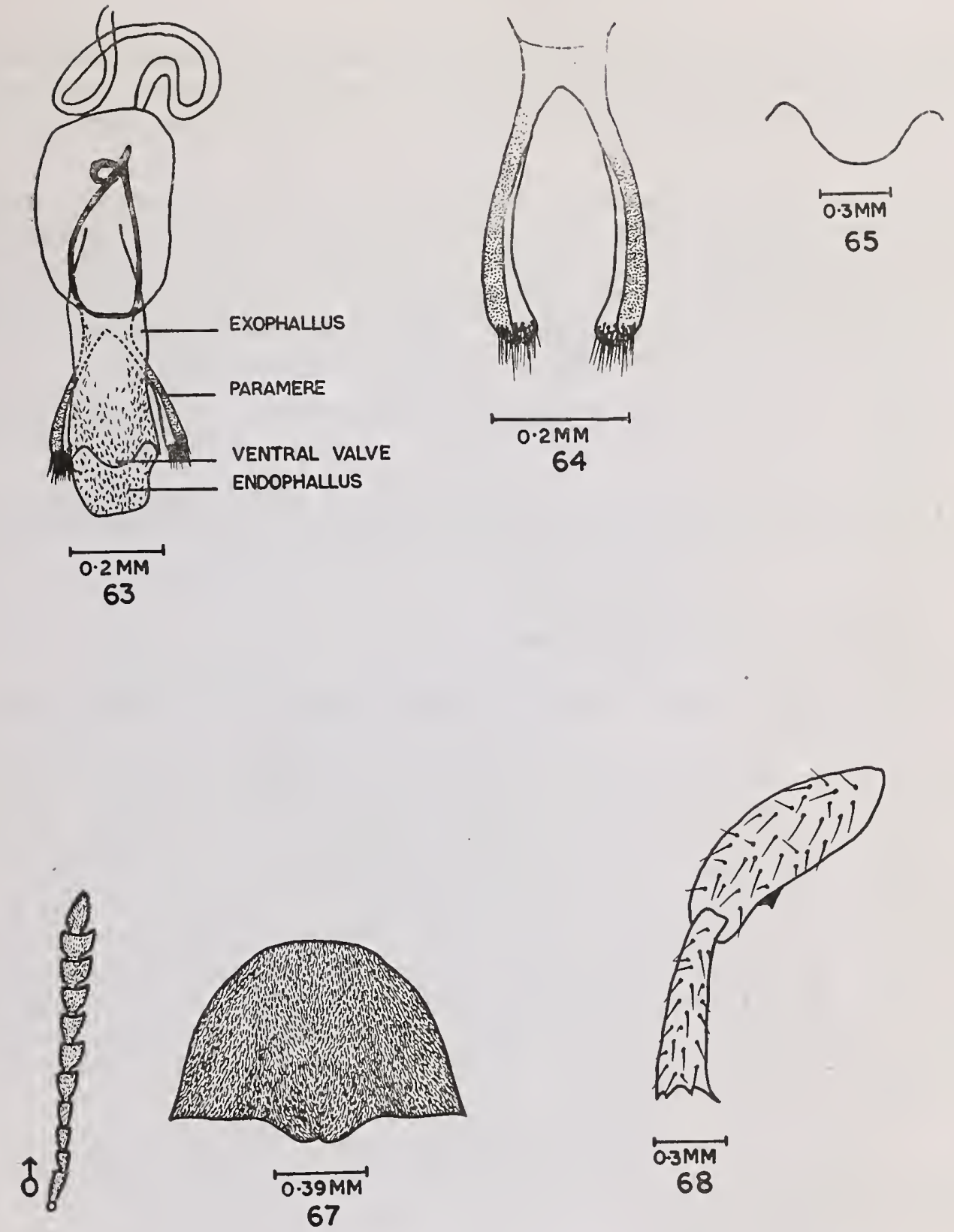

\section{$0.39 M M$ \\ 66}

Bruchidius brunnetashii sp. nov.

Figs. 63. Phallus; 64. Parameres; 65. Exophallic valve; 66. Antenna; 67. Pronotum; 68. Hind leg. 
BRUC HIDIUS SIWALIKUS sp. nov.

(Ref. No. 62) PHOTO X

(Pl. 10 figs. 69-77)

Head black, broader posteriorly; frons without carina, its surface bearing yellow pubesence; eyes bulging, emarginate, canthus narrow and shallow, its surface covered with yellow pubescence. Antennae testaceous, sub-serrate, long and surpassing base of pronotum, segments 1-3. cylindrical, segments 4-10 as long as broad.

Pronotum black,sub-conical, its surface uniformly covered with pale yellow pubescence. Scutellum black, squarish, its surface covered with pale-yellow pubescence. Elytra black, together longer than broad, and covering anterior part of pygidium; without any basal strial tubercles, its surface covered with pale setae, spots of white setae and some dark areas. Fore and middle legs testaceous with tarsi and claws blacks; hind legs black, hind femur bicarinate below and its inner carina bearing a small preapical tooth. Pygidium black, sub-vertical in both sexes, its surface covered with pale yellow pubescence.

Phallus $1.018 \mathrm{~mm}$. long; parameres fused at base to slightly more than, $1 / 2$ length, flattened tip. carrying 4 short setae.

Saccus of endophallus elongated and provided terminally with 2 small denticulated plates, and a third plate behind, bifid posteriorly with one arm fairly 'long; endophallus beset with numerous rows of strong, pointed tubercles; exophallic valve an elongated cone. '

Size small : length male $1.80 \mathrm{~mm}$ to $2.00 \mathrm{~mm}$

length female $1.70 \mathrm{~mm}$ to $2,00 \mathrm{~mm}$

Host : collected from grass.

Localities : Palampur, Mandi (H.P.) Uttar Pradesh, Gujarat, Madhya Pradesh, Bihar, Orissa and Maharashtra.

Hototype $M$, INDIA, HIMACHAL PRADESH : Kangra, vi. 1976 collected from grass. Allotype $F$, INDIA : HIMACHAL PRADESH; Mandi vi, 1976, collected from grass. Paratypes $4 M M$ with same data as holotype. Paratypes $6 \mathrm{MM}$, HIMACHAL PRADESH : Palampur, vi, 1976. Paratype $1 \mathrm{M}$, with same data as to allotype. Paratype $1 M$, HIMACHAL PRADESH : Kulu, vi, 1976. Paratypes $1 M$, $1 F$, HIMACHAL PRADESH : Sundernagar, vi, 1976. Paratype $1 F$, ORISSA : Simlipal Forest, i, 1977. Paratypes 6 MM, $1 F$, BIHAR : Ranchi i, 1977. Paratype $1 M$, BlHAR : Ramgarh ii, 1977. Paratypes $11 M M, 4 F F$, GUJARAT: Junagarh, i, 1978. Paratypes $16 \dot{M} M, 6 F F$, MAHARASHTRA: Poona, i, 1978. Paratypes/ $M M, 7 F$, MAHARASHTRA, Parbhani, i, 1978, Paratypes $4 M M, 2 F F$ MAHARASHTRA : Nagpur, ii, 1978. Paratypes $6 \mathrm{MM}, 4 \mathrm{FF}$, MADHYA PRADESH : Jabalpur, ii, 1978, Paratypes, 8 MM, 5 FF, UTTAR PRADESH : Dehradun vi, 1978. Deposited in Zoology Museum (Project Section), Panjab University, Chandigarh.

Salient features : 1. Elytra without basal 'strial tubercles; with pale setae, spots of white setae and dark areas;

2. Endophallus with 3; endophallic plates;

3. Scutellum squarish ;

4. Parameres distended distally, rounded, each carrying 4 setae;

\section{Remarks}

With long unicolorous antennae, surpassing base of pronotum; greatly bulging eyes; size less than $2.5 \mathrm{~mm}$; ground colour black; elytra without basal strial tubercles; and endophallus with 3 endophallic 
PLATE 10

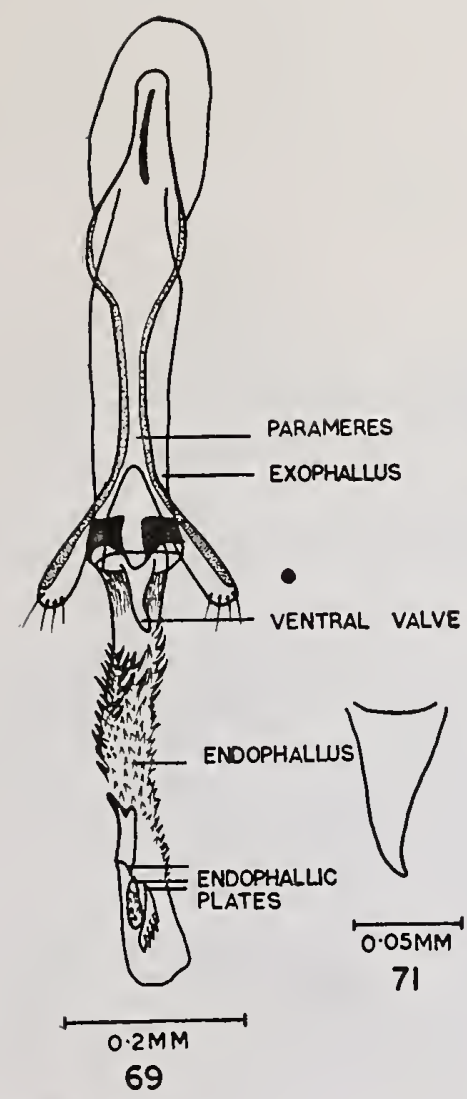

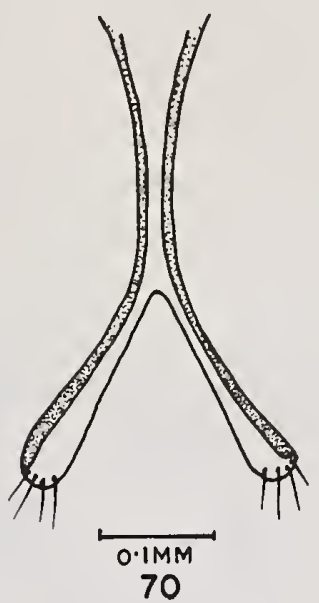

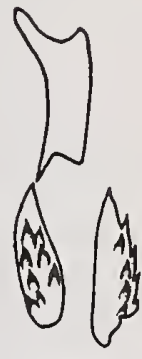

$0.05 \mathrm{MM}$

72

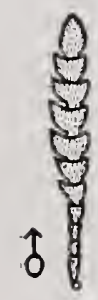

$0.39 \mathrm{MM}$

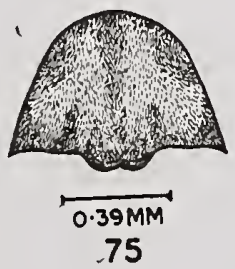

.75

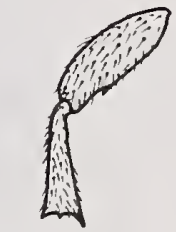

$0.4 \mathrm{MM}$

76
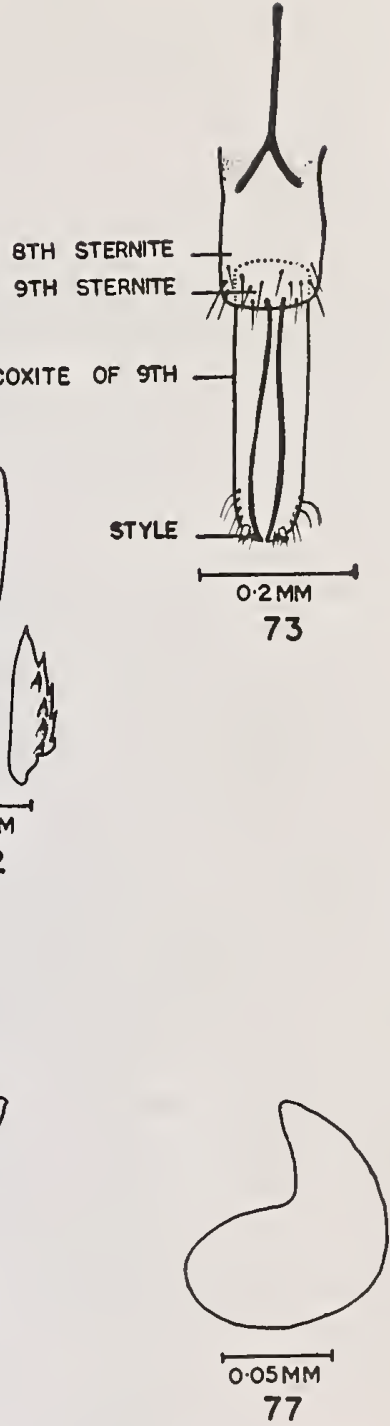

Bruchidius siwalikus sp. nov.

Figs. 69. Phallus; 70. Parameres; 71. Exophallic valve; 72. Endophallic plates;

73. Female genitalia; 74. Antenna; 75. Pronotum; 76. Hind femur; 77. Spermatheca. 
plates, the present species is allied to $B$. desmodei sp. nov. (Ref. No. 64) and B. anusurindrii sp. nov. (Ref. No. 74). It, however, differs from them in having squarish scutellum (Scutellum broader than long in B. desmodei : and longer than broad in B.amusurindrii), in having elytra with pale setae and spots of white setae intermingled with dark areas (elytra with golden setae and without dark areas in the other two), in having tips of parameres rounded with 4 parameral setae (parameres truncated distally and carrying 5 parameral setae in $B$. desmodei; and notched distally and carrying 7 parameral setae in $B$. anusurindrii

\section{BRUCHIDIUS ORISSIENSIS sp. nov.}

(Ref. No. 63) PHOTO XI

\section{(P1 11. figs. 78-83)}

Head dark brown, slightly broader at pssterior end; frons ecarinate, its surface beset with pale pubescence; eyes greatly bulging, emarginate, canthus broad and shallow, beset with pale setae. Antennae long, yellowish, sub-serrate, surpassing base of pronotum and reaching the middle of elytra, segments 1-10 cylindrical, longer than broad, segment 11 black and conical.

Pronotum sub-conical, dark brown, covered with golden setae all over with a well marked, raised quadrangular, prescutellar area.

Scutellum broader than long, apically bifid, its surface covered with white setae. Elytra mostly darkbrown except their apices which are yellowsih, the two elytra together longer than broad, with a basa] strial tubercle each at the bases of 3rd and 4th striae, its surface covered uniformly with golden setae. Legs. testaceous except claws which are black; hind femur bicarinate below, inner carina with a small, broad, pre-apical tooth; hind tibia produced apically into a large inner spine, a slightly smaller median spine and outer denticles. Pygidium vertical, light brown, uniformly covered with golden setae.

Phallus $0.942 \mathrm{~mm}$. long; parameres elongated, terminally dilated and notched, each bearing 4 sler der se tate, fused at base to $1 / 3$ total length; endophallus tubular, covered with short blunt tubercles with a pair of small, overlapping, weakly denticulated plates; exophallic value conical; dorsal valve composed of two beak-shaped, multipronged plates, laterally connected to exophallic rim; a pair of lateral sclerotizations. and a pair of medio-lateral hair brushes also present.

Size : length of male $2.40 \mathrm{~mm}$

Host : Grass

Locality : Simlipal forest, Jaishipur (Orissa)

Holotype $M$, : INDIA : ORISSA : Simlipal Hill forest, Jashipur, i, 1977, one specimen only collected from grass. Deposited in Zoology Museum (Project Section), Panjab University, Chandigarh.

Salient features : 1. Antennae yellowish with a black terminal segment;

2. A well marked, raised prescutellar area on pronotum;

3. A dorsal value on the phallus,

4. Endophallus with 2 endophallic plates.

Remarks

With long antennae, surpassing base of pronotum; greatly bulging eyes; size less than $2.50 \mathrm{~mm}$; ground color dark brown; elytra with a tubercle each at the bases of 3rd and 4th striae; a raised prescutellar area on the pronotum; prominent terminal black segment on antenna; a dorsal valve on phallus and two endophallic plates, the present species is closely allied to B. puncto-terminalis sp. nov. (Ref. No. 66). It, however, differs from the latter in having the scutellum broader than long (scutellum longer than broad in 


\section{PLATE il}
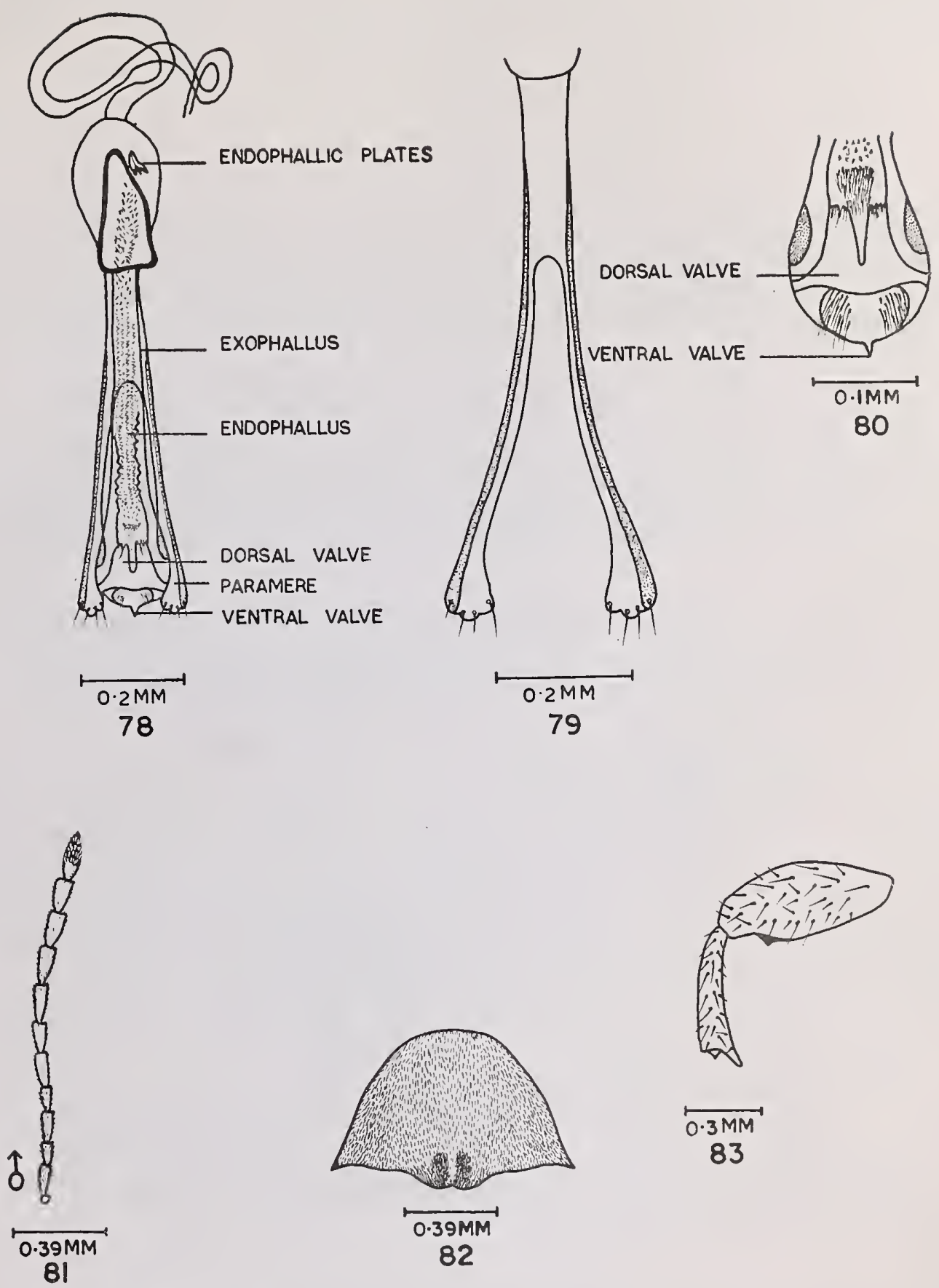

83

Bruchidius orissiensis sp. nov.

Figs. 78. Phallus; 79. Parameres; 80. Dorsal and ventral valves; 81. Antenna; 82. Pronotum; 83. Hind femur. 
$B$. punctoterminalis), in having elytra covered with golden setae (elytra in $B$. punctoterminalis havin g elongated spots of yellowish white and brown setae, and dark areas), in having parameres fused at base to $1 / 3$ total length (parameres fused at base to more than $1 / 2$ length in $B$. punctoterminalis) and in having a beakshaped dorsal valve (dorsal valve vase-shaped in $B$. punctoterminalis).

\section{BRUCHIDIUS DESMODEI sp. nov.}

\section{(Ref. No. 64) PHOTO XII}

(Pl. 12. figs. 84-92)

Head black, broader at posterior end; frons carinate, its surface beset with golden pubescence; eyes bulging, emarginate in front, canthus broad and shallow, with its surface covered with golden setae. Antennae testaceous in both sexes, slightly longer in male, reaching beyond base of pponotum, segments 1-4 cylindrical, segments 5-10 slightly broader than long in female, and nearly as long as broad in male, sub-serrate, segment 11 conical.

Pronotum black, sub-conical, with its surface pitted and uniformly covered with golden setae.

Scutellum black, slightly broader than long, apically bifid. Elytra black, together longer than broad, without basal strial tubercles, its surface covered mostly with golden setae, intermingled with spots of white setae. Legs testaceous, except dark claws; hind femur bicarinate below, with inner carina carrying a small pre-apical tooth. Pygidium black, vertical in both sexes, its surface uniformly covered with golden and white setae.

Phallus $0.854 \mathrm{~mm}$. long; parameres fused at base to slightly more than $1 / 2$ total length, truncated distally, each carrying 5 setae; endophallus with two rows of flattened disc-shaped tubercles and 3 toothed plates on saccus, one behind the other, the second one being the longest; exophallic valve conical.

Size short : length male $1.90-2.00 \mathrm{~mm}$ length female $1.80-2.00 \mathrm{~mm}$

Host : plant - Desmodium pulchellum Benth

Localities: $\quad$ Simlipal Hills, Jaishipur (Orissa); Himachal Pradesh and Tamil Nadu.

Holotype $M$, allotype $F$; INDIA : ORISSA; Simlipal Hill forest, Jaishipur, i, 1977, collected from Desmodium pulchellum. Paratypes $19 \mathrm{MM}, 19 \mathrm{FF}$, with the same data as holotype. Paratypes $9 \mathrm{MM}, 8 \mathrm{FF}$, HIMACHAL PRADESH; Kangra $x$, 1977. Paratypes (Washington collection) TAMIL NADU : Coimbatore. Deposited in Zoology Museum (Project Section), Panjab University, Chandigarh.

Salient features : 1. Elytra without basal strial tubercles; with golden setae and without dark areas;

2. Antennae testaceous;

3. Scutellum broader than long;

4. Parameres fused at base to more than $1 / 2$ total length, tuncated distally and bearing 5 parameral setae;

5. Endophallus with 2 rows of disc-shaped tubercles and 3 endophallic plates;

6. Exophallic valve short and conical.

Remarks

With long antennae, surpassing base of pronotum; greatly bulging eyes; size less than $2.5 \mathrm{~mm}$; ground colour black; elytra without basal strial tubercles; unicolorous testaceous antennae; elytra with gloden seatae and without dark areas, and 3 endophallic plates, the present species is closely related 
PLATE 12
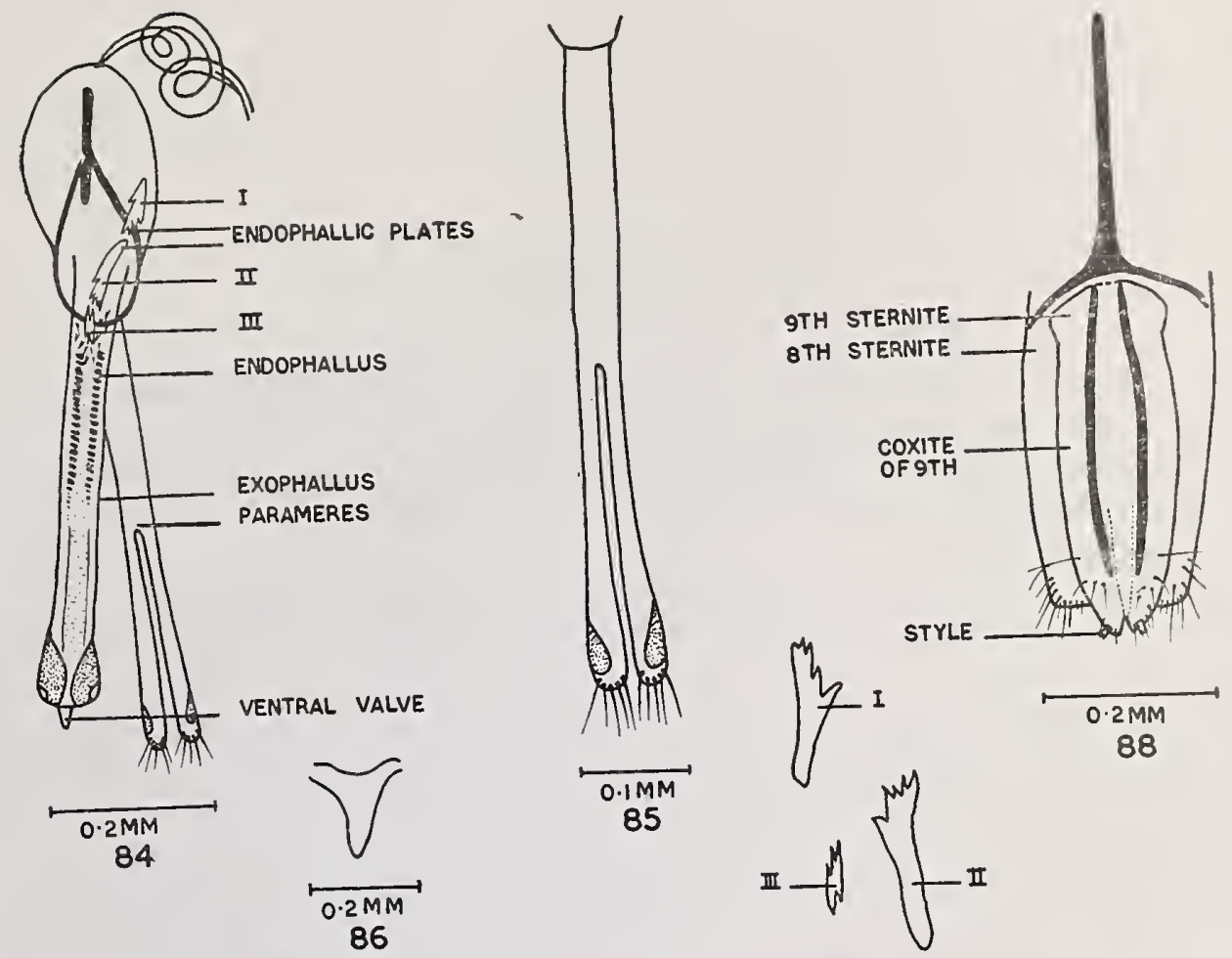

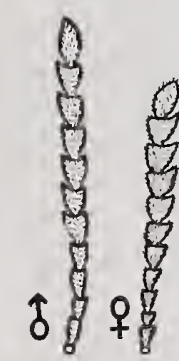

$0.39 \mathrm{MM}$ 89

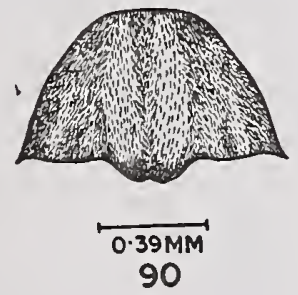

90
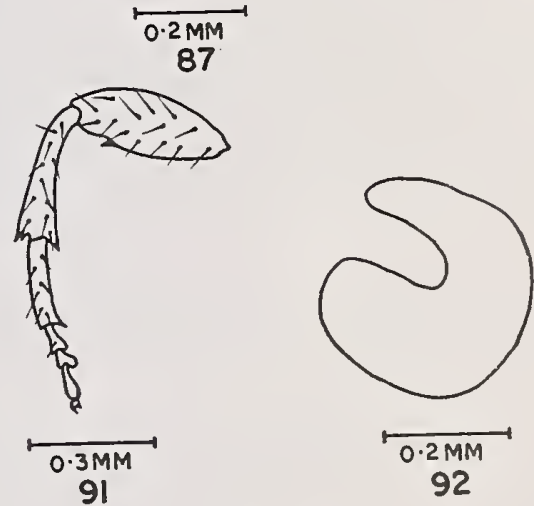

Bruchidius desmodei sp. nov.

Figs. 84. Phallus; 85. Parameres; 86. Exophallic valve; 87. Endophallic plates; 88. Female genitalia; 89. Antennae; 90. Pronotum; 91. Hind leg; 92. Spermatheca. 
B. anusurindrii sp. nov. (Ref. No. 74) It, however, differs from the latter in having scutellum broader than long (Scutellum longer than broad in B. anusurindrii), in having parameres truncated distally and fused at base to more than $1 / 2$ length (Parameres notched distally and fused at base to less than $1 / 2$ length in the other), in having 5 parameral setae ( 7 parameral setae in $B$. anusurindrii), in having endophallus with disc-shaped tubercles and a small basal endophallic plate (endophallus with short, pointed tubercles and an elongated basal endophallic plate, bifid anteriorly and trifid posteriorly in $B$. anusurindrii), and in having a short, conical exophallic valve (exophallic valve a long cone in $B$. anusurindrii).

BRUCHIDIUS DORSIVALVIA sp. nov.

(Ref. No. 65) PHOTOS XIII A \& B

(Pl. 13. figs. 93-100)

Head black, broader at posterior end; frons carinate, punctate between eyes, its surface covered with golden and white setae; eyes bulging, emarginate, canthus shallow and narrow, beset with white setae. Antennae long, surpassing base of pronotum, longer and deeply serrate in male, comparatively short and serrate in female, antennal segments 1. 4 testaceous, rest black, segments 5-10 longer than broad in male and broader than long in female.

Pronotum black, sub-conical, its surface pitted, with a posterior median row of white setae in front of scutellum.

Scutellum black, longer than broad, apically bifid. Elytra black, together longer than broad, striae punctate, without basal strial tubercles, its surface sparsely covered with golden and white setae, latter forming irregular transverse rows (distinctly marked spots in female). Fore and middle legs light yellowish except distal, black tarsal segments; hind legs light brown, hind femur bicarinate below, its inner carina with a small blunt spine; hind tibia produced apically into a big internal spine, a small median and two outer denticles. Pygidium black, sub-vertical, roughly triangular and sparsely beset with small setae.

Phallus $0.866 \mathrm{~mm}$. long; parameres fused at base to $1 / 5$ total length, slightly broadened distally, each bearing 5 long setae; endophallus short, tubular, profusely studded with prominent sharp pointed tubercles all over, and a pair of narrow, elongated somewhat tuberculated plates a little behind its terminal end; exophallic valve like a dome at base and produced into a triangular process; a quadrangular dorsal valve, a pically bifid and hinged at two basal points on exophallic rim; exophallic rim with a pair of lateral sclerotizations.

Size : length male $1.80-2.2 \mathrm{~mm}$ length female $1.80-2.17 \mathrm{~mm}$

Host : from grass

Localities : $\quad$ West Bengal, Bihar, Maharashtra, Andhra Pradesh

Holotype $M$, INDIA : WEST BENGAL : Burdwan, i, 1977, collected from grass. Allotype F, INDIA : BIHAR; Patna, ii, 1977, collected from grass. Paratype $1 F$, with the same data as holotype. Paratypes $2 M M, I F$, with the same data as allotype. Paratypes $6 M M, 11 F F$, MAHARASHTRA: Poona i, 1978. Paratypes $3 \mathrm{FF}$, ANDHRA PRADESH; Kinnersamiganj, xii, 1978. Deposited in Zoology Museum (Project Section), Panjab University, Chandigarh.

Salient features : 1. Elytra without basal strial. tubercles;

2. Endophallus short, tubular, profusely studded with sharply pointed tubercles all over and 2 narrow, elongated, tuberculate plates;

3. Exophallic valve dome-shaped at base with triangular pointed process ;

4. A quadrangular dorsal value, apically bifid and hinged to exophallic rim. 


\section{PLATE 13}
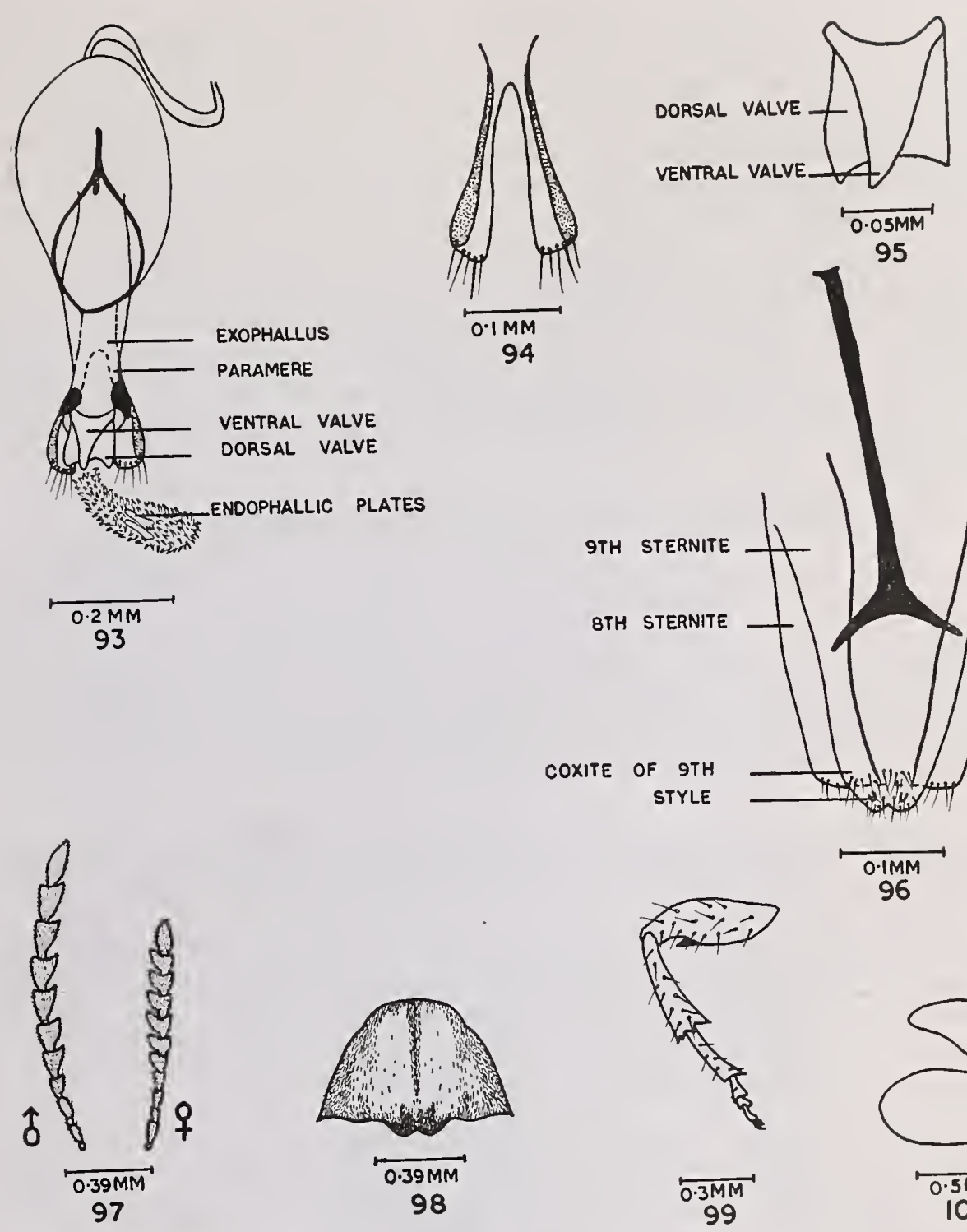

Bruchidius dorsivalvia sp. nov.

Figs. 93. Phallus; 94. Parameres; 95. Dorsal and ventral valves; 96. Female genitalia; 97. Antennae; 98. Pronotum; 99. Hind leg; 100. Spermatheca. 


\section{Remarks :}

With long antennae, surpassing base of pronotum; greatly bulging eyes; size less than $2.5 \mathrm{~mm}$; ground colour black; elytra without basal strial tubercles; with 4 basal antennal segments testaceous, rest black; elytra with white setose spots intermingled with spots of pale and golden setae, the precsent species is related to $B$. mimutus (F.) and B. microminutus sp. nov. (Ref. No. 73), the three forming a group; B. minutus (F.) being easily separated from the other two by its squarish scutellum, its parameres fused at base to much more than $1 / 2$ total length, bearing $9-10$ parameral setae, and in the absence of a dorsal valve (scutellum longer than broad, parameres fused to less that $1 / 2$ length and bearing 5-8 parameral setae, and the presence of a dorsal valve in the other two). The present species $B$. dorsivalvia sp. nov., however, differs from $B$. microminutus sp. nov. in having parameres fused at base to $1 / 5$ total length, each broadened terminally and bearing 5 long parameral setae (parameres fused to $1 / 4$ total length, each conical terminally and bearing 7-8 parameral setae in $B$. microminutus), in having 2 endophallic plates and the endophallus profusely studded with sharp, pointed tubercles (endophallus with 4 endophallic plates and numerous blunt tubercles in $B$. microminutus), and in having a quadrangular dorsal valve (dorsal valve composed of 2 wine-glass-shared plates in $B$. microminutus).

\section{BRUCHIDIUS PUNCTOTERMINALIS sp. nov.}

\section{(Ref. No. 66) PHOTO XIV}

(Pl. 14. figs. 101-106)

Head black; frons carinate, punctate between eyes, its surface covered with pale-white setae; eyes large, bulging and somewhat flattened from above, emarginate, canthus broad and shallow, its surface covered with pale yellow setae. Antennae long, surpassing the base of pronotum, testaceous with a black-tipped terminal segment, segments 1-10 cylindrical, longer than broad, sub-serrate, segment 11 conical, black tipped.

Pronotum dark-brown, sub-conical with a raised U-shaped, pre-scutellar area, thickly set with paleyellow setae, surface of pronotum pitted and clothed with pale-yellow and brown setae.

Scutellum black, longer than broad, its surface covered with pale-yellow setae. Elytra dark brown, together longer than broad, with a pair of tubercles at the bases of $3 \mathrm{rd}$ and 4th striae, surface of elytra with a large median, more or less triangular, and a pair of smaller, rectangular, postero-lateral dark brown areas, with numerous variously elongated spots of yellowish-white and brown setae, lying anterior and posterior to the dark areas, and the elytral apices densely covered with golden yellow setae.

Fore and middle legs testaceous; hind legs light brown; hind femur bicarinate below with a strong, bluntly pointed pre-apical tooth on inner carina; hind tibia produced apically into an internal large, pointed spine, a pair of small blunt external spines and a small median spine. Pygidium dark brown, vertical, longer than broad, its surface covered with pale-yellow setae.

Phallus $1.138 \mathrm{~mm}$ long; parameres elongated, slightly dilated terminally and notched, fused at base for more than $1 / 2$ total length, each bearing 5 slender setae; endophallus tuberculated with a pair of elongated, pointed, sclertozied plates behind its middle; exophallic valve conical; dorsal valve vase-shaped with the lateral semicircular sclerotizations and a median disc-shaped sclerotization, each plate of the valve articulating with exophallic rim; weak lateral sclerotizations on exophallic rim.

Size moderate : length male $2.50 \mathrm{~mm}$

Host : grass

Locality : Batote (Jammu and Kashmir) 


\section{PLATE 14}
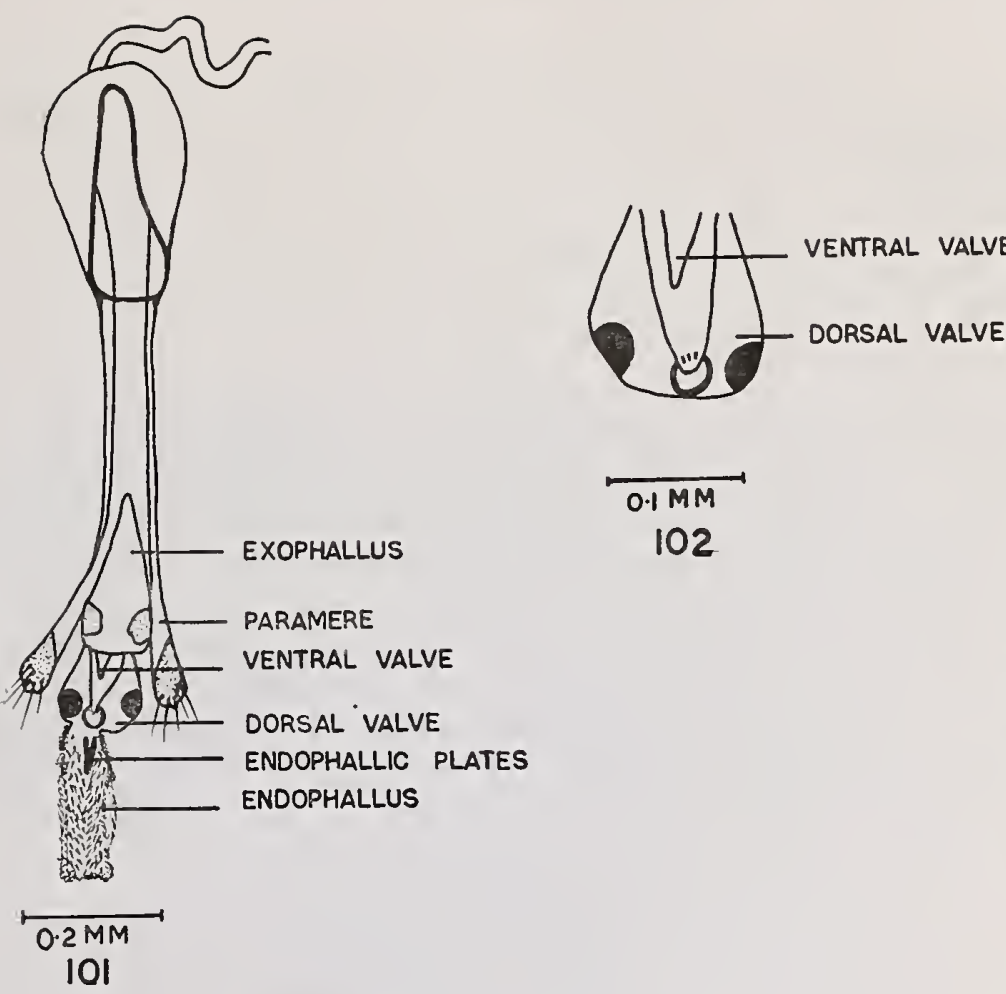

102
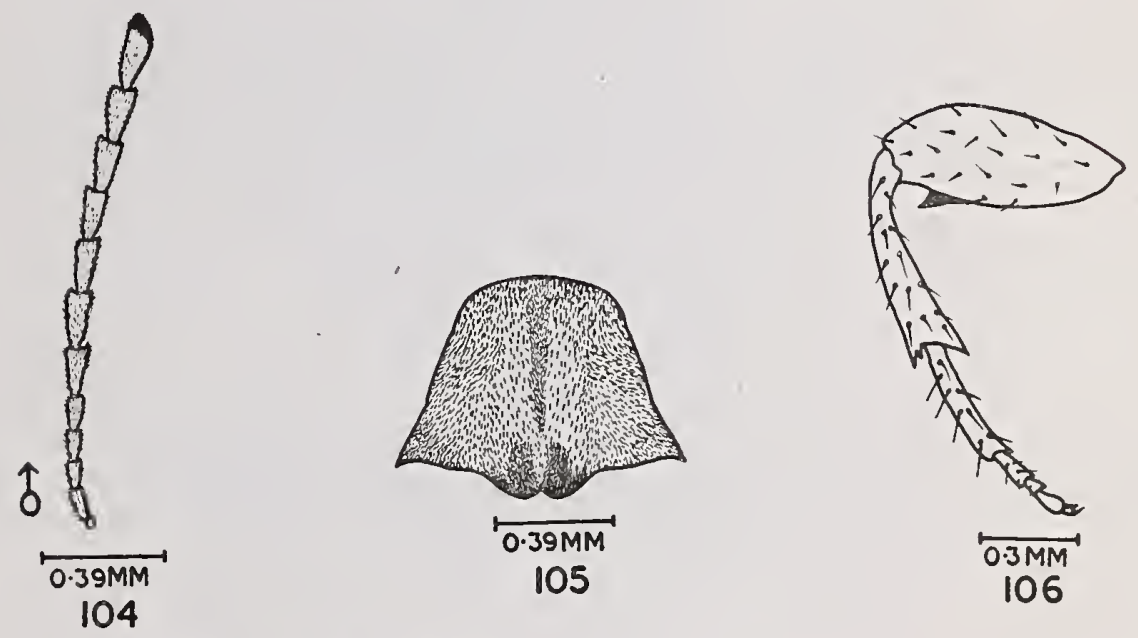

Bruchidius punctoterminalis sp. nov.

Figs. 101. Pnallus; 102. Ventral and dorsal valves; 103. Parameres; 104. Antenna; 105. Pronotum; 106. Hind leg. 
Holotype M, INDIA : JAMMU AND KASHMIR; Batote, viii, 1977, collected from grass. Deposited in Zoology Museum (Project section), Panjab University, Chandigarh.

Salient features :

1. Antennae long, surpassing base of pronotum, sub-serrate, testaceous with terminal segment: conical and black at tip;

2. Eyes flattened dorsally;

3. Raised, median posterior, U-shaped prescutellar area on pronotum;

4. Dorsal valve vase-shaped with 3 sclerotizations.

Remarks

With long yellowish antennae, surpassing base of pronotum; bulging eyes; size $2.5 \mathrm{~mm}$; ground colour black; obscure host-plant; elytra with a tubercle each at the bases of 3rd and 4th striae; pronotum with a raised pre-scutellar area; antennae yellowish with a terminal black segment; a dorsal valve and two endophallic plates, the present species is closely related to B. orissiensis sp. nov. (Ref. No. 63). It, however, differs from the latter in having scutellum longer than broad (scutellum broader than long in B. orissicnesis), in having elytra with elongated spots of yellowish-white and brown setae, and a large median and small lateral dark areas elytra with golden setae only and without dark areas in $B$. orissiensis), in having parameres fused at base to more than $1 / 2$ length (parameres in $B$. orissifensis fused at base to about $1 / 3$ length), and in having a vase-shaped dorsal valve with three sclerotizations (dorsal valve in B. orissifensis composed of beak-shaped plates and provided with brushes of hair).

BRUCHIDIUS KASHMIRENSIS sp. nov.

\section{(Ref. No. 67) PHOTO XV}

\section{(P1. 15. figs. 107-115)}

Head black; frons weakly carinate posteriorly, its surface covered with pale-white setae; eyes protruding, emarginate in front, canthus narrow and shallow, its surface covered with pale-white setae. Antennae brownish, longer in male, surpassing base of pronotum, serrate, segments 1-3 elongated, segments 4-10 nearly as long as broad in male, segments 4-10 slightly broader than long in female, segment 11 sub-conical.

Prontoum black, sub-conical, broader at base, narrowed anteriorly with punctate surface, its median prescutellar area slightly depressed and densely covered with pale-yellow setae.

Scutellum black, longer than broad, bifid posteriorly, its surface covered with pale-white setae. Elytra black, together longer than broad, with a tubercle each at the bases of 3rd and 4th striae, striae punctate, elytral surface showing narrow elongated spots in irregular, transverse rows covered with paleyellow setae, with a narrow dark median area continued laterally into apical dark areas. Fore and middle legs testaceous with femoral bases and tips of tarsi black; hind legs black, each femur bicarinate below, its inner carina with a small, pointed pre-apical tooth; hind tibia produced apically into a prominent internal spine and 2 small external spines. Pygidium, black, broader than long, vertical in both sexes, its surface covered with pale-white setae.

Phallus $1.046 \mathrm{~mm}$ long; parameres spoon-shaped, slightly dilated terminally, fused at bases to $1 / 6$ of their total length, each bearing 8 long parameral setae; emdophallus tubular, covered with rows of sharply pointed tubercles, saccus with two terminal, toothed endophallic plates and a narrow untoothed basal plate; exophallic valve alongated cone; exophallic rim with lateral sclerotizations. 
PLATE 15
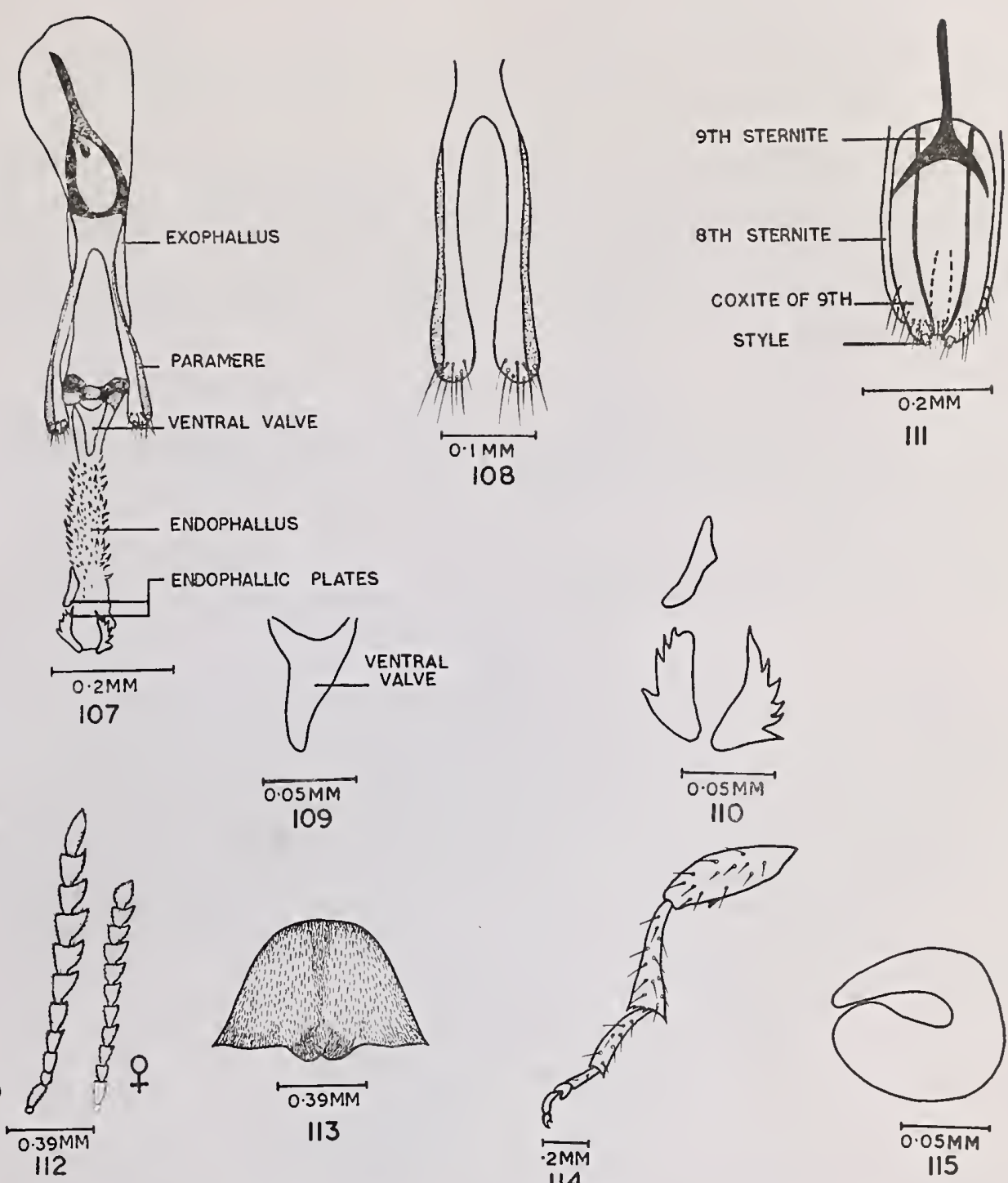

ENDOPHALLUS

ENDOPHALLIC PLATES
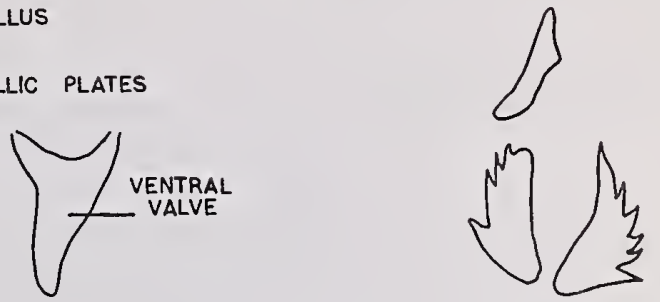

$0.05 \mathrm{MM}$

109

$\overrightarrow{0.05 \mathrm{MM}}$

110
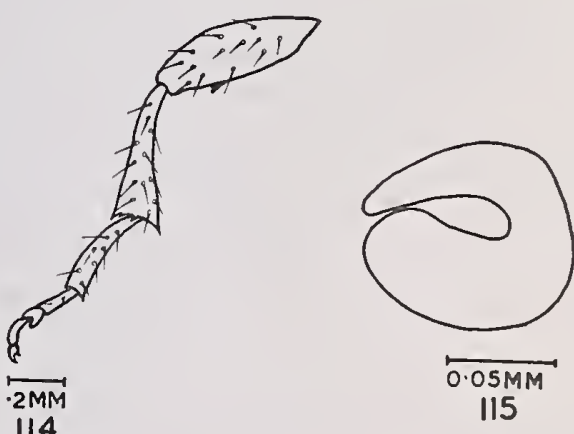

114

Bruchidius kashmirensis sp.nov.

Figs. 107. Phallus; 108. Parameres; 109. Exophallic valve; 110. Endophallic plates; 111. Female genitalia; 112. Antennae; 113. Pronotum; 114. Hind leg; 115. Spermatheca. 
Size small : length male $2.00-2.20 \mathrm{~mm}$ length female $2.00-2.10 \mathrm{~mm}$

Host plant : grass (transitional host)

Lozalities : Chashmashahi, Kukarnag, Harvan, Kangan, Srinagar, Sopore, Bhadarwah, Udhampur (Jammu and Kashmir)

Holotype $M$, allotype $F$, INDIA : JAMMU AND KASHMIR ; Srinagar, vii, 1977, collected from grass. Paratypes $28 \mathrm{MM}, 12 \mathrm{FF}$, with the same data as holotype. Paratypes $87 \mathrm{MM}, 40 \mathrm{FF}$, JAMMU AND KASHMIR : Kukarnag, vii, 1977. Paratypes $74 M M 46$ FF, JAMMU AND KASHMIR : Bhadarwah, viii, 1779. Paratypes $2 M M, 10 F$, JAMMU AND KASHMIR; Udhampur, viii, 1977. Paratypes $2 \mathrm{MM}$, 2FF, JAMMU AND KASHMIR, Garhi, viii, 1977. Deposited in Zoology Museum (Project Section), Panjab University, Chandigarh.

Salient features :

1. Elytra with a tubercle each at the bases of 3rd and 4th striae; elongated spots and dark areas;

2. pre-scutellar depressed area on pronotum;

3. No dorsal valve;

4. Antennae brown;

5. Endophallus with three endophallic plates.

Remarks :

With long antennae, surpassing base of pronotum; greatly protruding eyes; size not exceednig $2.5 \mathrm{~mm}$; ground colour black; host not know/ elytra with a tubercle each at the bases of 3rd and 4th striae, with elongated spots and black areas; pronotum without a raised prescutellar area, unicolorous antennae; scutellum longer than broad; and phallus without a dorsal valve, the present species is closely related to $B$. meibomica sp. nov. (Ref. No. 70). It, however, differs from the latter in having brown antennae (antennae light testaceous in B. meibomiaca), in having parameres fused at base to $1 / 6$ total length, bearing 8 parameral setae (parameres fused at base to $2 / 3$ total length and bearing 6 parameral setae each in $B$. meibomiaca), and in having endophallus with three endophallic plates (endophallus with two prominent longitudinal rows of sclerotized platelets in $B$. meibomiaca).

\section{BRUCHIDIUS FLAPOPARAMERICA sp. nov.}

\section{(Ref. No. 68) PHOTO XVI}

(P1. 16. figs. 116-122)

Head black, slightly broader posteriorly; frons carinate, punctate between eyes, its surface covered with golden setae; eyes small, protruding, emarginate in front, canthus broad and shallow with its surface covered with pale-yellow setae; Antennae testaceous, surpassing base of pronotum, more than half the length of the body in male, serrate with segments 1-2 cylindrical, segments 3-10 slightly longer than broad, segment 11 elongate and conical, antennae in female comparatively short with segments 3-10 sub-serrate, nearly as long as broad.

Prontoum, black, sub-conical, produced posteriorly into a bilobate area in the middle, its surface uniformly punatate and beset with golden setae, inermingled with a few white setae here and there.

Scutellum black, slightly longer than broad, with its surface covered with golden setae. Elytra black, together longer than broad, each with a distinct tubercle at the base of 4th stria, striae punctate,elytral surface covered with golden setae, interrupted by narrow elongated spots of white setae, forming irregular transverse 
PLATE 16

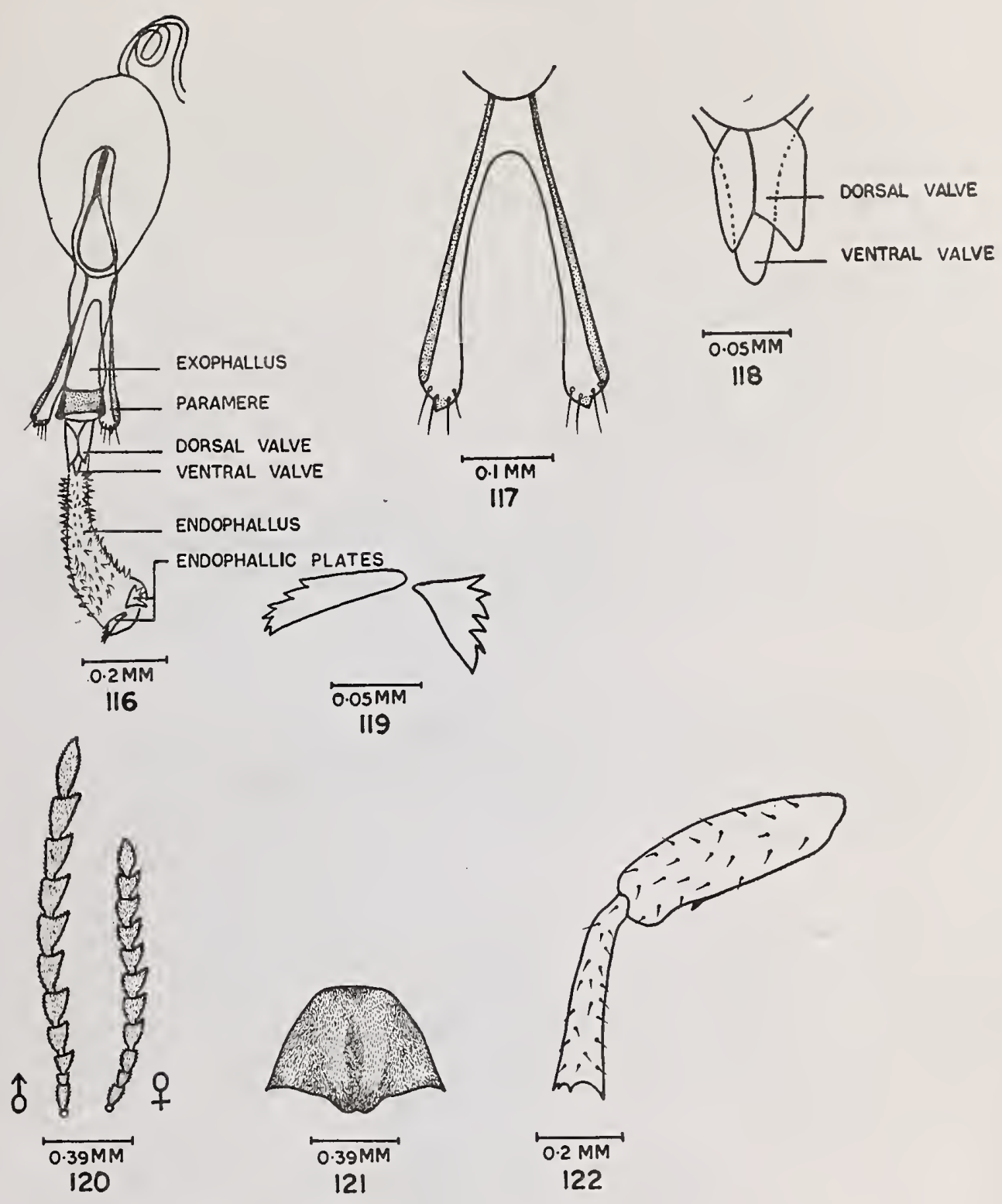

Bruchidius flapoparamerica sp. nov.

Figs. 116. Phallus; 117. Parameres; 118. Dorsal and ventral valves; 119. Endophallic plates; 120. Antennae; 121. Pronotum; 122. Hind femur. 
rows in the anterior, middle and apical regions. Legs testaceous with dark claws; hind femur bicarinate below with a small pointed preapical spine on inner carina. Pygidium black, sub-vertical in both sexes, its surface adorned with golden and white setae.

Phallus $1.372 \mathrm{~mm}$ long; parameres elongated, dilated and produced medially into a conícal flap each at its distal end and bearing 4 long setae, parmeres fused at base to 1/6 total length; endophallus tubular, long and narrow at base, expanded terminally with large sharp tubercles all along and a pair of laterally placed, toothed endophallic plates on the saccus; exophallic valve conical; dorsal valve consisting of two lateral, almost conical plates, articulated to the exophallic rim; a pair of lateral sclerotizations at the exophallic rim.

Size short : $\quad$ length male $2.00-2.20 \mathrm{~mm}$

length female $2.00-2.10 \mathrm{~mm}$

Host : grass (transitory).

Localities : $\quad$ Sasangir forest (Gujrat),

Poona (Maharashtra)

Bhopal (Madhya Pradesh)

Holotype F, INDIA : GUJARAT; Ahmadabad, i, 1978, collected from grass. Allotype M, INDIA : GUJARAT : Sasangir forest, i, 1978. Paratypes $3 M M$, with the same data as allotype. Paratypes $2 M M, 2 F F$, MAHARASHTRA : Poona, i, 1978. Paratypes 6 MM, MADHYA PRADESH; Bhopal, ii, 1978. Deposited in Zoology Museum (Project Section), Panjab University, Chandigarh.

\section{Salient features :}

1. Scutellum longer than broad;

2. Elytra each with a tubercle at the base of 4th stria;

3. Endophallus with 2 endophallic plates, and sharply pointed tubercles;

4. Paramere with a conical flap at distal end;

5. A prominent dorsal valve.

\section{Remarks :}

With long antennae, surpassing base of pronotum; bulging eyes; size less than $2.5 \mathrm{~mm}$; black ground colour; scutellum longer than broad; host unknown; eltra with a tubercle at the base of 4th stria and endophallus with 2 endophallic plates and sharply pointed tubercles, the present species is closely related to $B$. compositus Arora. It, however, differs from the latter in having parameres fused at base to $1 / 6$ total length with a distal conical flap and bearing 4 parameral setae (parameres in $B$. compositus fused at base to $1 / 4$ total length, without a flap, bearing 5-6 parameral setae), and having a prominent dorsal valve (dorsal valve absent in $B$. compositus).

\section{BRUCHIDIUS MEIBOMIACA sp. nov. (Ref. No. 70) PHOTO XVII}

(P1. 17. figs. 123-129)

Head black, broader posteriorly; frons weakly carinate, minutely punctate between and behind the eyes, its surface beset with whitish pubescence; eyes widely separated in male, protruding, emarginate in front, canthus narrow and long in male, small in female, its surface covered with white pubescence. Antennae long, testaceous, surpassing base of pronotum, longer in male and reaching middle of elytra with segments 1-4 cylindrical, segments 5-10 longer than broad, sub-serrate, segment 11 oblong, in female segments 1-4 cylindrical, segments 5-10 as long as broad, segment 11 small cone. 


\section{PLATE 17}
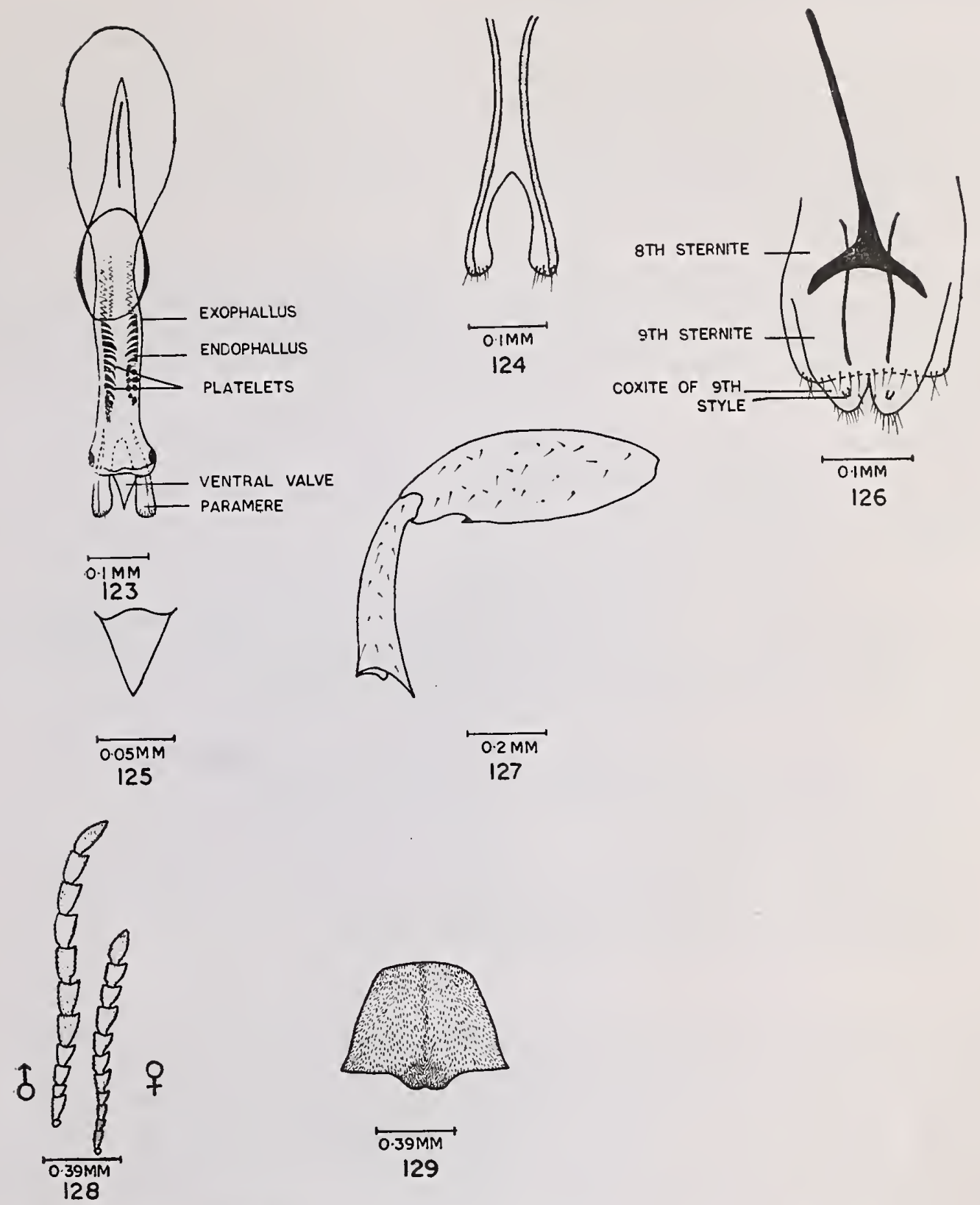

Bruchidius meibomiaca sp. nov.

Figs. 123. Phallus; 124. Parameres; 125. Exophallic valve; 126. Female genitalia; 127. Hind femur; 128. Antennae; 129. Pronotum. 
Pronotum black, sub-conical, its surface uniformly covered with pale-white setae and a faint longitudinal streak of white setae in the middle.

Scutellum black, longer than broad, bifid posteriorly, its surface beset with whitish setae. Elytra black, together nearly one and half times as long as broad, each with a pair of tubercles at bases of 3rd and 4th striae, elytral surface covered with elongated spots of pale-white setae, forming almost three irregular transverse rows in the anterior half. Fore and middle legs testaceous; hind.legs dark brown with bases of femora black, each femur bicarinate below having a small pre-apical tooth on inner carina. Pygidium black, vertical in male, sub-vertical in female, its surface uniformly covered with whitish setae with a white median streak.

Phallus $0.90 \mathrm{~mm}$ long; parameres fused at base to $2 / 3$ total length, sclerotized along outer margins, apically dilated, spoon-shaped bearing 6 slender setae; endophallus with two lateral rows of teeth-like platelets which are small and pointed at base, curved and increasing progressively in size towards middle and becoming somewhat flattened distally; exophallic valve triangular and pointed; exophallic rim with a pair of lateral sclerotizations.

Size small : length male-1.90-2.00 mm length female-1.80-2.00 $\mathrm{mm}$

Host plant : Meibomia ambellata

Localities : Savantvadi State, India

Mangalore (Washinton collection)

Holotype $M$, allotype $F$, INDIA : KARNATKA; Mangalore, iv, 1926 collected from Meibomia triguetru and Meibomia ambellata Paratypes $4 M M, 3 F F$, with the same data as holotype. Specimens retained in the Zoology Museum (Project Section), Panjab University, Chandigarh.

Salient features :

1. Two elytra basal strial tubercles at bases of 3 rd and 4th striae;

2. Phallus without dorsal valve;

3. Antennae unicolorous;

4. Scutellum longer than broad

5. Elytra with elongated spots of pale-white setae;

6. Endophallus with 2 lateral rows of sclerotized platelets.

\section{Remarks}

With long antennae, surpassing base of pronotum; greatly bulging eyes; size less than $2.5 \mathrm{~mm}$; black ground color; elytral basal strial tubercles at bases of 3rd and 4th striae; scutellum longer than broad; phallus without dorsal valve and elytcal surface with elongated spots of whitish setae, the present species is allied to B.kashmirensis sp. nov. It, however, differs from the latter in having light testaceous antennae (antennae brown in $B$. kashmirensis), in having parameres fused at base to $2 / 3$ length (parameres fused at base to $1 / 6$ length in $B$. kashmirensis), in having 6 parameral setae. ( 8 parameral setae in the other) and in having 2 rows of platelets on endophallus (endophallus with 3 endophallic plates in B. kashmirensis).

\section{BRUCHIDIUS MUSSOORIENSIS sp. nov.}

(Ref. No. 71) PHOTO XVIII

(P1. 18. figs. $130-137$ )

Head black, slightly constricted behind; frons strongly carinate, minutely punctate between eyes, its surface sparsely convered with yellowish pubescence; eyes large, protruding, emarginate in front, canthus broad 


\section{PLATE 18}
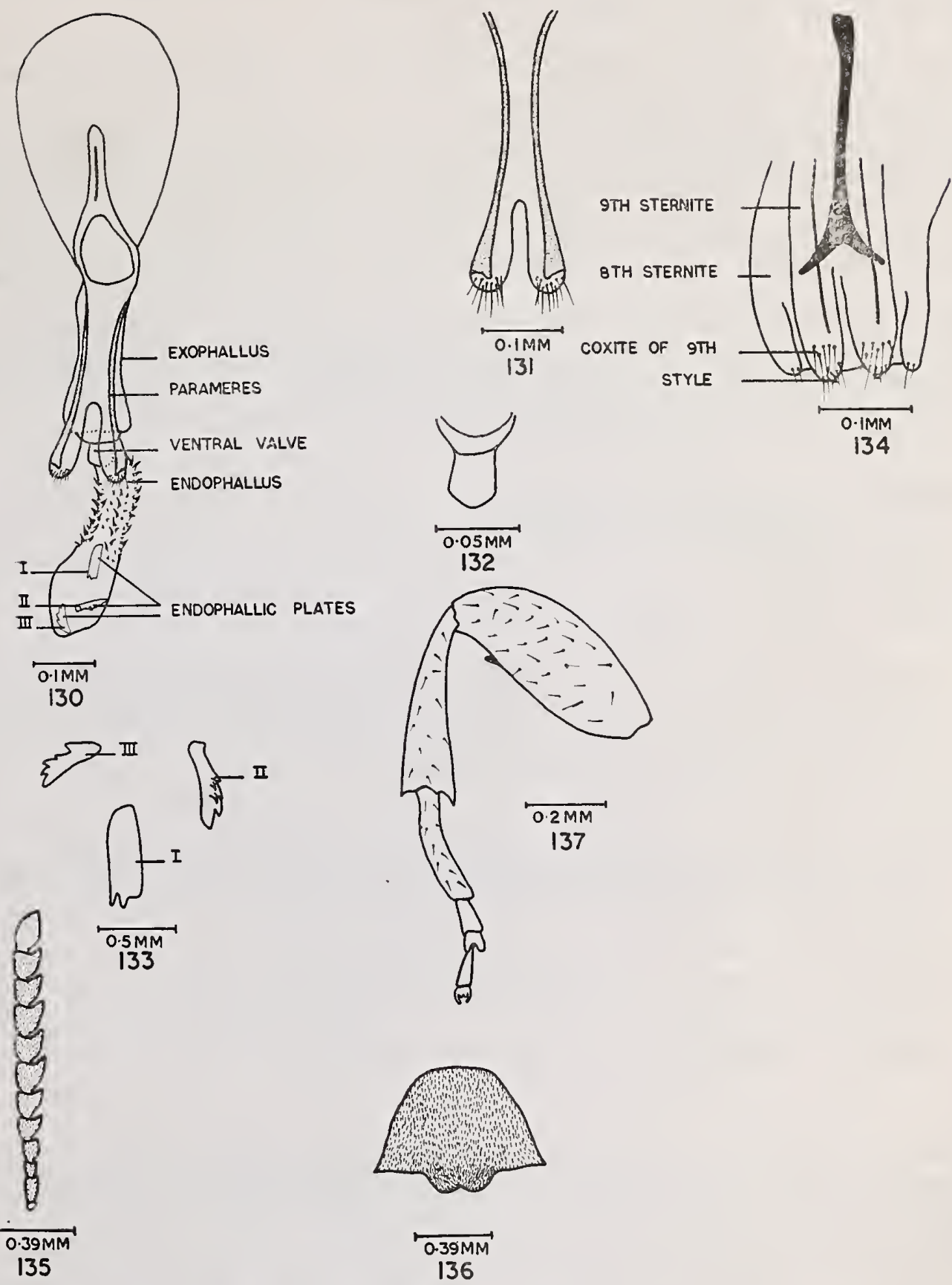

134

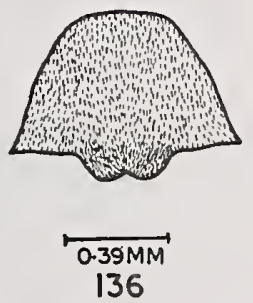

Bruchidius mussooriensis sp. nov.

Figs. 130. Phallus; 131. Parameres; 132. Exophallic valve; 133. Endophallic plates; 134. Female genitalia; 135. Antenna; 136. Pronotum; 137. Hind leg. 
and shallow, its surface covered with yellowish pubescence. Antennae long surpassing base of pronotum, longer in male, segments 1-3 cylindrical and testaceous, segments 4-10 nearly as long as broad, serrate, black, segment 11 conical, longer in the male.

Pronotum black, sub-conical, its surface minutely pitted and covered with yellowish pubescence with a prescutellar patch covered with white setae.

Scutellum black, broader than long, its surface covered with yellowish pubescence. Elytra black, together longer than broad with a tubercle each at bases of 3rd and 4th striae, its surface sparsely covered with yellowish pubescence. Fore and middle legs testaceous, with bases of femora, tarsi and claws dark brown; hind legs black, each femur bicarinate below with a small pre-apical tooth on inner carina. Pygidium black, subvertical in female, verticalin male, its surface covered with whitish pubescence.

Phallus $1.65 \mathrm{~mm}$ long; parameres fused at base to $3 / 4$ total length, rounded apically and bearing 7-8 setae; endophallus long, distended apically, its surface bearing small, sharp tubercles and saccus provided with three plates, the apical pair toothed laterally and the basal plate tridented posteriorly; exophallic valve somewhat rounded at apex and broadened at base.

$\begin{array}{ll}\text { Size small : } & \text { length male } 1.90-2.10 \mathrm{~mm} \\ \text { length female } 1.90 \mathrm{~mm}-2.00 \mathrm{~mm}\end{array}$

Host : grass

Localities : Dehradun, Rajpur.

Holotype $M$, allotype $F$, INDIA : UTTAR PRADESH; Dehradun, v, 1978, collected from grass. Paratypes $2 M M, 1 F$, with the same data as holotype. Paratypes $1 M, 1 F$, UTTAR PRADESH; Rajpur, vi, 1978. Paratypes $2 \mathrm{MM}, 3 \mathrm{FF}$, UTTAR PRADESH : Mussoorie, vi, 1978. Deposited in Zoology Museum (Project Section), Panjab University, Chandigarh.

\section{Salient features :}

1. Elytra with a tubercle each at the bases of $3 \mathrm{rd}$ and 4 th striae, surface uniformly covered with sparse yellowish pubescence;

2. Antennae with 3 basal segments light testaceous, rest black;

3. Without a dorsal valve;

4. Scutellum broader than long.

Remaks

With long antennae, surpassing base of pronotum; greatly bulging eyes; size less than $2.5 \mathrm{~mm}$; ground colour black; obscure host plant; elytra with a tubercle each at the bases of 3rd and 4th striae; 3 basal segments of antennae light testaceous, rest black; scutellum broader than long; elytra covered uniformly with sparse yellowish pubescence and phallus without dorsal valve, the present species is allied to $B$. kushmirensis sp. nov. and $B$. meibomiaca sp. nov. It differs from them in having 3 light testaceous basal segments of antennae and rest black (antennae unicolorous brown in $B$. kashmirensis, and light testaceous in $B$. meibomiaca), in having parameres fused at base to $3 / 4$ total length (parameres fused at base to $1 / 6$ length in $B$. kashmirensis and $2 / 3$ fusin at base in $B$. meibomiaca) and in having 3 endophallic plates as in $B$. kashmirensis (endophallaus with 2 longitudinal rows of platelets in $B$. meibomiaca). 
BRUC HIDIUS NANGALENSIS sp. nov.

\section{(Ref. No. 72) РHOTO XIX}

(Pl. 19. figs. $138-144)$

Head black; frons without carina, its surface covered with scattered dull-white setae; eyes highly bulging and protruding on sides, emarginate, cantinus very small, narrow and shallow, its surface covered with dullwhite setae. Antennae long, testaceous to light brown, surpassing base of pronotum, sub-serrate, segments 1-3 cylindrical, segments $4-10$ broad, segment 11 conical.

Pronotum black, sub-conical with a slightly raised pre-scutellar area, its surface uniformly covered with pale-yellow and white setae.

Scutellum black, squarish, its surface covered with dull-white setae. Elytra black, together longer than broad with a pair of basal strial tubercles at the bases of $3 \mathrm{rd}$ and 4 th striae, its surface covered with pale-yellow and white setae. Fore and middle legs testaceous with tarsi and claws black; hind legs black, hind femur bicarinate below with its inner carina bearing a small, pre-apical tooth. Pygidium black, sub-vertical in both sexes, its surface covered with pale-yellow and white setae.

Phallus $0.792 \mathrm{~mm}$ long; parameres fused at their bases up to $2 / 3$ their total length, sclerotized along outer distal margins, tips rounded, each carrying 11-12 setae; endophallus provided with 4 plates; a pair of peg-shaped plates, a large flat plate, bifid posteriorly, and a 4th plate, bifid posteriorly and many pronged anteriorly, endophallic surface beset with two longitudinal rows of pointed tubercles; exophallic valve conical; dorsal valve composed of 2 flat, somewhat trough-shaped plates

Size small: length male $1.90 \mathrm{~mm}-2.15 \mathrm{~mm}$

length female $1.90 \mathrm{~mm}-2.00 \mathrm{~mm}$.

Host : grass

Localities : Nangal, Kasauli.

Holotype M, allotype F, INDIA: PUNJAB; Nangal, xi, 1978; collected from grass. Paratypes 3. MM with the same data as holotype. Paratypes $3 M M 2 F F$, HIMACHAL PRADESH, Kasauali, xi, 1978. Deposited in Zoology Museum (Project Section) Panjab University, Chandigarh.

Salient features :

1. Pronotum with a raised pre-scutellar area;

2. Elytra with a tubercle each at bases of $3 \mathrm{rd}$ and 4 th striae;

3. Endophallus with 4 endophallic plates;

4. Dorsal valve, formed of 2 trough-shaped plates (double-trough-shaped).

Remarks ;

With long antennae, surpassing base of pronotum; bulging eyes; size less than $2.5 \mathrm{~mm}$; black ground colour; obscure host; elytra with a tubercle each at the bases of 3rd and 4th striae; pronotum with a riased pre-scutellar area, and phallus with a dorsal valve, the species is related to $B$. orissiensis sp. nov. and $B$. punctoterminalis sp. nov. It, however, differs from them in having light-brown antennae without a terminal black segment (antennae with a terminal black segment in the other two), in having a squrish scutellum (scutellum broader than long in $B$. orissiensis and longer than broad in B.punctoterminalis), in having 4 endophallic plates (Two endophallic plates in the other two), and in having a doble troughshaped dorsal valve (dorsal valve beak-shaped in $B$. orissiensis and vase-shaped in $B$, punctoterminalis).

It is named after its local Nangal dam area where it was obtained from. 
Final Technical Report 1974-79

PLATE 19
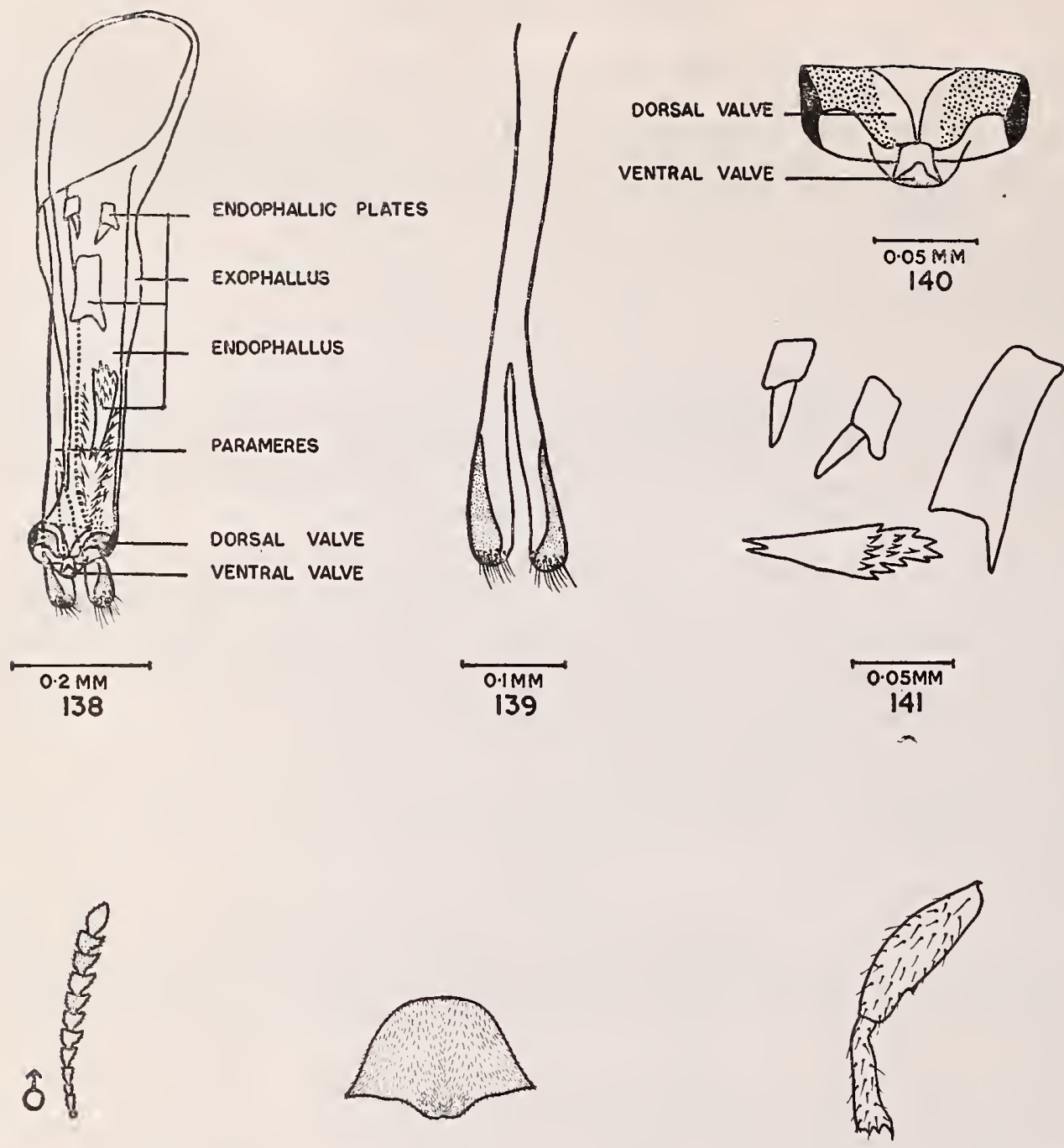

$0.39 \mathrm{MM}$

142

$0.39 \mathrm{MM}$

143

$0.4 \mathrm{MM}$

144

Bruchidius nangalensis sp. nov.

Figs. 138. Phallus; 139. Parameres; 140. Dorsal and ventral valves; 141. Endophallic plates; 142. Antenia; 143. Pronotum; 144. Hind femur. 
BRUCHIDIUS, MICROMINUTUS sp. nov.

(Ref. No. 73) РНОTO XX

(P1. 20 figs. 145-153)

Head black; frons ecarinate, its surface beset with golden setae; eyes highly bulging, eamarginate, canthus narrow and long, covered with pale-yellow setae. Antennae long, surpassing base of pronotum, sub-serrate, segments 1-4 light colored and cylindrical, rest black of which 5-10 are broad and segment 11 conical.

Pronotum black, sub-conical, covered uniformely with golden setae.

Scutellum black, slightly longer than broad, its surface adorned with golden setae. Elytra black, together longer than broad, without any basal strial tubercles, its surface covered with golden setae intermingled with white setae. Fore and middle legs testaceous with tarsi and claws black; hind legs black, hind femur bicarinate below, its inner carina with a small pre-apical tooth. Pygidium black, sub-vertical in both sexes, covered uniformly with golden setae intermingled with white setae.

Phallus $0.60 \mathrm{~mm}$ long; parameres fused at base to less than $1 / 2$ length $(3 / 8)$ total length, with their tips conical, each carrying 7-8 parameral setae ; endophallus with 4 endophallic plates, a pair of flat, denticulatd plates on the saccus, a third plate of the shape of inverted and a denticulated 4 th plate behind, the long endophallus beset with numerous blunt tubercles: exophallic valve broad at base with terminal curved cone; dorsal valve composed of two wine-glass-shaped plates, attached to the exophallic rim.

Size very small, the smallest species of the genus Bruchidius

Length male-1.50-1.70 mm

Lergth female-1.35-1.50 mm

Host : grass

Localities: Nalgonda, Khammam, Anantapur, Hyderabad (Andhra Pradesh).

Holotype $M$, INDIA : ANDHRA PRADESH; Nalgonda, xii, 1978, collected from grass. Paratype $1 M$ with the same data as holotype. Paratypes 2MM, ANDHRA PRADESH: Khammam, xii, 1978. Allotype $F$, INDIA: ANDHRA PRADESH; Anantapur, i, 1979, collected from grass. Paratypes $10 M M, 4 F F$, with the same data as allotype. Paratypes $3 M M, 1 F$, ANDHRA PRADESH; Hyderabad i, 1979. Deposited in Zoology Museum (Project Section), Panjab University, Chandigarh.

\section{Salient features:}

1. Scutellum longer than broad;

2. Elytra without basal strial tubercles;

3. Smallest species;

4. Endophallus with 4 endophallic plates;

5. Dorsal valve comprising a pair of wine-glass-shaped plates.

\section{Remarks :}

With long an tennae, surpassing base of pronotum; bulging eyes; size less than $2.5 \mathrm{~mm}$; ground colour black; obscure host plant; elytra without basal strial tubercles; antennae with 4 basal segments lightcolored and rest black; elytra with white setose spots intermingled with golden setae; scutellum longer 


\section{PLATE 20}
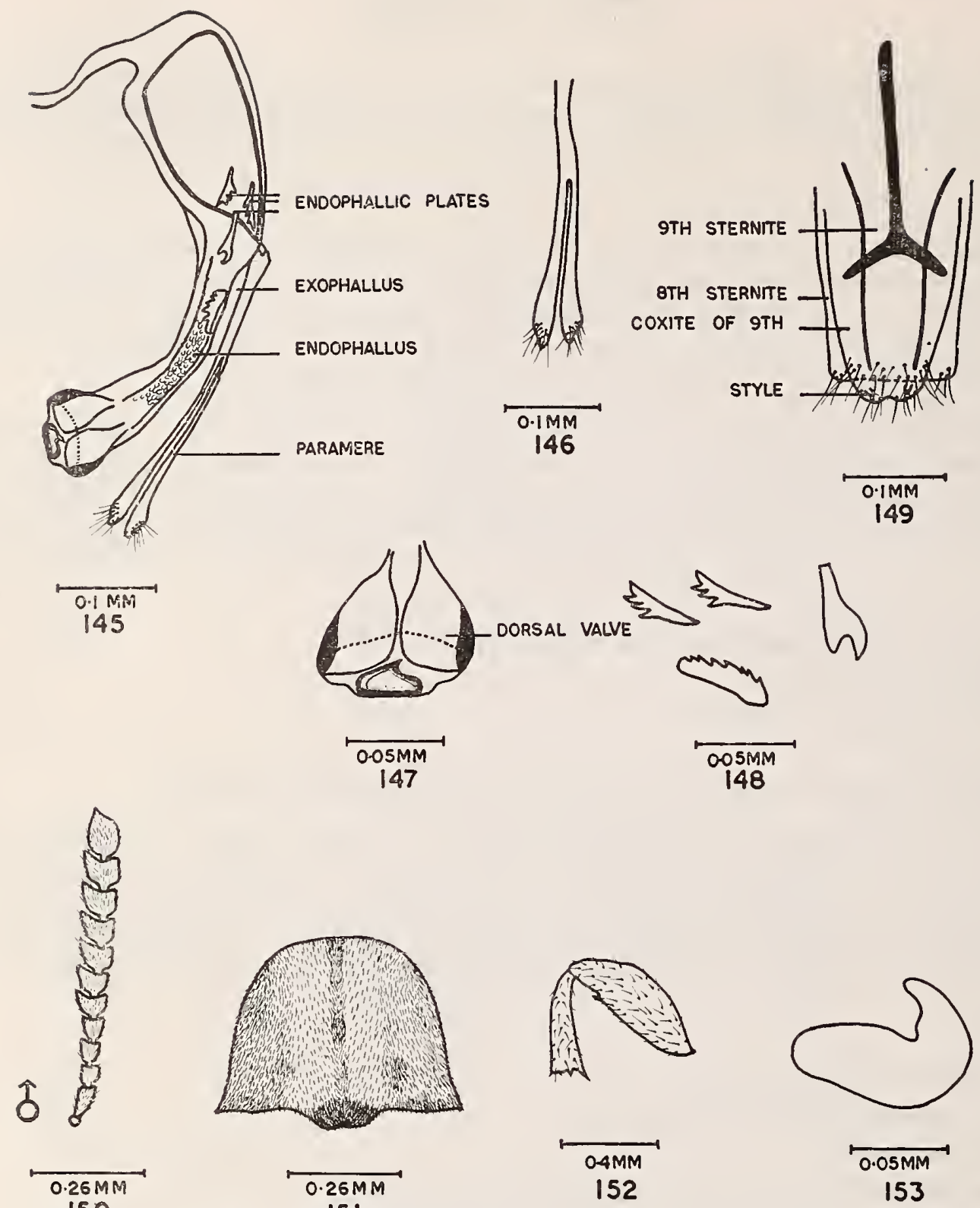

150

$0.26 \mathrm{MM}$

151
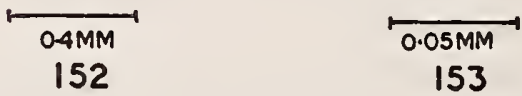

153

Eruchidius microminutus sp. nov.

Figs. 145. Phallus; 146. Parameres; 147. Dorsal valve; 148. Endophallic plates; 149. Female genitalia; 150 . Antenna; 151. Pronotum; 152. Hind femur; 153. Spermatheca. 
than broad and phallus with a dorsal valve, the present species is allied to B.dorsivalvia sp. nov. It, however, differs from the latter in having parameres fused at base to $3 / 8$ total length, conical terminally and bearing 7-8 parameral setae (parameres fused at base to $1 / 5$ length, broadened terminally and bearing 5 long parameral setae in B.dorsivalvia), in having endophallus with 4 endophallic plates and numerous blunt tubercles (B.dorsivalvia having 2 endophallic plates and profusely studded with sharp tubercles), and in having the dorsal valve comprising 2 wine-glass-shaped plates (dorsal valve formed of 2 quadrangular plates, apically bifid, in B.dorsivalvia).

\section{BRUCHIDIUS ANUSURINDRII sp. nov. \\ (Ref. No. 74) PHOTOS XXI A \& B}

( Pl. 21 figs. 154-162)

Head black; frons without carina, its surface covered over with dull golden setae; eyes highly bulging, emarginate in front, canthus small, narrow and shallow, its surface covered with dull golden setae. Antennae long, surpassing base of pronotum, testaceous with segments margined black, sub-serrate, longer in male, with segments $1-3$ cylindrical, segments $4-10$ broad, segment 11 conical.

Pronotum black, sub-conical, its surface covered uniformly with dull golden and a few white setae: with a riased, prominent prescutellar area.

Scutellum black, longer than broad, its surface covered with dull golden setae. Elytra black without any basal strial tubercles, its surface covered with dull golden setae and a few spots of white setae. Fore and middle legs testaceous with tarsi and claws black; hind legs black, hind femur bicarinate below, its inner carina with a small preapical tooth. Pygidium black, vertical in male and sub-vertical in female, its surface covered with golden and white setae.

Phallus $0.666 \mathrm{~mm}$ long; parameres fused at their bases to less than one-half of their total length sclerotized along their outer margins, with their tips notched and flattened, each carrying 7 parameral setae. Saccus of endophallus provided with a pair of large, denticulated plates and a third plate bifid anteriorly and trifid posteriorly, with numerous rows of sharply pointed tubercles on the endophallus; exophallic valve an elongated cone and a pair of lateral sclerotizations on the exophallic rim.

Size small: length male-1.95 mm-2. $00 \mathrm{~mm}$.

length female- $1.90 \mathrm{~mm}-2.00 \mathrm{~mm}$.

Host : grass, flowers of Sesbania and Lantana sp.

Locality : Anantapur (Andhra Pradesh)

Named after our hostess.

Holotype $M$, allotype F, INDIA: ANDHRA PRADESH; Anantapur, i, 1979, collected from grass flowers of Sesbania Paratypes, $4 M M, 1 F$, with the same data as holotype. Paratypes $2 F F$ ANDHRA PRADESH; Hydrabad, i, 1979 collected from grass near Lantana flowers. Deposited in Zoology Museum (Project Section) Panjab University, Chandigarh.

\section{Salient features:}

1. Scutellum longer than broad;

2. Antennae testaceous, segments with margins black, longer in male;

3. Pronotum with a raised pre-scutellar area, beset with dull golden setae; 


\section{PLATE 21}
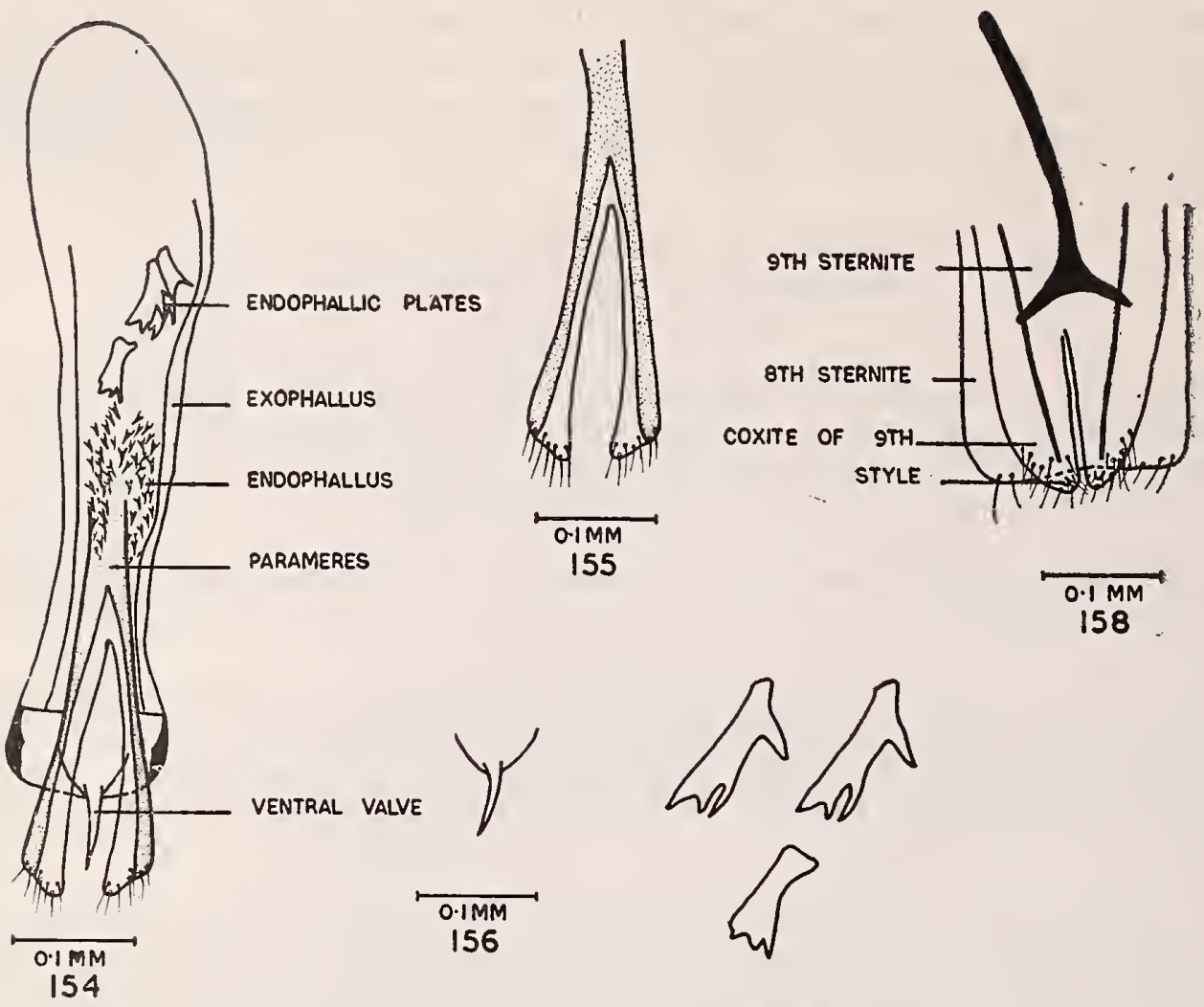

PARAMERES

C PLATES

EXOPHALLUS

ENDOPHALLUS

VENTRAL VALVE
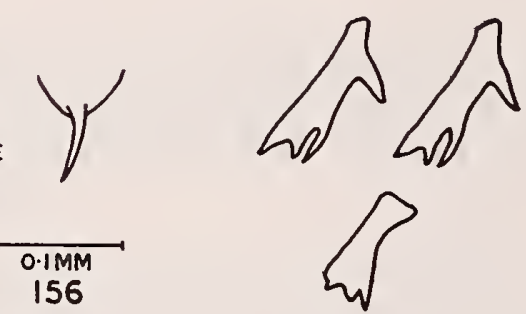

156

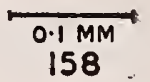

154

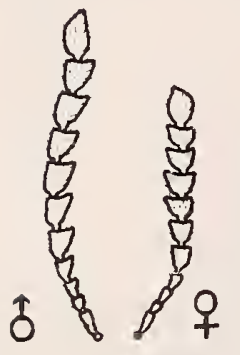

$0.39 M M$

159

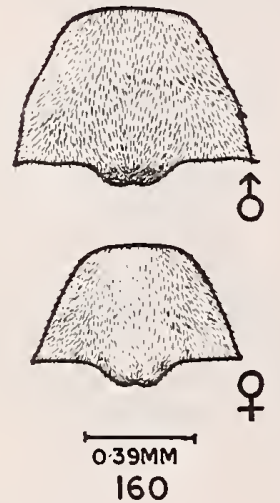

160

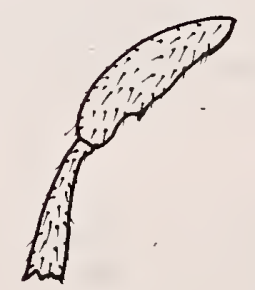

$0.4 M M$

161

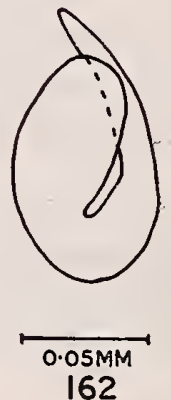

Bruchidius anusurindrii sp. nov.

Figs, 154. Phallus; 155. Parameres; 156. Exophallic value; 157. Endophallic plates:. 158. Female genitalia; 159. Antennae; 160. Pronota; 161. Hind femur: 162. Spermatheca. 
4. Elytra with dull golden setae and a few white setae, no dark areas, without basal strial tubercles;

5. Parameres fused at base to less than $1 / 2$ total length, tips notched and flattened, 7 parameral setae;

6. Endophallus with 3 plates and rows of strong and pointed tubercles;

7. Exophallic valve, a long cone.

\section{Remarks :}

With long antennae, surpassing base of pronotum; bulging eyes; size less than $2.5 \mathrm{~mm}$, ground color black; without basal strial tubercles and 3 endophallic plates, the present species is related to B.siwalikus sp. nov. and $B$. desmodei $\mathrm{sp}$. nov. It however, differs from them in having scutellum longer than broad (scutellum squarish in B.siwalikus, and broader than long in B.desmode $i$ ), in having parameres fused at base to less than $1 / 2$ total length (parameres fused at base to more than $1 / 2$ total length in the other two), and basal endophallic plate bifid anteriorly and trifid posteriorly (basal endophallic plate bifid posteriorly in B.siwalikus and small in B.desmodei) and in having exophallic valve a long cone (exophallic valve short and conical in $B$. desmodei).

\section{BIOLOGY OF SOME SPECIES OF GENUS BRUCHIDIUS}

The biology and Life-histories of 4 species of the genus Bruchidius viz. B.pygomaculatus Arora, B. mimosal Arora, B. angustifrons Schilsky and B. tephrosiae Arora have been dealt with in detail, covering their early feeding on pollen, sexual preliminaries, copulation and ovipositional behaviours, the larval and subsequent stages inside the seeds of their host-plants, and the final emergence of the adults.

The following are the detailed observations on the biology and life-history of the species :-

Biology and Life-history of Bruchidius pygomaculatus Arora. (Pl. 22 figs. 163-168)

Bruchidius pygomaculatus Arora attacks primarily the pods and seeds of the host-plants Albizzia lebbek Benth. (Sarin) and Albizzia procera (Roxb.) Benth. (Kala Sarin), as well as of Acacia modesta Wall. (Phalla) and of Acacia katechu Willd (Katha). The flowering of the host-plant extends from April through August when the pods make their appearance. The pods are strap-shaped, 8-30 cms. in length and $2.5-5.00 \mathrm{~cm}$ in breadth. The young pods, after receiving the eggs from the copulated female insects, remain hanging on the host-plant, ripen and dry up. The bruchids pass through the various lifehistory stages during this period, followed by the emergence of the adult insects and a final shedding of the pods in February, March and early April.

The adults of B.pygomaculatus 'do not feed on the pollen but rush to to the flowers during the flowering season to hide for 1-3 months among them and mate ultimately when the pods appear. The male performs some sexual preliminaries of touching the pygidium of the female by his antennae. The female stops, when receptive, revolves round itself and touches the antennae of the persuing male with her own antennae and offers her back, guiding him to ride her back and hold her. The male then bends the tip of its abdomen to bring it in contact with that of its mate and inserts his extruded aedeagus into the female genital opening, the female making some backwards movements of her abdomen to facilitate the entry of the aedeagus. The exophallic value, during coition, takes an upward position to allow a continuous passage of the spermatophores from the male to the female. The average duration of copulation is 2.19 minutes. The copulating partners then move apart, assisted by some backward strokes of the hind legs of the female and the withdrawal of the aedeagus by the male. The copulated male refuses to mate the second time and dies within 3 days after copulation. 

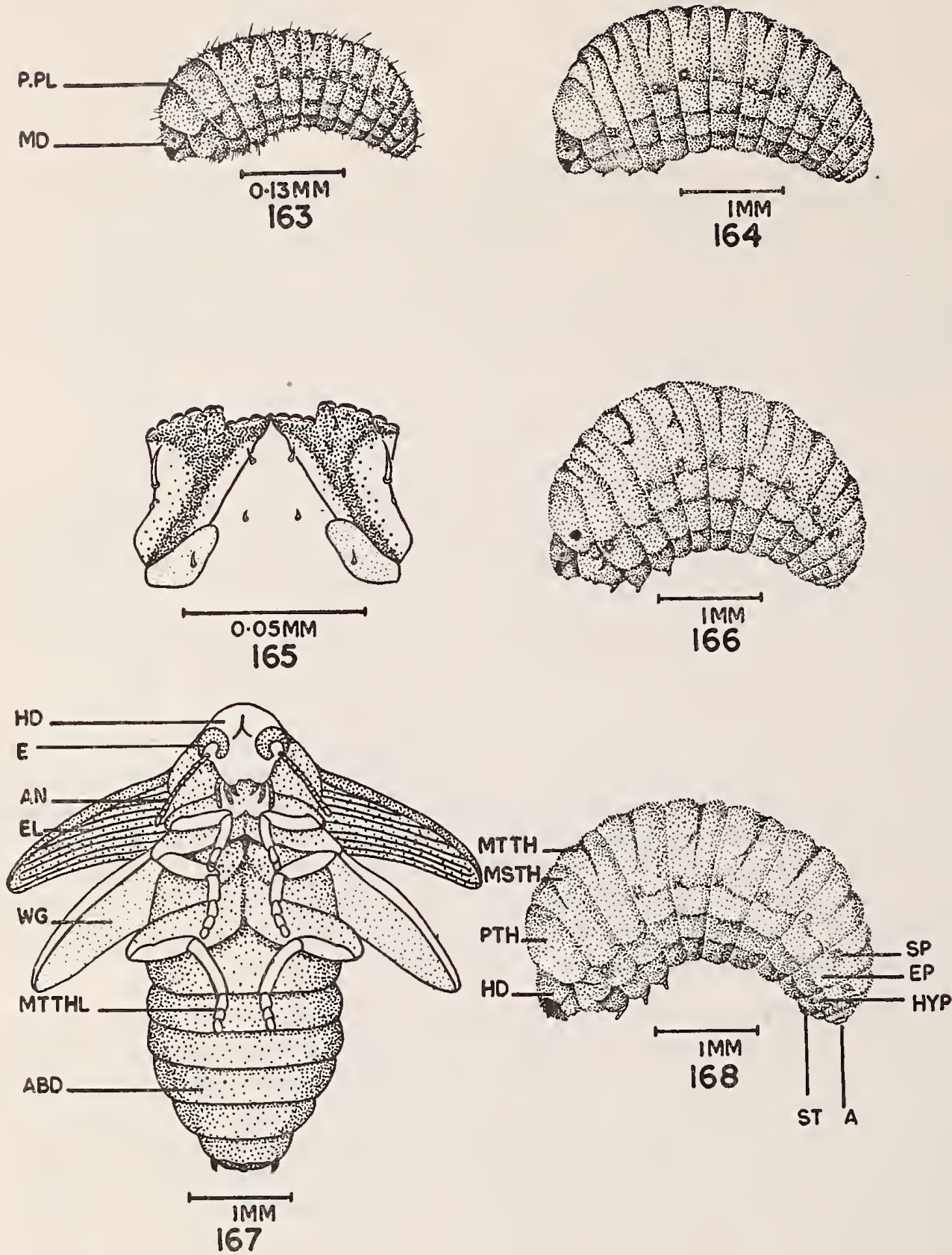

Bruchidius pygomaculatus Arora

Figs. 163. First instar. larva; 164. Second instar larva; 165. Prothoracic plate; 166. Third instar larva; 167. Pupa; 168. Fourth instar larva.

Abbre viations for Ptates 22-25

A-Anal lobe, ABD-Abdomen; AN-Antennae; E-Eye; EL-Elytra; EP-Epipleure; HD-Head; HYP-Hypopleure; MSTH-Mesothorax; MTTH-Metathorax; PTH-Prothorax ; SP-Spiracle; ST-Starnum; WG-Wing. 
The copulated female in 1-20 hours after copulating becomes somewhat uneasy when she extends and folds her wings alternately, and rubs her body with her legs. She then stops at a suitable spot on the surface of the pod, exudes a transparent yellowish, sticky fluid from her genital opening and spreads it there with the tip of her abdomen. An egg is passed out through the genital opening and deposited on the sticky surface with its pointed end coming out first, taking 20-30 seconds in the process. The interval between two successively laid eggs varies from 10 minutes to 3 hours. The eggs are laid on both sides of the pod, generally against the developing seeds within, with about nine eggs on either side. The number of eggs laid by a copulated female varies from 15-37, laying eggs for 2-3 days in succession, followed by its death within 6-24 hours after its full quota of eggs has been laid.

The eggs of B.pygomaculatus are yellowish in colour. They are oval in shape, rounded at the anterior end and pointed at the posterior, convex above and somewhat flattened below. The egg measures from $0.50 \mathrm{~mm}$ to $0.60 \mathrm{~mm}$ in its long diameter. The freshly laid egg is soft and transparent, becoming hard on exposure to air.

Experimental studies in the laboratory environmental conditions of temperature and humidity, under controlled conditions in laboratory and those on the eggs laid on pods of the host-plant in the field show that the incubation period varies from 7-9 days in the laboratory under average temperature $27.75^{\circ} \mathrm{C}$ and average R.H. $69.5 \%$; from 5-7 days under controlled temperature $30^{\circ} 32^{\circ}$ and R.H. $70 \%$; from 10-13 days under controlled temperature $24^{\circ}-26^{\circ}$ and R.H. $70^{\circ}$, and from $9-12$ days in the field under av. temperature $27.75^{\circ}$ and R.H. $71 \%$.

The embryo inside the egg-shell within three days after oviposition lies with its ventral side upward and its head towards the rounded end of the egg. When fully formed, the embryo shows movements inside the egg-shell and its sclerotized prothoracic plate works forwards, downwards and backwards against the inner surface of the shell, producing grooves and ridges. The embryo then turns upside down and cuts a small hole in the anteroventral aspect of the region of the grooves with the help of its mandibles and hatches out as the first instar larva.

The first instar larva is cream-colored except for its mandibles, frons, clypeus and the prothoracic plate which are sclerotized and dark brown. The sterna of thoracic and the first eight abdominal segments bear latero-ventrally each a pair of pigmented, sclerotized pieces. The body of the larva measures $0.47 \mathrm{~mm}$ to $0.55 \mathrm{~mm}$ in length and $0.20 \mathrm{~mm}$ to $0.25 \mathrm{~mm}$ in breadth, and bears sharp, stiff setae on its surface. The head capsule is deeply invaginated into the prothorax. The mandibles are strong and triangular, and are of the cutting type. The thoracic segments bear each a pair of rudimentary legs. The prothorax also carries a conscpicuous, highly sclerotised prothoracic plate, movably attached to it by a fold of the skin. The prothoracic plate is $\mathrm{H}$-shaped formed of two equal tri-radiate, setose plates, each consisting of the posterior and the anterior arms united by a transverse bridge. The posterior arm of each half bears 5 teeth distally and is produced laterally inward into a thin plate carrying 3-teeth and meeting its fellow of the other half in a bridge. The anterior arms are long and directed outward. The arrangement of teeth is $3+5$. There are 3 pairs of setae on the prothoracic plate and two pairs of setae situated in between the two halves. The abdomen is ten-segmented.

Thz first instar larva cuts a small hole in the surface of the pod right underneath the egg and eats its way through the pod into the green developing seed below near its plumule, the whole process taking 5-10 hours. It comes to lie in a depression, grows at the expense of the green substance of the plumule and, after a period of 13-15 days, moults to change into the second instar larva, discarding its skin (exuvium) along with the prothoracic plate. 
The second instar larva is dull white to light-yellow in color with a curved and thick body. It measures $1.00 \mathrm{~mm}$ to $1.75 \mathrm{~mm}$ in length and 0.60 to $0.70 \mathrm{~mm}$ in breadth, and is devoid of setae. The head is further invaginated into the prothorax with only the brown mandibles visible outside. The thoracic legs have grown shorter. The second instar larva moves deep into the seed, grows in size at the expense of the seed substance and moults into the third instar larva, taking 7-10 days for doing so.

The third instar larva is yellow in colour except the frons, the clypeus and the mandibles which are dark-brown. The body is thick and curved, measuring 2.25 to $2.75 \mathrm{~mm}$ in length and 1.10 to $1.25 \mathrm{~mm}$ in breadth. The head is still deeply invaginated into the prothorax. The legs have grown in size and are two-segmented. The third instar larva is a voracious eater and takes 10-13 days to moult into the fourth instar larva.

The fourth instar larva has a comma-shaped body, creamish-yellow in colour except the frons, the clypeus, the labrum and the mandibles which are dark-brown. It measures $3.25 \mathrm{~mm}$ to $3.75 \mathrm{~mm}$ in length and 1.80 to $2.20 \mathrm{~mm}$ in breadth. The head is hypognathous, a little longer than broad, slightly pigmented and sclerotized around the mouth-parts, and deeply invaginated into the prothorax. A prominent epicranial suture runs from the vertex and bifurcates to reach the antennary sockets. The antennae are short and 2-segmented, the clypeus undivided and the mandibles triangular. The thoracic segments bear each a pair of 3-segmented legs. The tergum of the prothorax is undivided whereas those of the meso and metathorax are transversely divided into the anterior and posterior parts. The abdominal segments $1-7$ are biannulate and segments 8-10 uniannulate.

The late fourth instar larva stops feeding and smoothens the cavity inside the seed by depositing its faecal matter and moistening the inside with its body secretions. The fourth instar larva takes 10-14 days to moult into the prepupa.

The prepupa is of a yellowish colour, and measures 3.75 to $4.00 \mathrm{~mm}$ in length and 1.50 to $1.75 \mathrm{~mm}$ in breadth. The head capsule is fully pulled out of the prothorax and the legs are bulging out. The abdomen is blunt and rounded distally. The prepupa stage lasts for 1-2 days after which it is transformed into the pupa.

The pupa is pale-yellowish in colour, lying with its ventral side upward. The body is devoid of bristles and measures 4.25 to $4.50 \mathrm{~mm}$ in length and 2.10 to $2.25 \mathrm{~mm}$ in breadth. The legs are folded back on themselves. The elytral sheaths are closely pressed against the body and the sheaths of the hind wings extended backward under the elytral sheaths. The abdomen shows six tergites, the seventh being the largest and forming the pygidium. The first two abdominal sternites are fused whereas sternites 3-7 are free.

The pupa darkens in colour and takes 11-13 days to be transformed into the adult when the pupal skin becomes loose and the adult inside gets separated. The adult before eclosion makes slow movements of its body and ultimately ruptures the pupal skin on the head, the thorax and the body. The adult finally withdraws itself from the puparium as a fully-formed insect inside the seed. It then cuts a circular hole in the seed coat and through the pod to emerge as a free insect after a period of 2-3 days.

The total life-history span from the egg to the adult varies rom 63-82 days depending on the drying up condition of the pods and the seeds. A healthy seed, rich in nutrient material, may harbour as many as three larvae to develop into full-fledged adults whereas weak individuals are produced from unhealthy seeds. 
PLATE 23
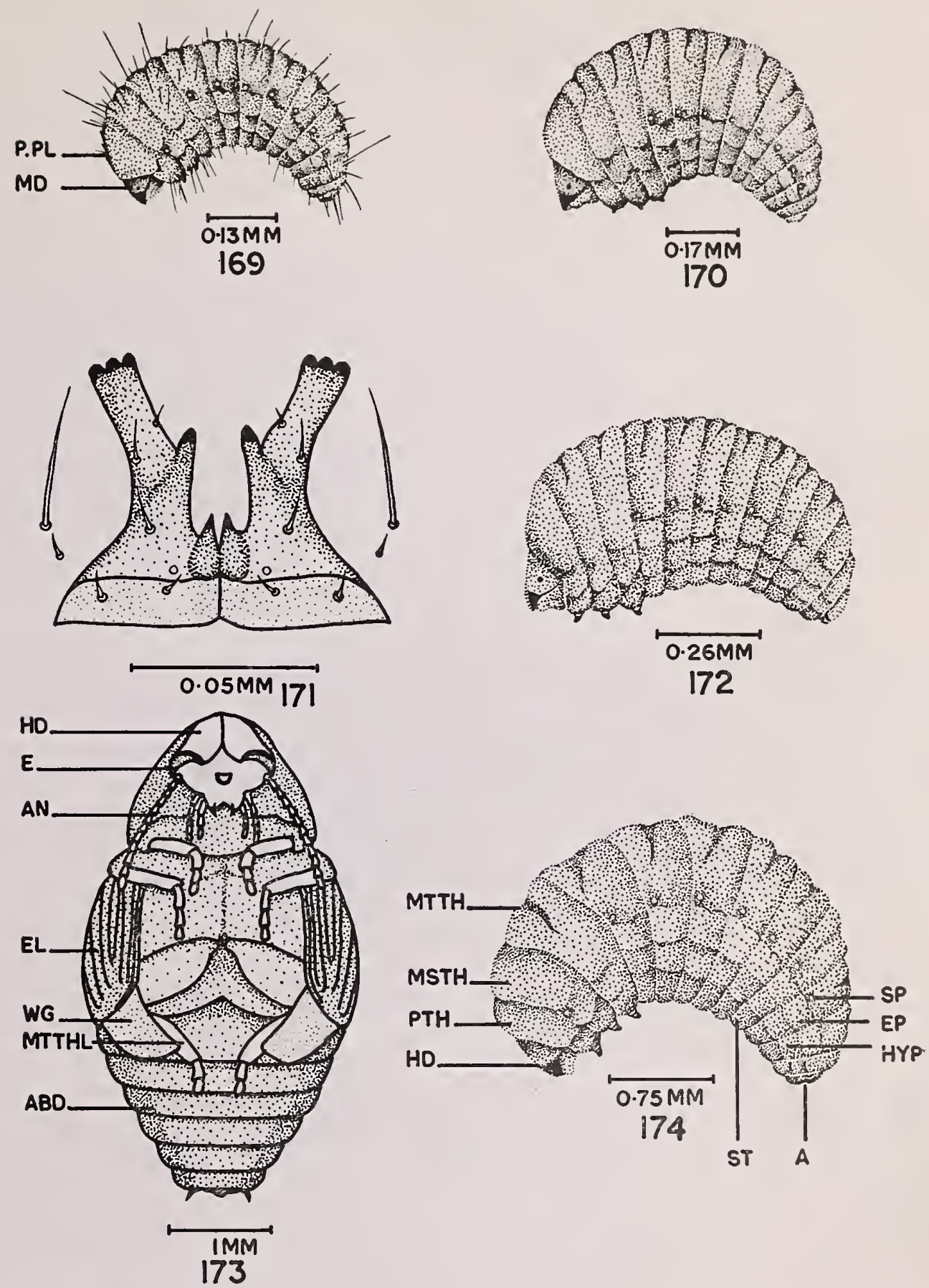

Bruchidius angustifrons Schilsky

Figs. 169. First instar larva; 170. Second instar larva; 172. Third instar larva; 173. Pupa; 174. Fourth instar larva.

171. Prothoracic plate; 


\section{PLATE 24}
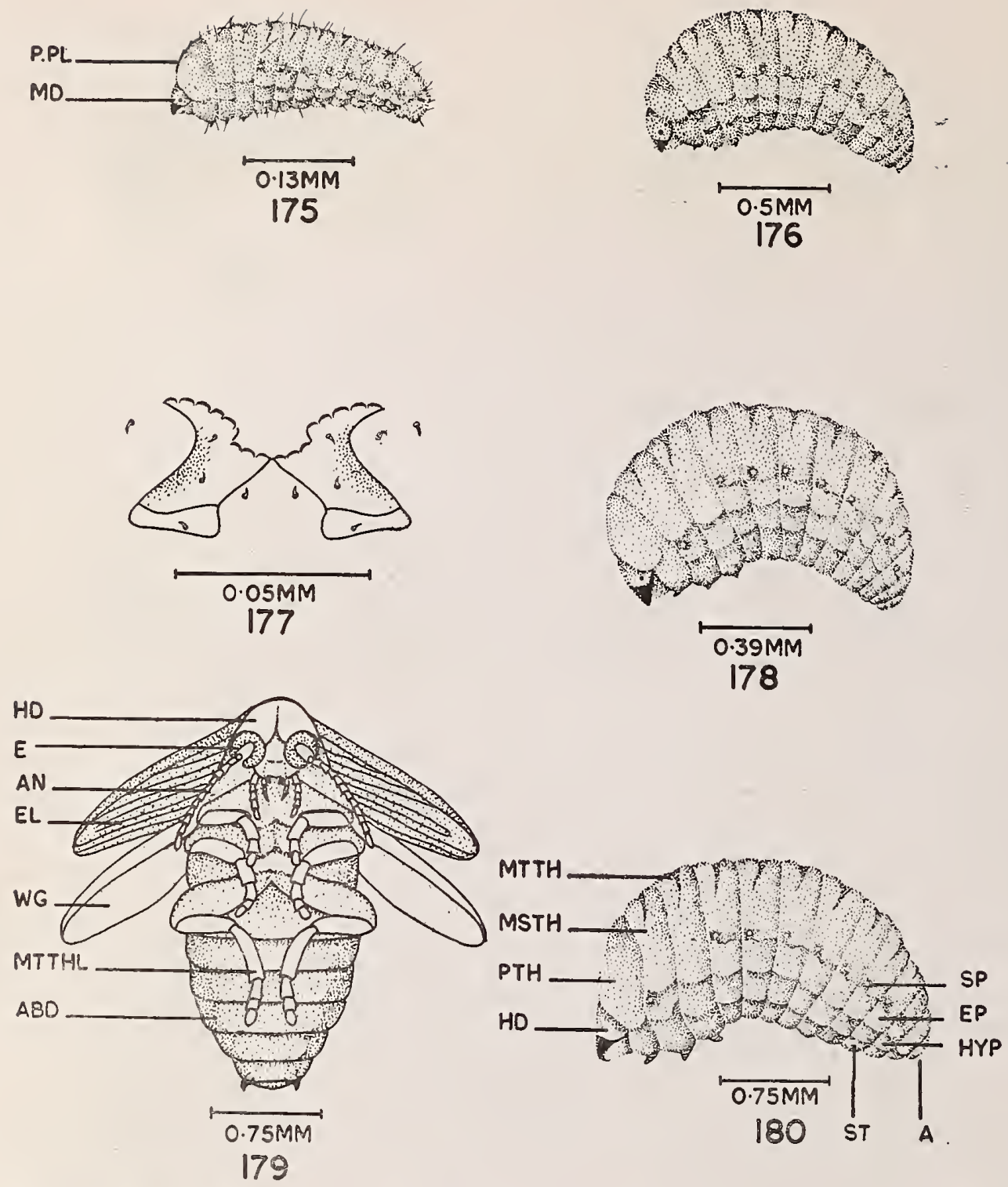

Bruchidius mimosae Arora

Figs. 175. First instar larva; 176. Second instar larva; 177. Prothoracic plate; 178 Third instar larva; 179. Pupa; 180. Fourth instar larva. 
Biology and Life-history of Bruchidius mimosae Arora (Pl. 24 figs. 175-180)

Bruchidius mimosae Arora attacks the pods and the seeds of the host plant Mimosa rubicaulis Lamk., a common shrub of the forests in India which flowers in August through September and October, the pods becoming available in September and later. The pods are slightly curved, $7-13 \mathrm{~cm}$ in length and about $1.25 \mathrm{~cm}$ in breadth, having $6-10$, one seeded, squarish joints.

The emergence of the adults takes place in January through February, March and April after which they lie in wait for 2-4 months in grass or a transitory host till the onset on flowering and fruiting of the host-plant in August and September. The adults then rush to the flowers, attracted by their fragrance. The male follows the female and continues to touch her pygidium with his antennae till she becomes receptive when the male rides her back and holds her body with his fore and middle legs. He then bends the tip of his abdomen to bring it in contact with the adbomen of his mate and tries to introduce his extruded aedeagus into the famale genital opening. A slight widening of the female genital opening to facilitate the entry of the aedeagus coupled with a forward movement of the male abdomen brings about a complete coition, lasting for an average duration of 1.46 minutes; the exophallic valve takes up an upward position to allow a continuous flow of the spermatophores from the male to the female.

The separation of the copulating partners is initiated by the female who pushes the male back by the backward strokes of her hind legs and drags him along till he withdraws his aedeagus, the whole process taking $10-20$ seconds.

The male does not copulate the second time when fresh virgins are provided. He, however, dies within 6-24 hours after copulation.

The freshly copulated female, during the pre-oviposition period of 3-18 hours, becomes uneasy, stretches and folds her wings alternately and rubs her body with her legs. She then stops at a suitable place, exudes a transparent, sticky fluid from her genital opening and spreads it on the surface of the pod wit the tip of her abdomen. An egg is passed out through the genital opening by successive movements of the abdomen, with the pointed end of the egg coming out first. It takes 45 seconds to 2 minutes to lay an egg. The interval between the successive laying of two eggs varies from 5 minutes to 2 hours. The eggs are laid singly on both sides of a pod with as many as 2-3 on either side, generally against the developing seed within. The total number of eggs laid by a copulated female varies from 19-47, laying eggs for 2-3 days in succession, followed by its death within 6-20 hours after her full quota of eggs has been deposited.

Life-history studies of $B$. mimosae conducted on the host plants growing in the forest areas around Chandigarh under natural envoironmental conditions from August to April show that the egg is whitishyellow in colour. It is more or less spindle-shaped, measuring 0.45 to $0.60 \mathrm{~mm}$ in length and 0.10 to 0.13 $\mathrm{mm}$ in diameter. It is soft and transluscent when freshly laid, becoming tough on exposure to air.

The developing embryo inside the egg-shell is clearly marked in 2-3 days when it lies with its ventral side up and its haad towards the anterior end. The incubation period in the field varies from 8-11 days when the average temperature is $27.55^{\circ} \mathrm{C}$ and average $\mathrm{RH} 76 \%$ during the month of September, whereas it varies from 6-8 days in the laboratory as it is comparatively warm indoors. The incubation period under controlled conditions varies from $5-7$ days when the temperature is $30^{\circ} \mathrm{C}-32{ }^{\circ} \mathrm{C}$ with $\mathrm{RH} 70 \%$. It, however, rises to $11-14$ days when the temperature is $24{ }^{\circ} \mathrm{C}-26^{\circ} \mathrm{C}$ with $\mathrm{RH} 70 \%$. The temperature thus has a significant effect on the incubation period, the incubation period rising with the fall in temperature and vice-versa. 
The fully-developed embryo shows movements inside the egg-shell. Its prothoracic plate works forwards, dowanwards and backwards against the lower inner surface of the shell, producing grooves and ridges. The embryo then takes a turn upside down and makes a small hole in the region of the grooves and ridges of the egg-shell by means of its mandibles, hatching out through it as the first instar larva.

The first instar larva is whitish in color except for the head capsule and the prothoracic plate which are sclerotized and brown. It measures 0.40 to $0.55 \mathrm{~mm}$ in length and 0.10 to $0.12 \mathrm{~mm}$ in breadth. Its body is almost straight, broader anteriorly and tapering posteriorly, and bears setae on its surface. The head capsude is deeply invaginated into the prothorax. The mandibles are strong and triangular of the cutting type. The thoracic segments bear each a pair of rudimentary legs, the prothorax carrying a sclerotized prothoracicplate in addition, attached to it by a fold of the skin. The prothoracic plate of $B$. mimose $a$ j: H-shaped, formed of 2 equal tri-radiate, setose plates, each half consisting of the posterior and and the anterior arms, united by a transverse bridge. The posterior arm on each side bears 5-teeth distally and is produced inward into a 3-toothed plate, the latter meeting its fellow of the other half in a bridge. The anterior arms are directed outward. The arrangement of teeth is $3+5$. The plate is associated with 5 pairs of setae, 3 pairs borne on the surface of the prothoracic plate, a pair in between the two halves and a seta. on either side of the plate.

The abdomen is ten-segmented.

The first instar larva, immediately after making a hole in the egg-shell, cuts a small hole in the surface of the pod lying directly underneath. The larva eats its way through the pod into the green developing seed below, entering generally near the plumular end of the seed. The eclosion of the larva and its entrance. into the seed take 6-14 hours. The larva makes a depression in the seed, grows in size at the expense of the seed contents and moults after a period of 4-6 days, discarding its exuvium and its prothoracic plate to change into the second instar larva.

The second instar larva is dull-white in color to begin with but becomes pale-yellow a little later. The body becomes curved and is devoid of setae. It measures 0.75 to $1.00 \mathrm{~mm}$ in length and 0.20 to 0.30 $\mathrm{mm}$ in breadth. The head capsule is deeply invaginated into the prothorax. The thoracic segments bear each a pair of compar tively short legs. The tergum of the prothorax is undivided whereas the terga of the meso and the metathorax are transversely divided into an anterior and posterior part. The abdomen is ten-segmented. The second instar larva moves deep into the seed, grows in size as it consumes the material. of the cotyledons and ultimately moults after 12-16 days into the third instar larva.

The third instar larva is bright-yellow in colour, its frons, clypeus and mandibles being dark-brown. The body is thickened and curved, measuring 1.25 to $2.00 \mathrm{~mm}$ in length and 0.60 to $1.00 \mathrm{~mm}$ in breadth. The legs are two-segmented. The larva is a voracious eater and moults after 10-15 days into the fourth instar larva.

The fourth instar larva is bright-yellow in colour with dark-brown frons, clypeus and the mandibles. The body is comma-shaped measuring 2.10 to $3.25 \mathrm{~mm}$ in length, and 1.00 to $1.50 \mathrm{~mm}$ in breadth. The head is hypognathous, slightly pigmented and sclerotized around the mouth-parts. It is deeply invaginated into the prothorax with a marked epicranial suture, running from the vertex and bifurcating: further down to reach the antennary sockets. The antennae are short and two-segmented, the clypeus undivided and the mandibles triangular. The thoracic segments bear each a pair of 3-segmented legs. The abdominal segments 1-7 are biannulate and segments 8-10 uniannulate. 
The late fourth instar larva stops feeding, smoothens the cavity in which it lies inside the seed and ultimately moults within 15-20 days into the prepupa.

The body of the prepupa becomes almost straight. It is yellow in colour and measures 2.50 to 3.25 $\mathrm{mm}$ in length and 1.25 to $1.75 \mathrm{~mm}$ in breadth. The head is fully extended out of the prothorax and the legs are bulging out. The abdomen is blunt distally. The prepupa stage lasts for 1-2 days after which it is transformed into the pupa.

The pupa is a dormant stage in the seed cavity with its ventral side up. It is pale-yellow in colour, becoming darker as it grows. It measures 3.25 to $3.75 \mathrm{~mm}$ in length and 2.00 to $2.25 \mathrm{~mm}$ in breadth. The head bears prominent C-shaped eyes. The antennal sheaths pass laterally in front of the fore legs, lying below the elytral sheaths. The pro, the mes ${ }^{\circ}$ - and the meta legs are folded back on themselves. The sheaths of the hind wings extend backward under the elytral sheaths. The abdomen shows 7 tergites, the seventh being the largest and forming the pygidium. The first two abdominal sternites are fused whereas the remaining $3-7$ sternites are free.

Prior to eclosion, the pupa darkens in colour. Its skin becomes loose and the adult inside gets separated in 20-25 days. With vigorous movements of the legs and the body, the pupal skin is ultimately ruptured on the head, thorax and in the region of the legs. The adult then withdaraws its body from the puparium as a full-fledged insect inside the seed. This insect cuts a circular opening in the seed coat as well as in the pod outside. The emergence is generally delayed for 15-20 days and the adults start coming out in January. B. mimosae takes $70-85$ days to complete its life-history but may live for another 1-3 months inside the seed depending on the maturing of the pods under the related environmental conditions. A healthy seed may harbour as many as two larvae to develop into adults.

\section{Biology and Life-history of Bruchidius angustifrons Schilsky.}

$$
\text { (P1. } 23 \text { figs. 169-174) }
$$

Bruchidius angustifrons Schilsky attacks the pods and seeds of the host-plant Sesbania sesban (L.) (Chinjan) which is a common wild, perennial, hedge-forming weed. The flowering and fruiting (forming of pods) of the host plant takes place twice in the year, first from early February to early May and the second from early July to end of November. The emergence of adult insects from the pods takes place during the hot months of May and June and during the cold months of December and January, followed each time by the shedding of the old pods. The pods of the host-plant are $15-22 \mathrm{~cm} \mathrm{long}, 3-5 \mathrm{~mm}$ in diameter and are 20-30 seeded. The freshly emerged insects hide themselves in grass till the new flowering season sets in when they rush to the flowers and eat the pollen from the bursted anthers.

The male follows the female and after performing some sexual preliminaries of striking the pygidium of the female by his antennae, rides the back of the receptive female, grasping her body with his fore and middle legs. He then bends the tip of his abdomen to bring it in contact with that of his mate and inserts his extruded aedeagus into the female genital opening, bringing about a complete coition by a slight widening by the female of her genital aperture to facilitate the entry of the aedeagus and the corresponding forward movements of abdomen of the male. The exophallic valve moves rhythmically up and down to allow a flow of the spermatophores from the male to the female. The duration of copulation on an average lasts for 2.39 minutes at a temperature from $26^{\circ} \mathrm{C}$ to $30^{\circ} \mathrm{C}$ and $\mathrm{R}$. $\mathrm{H}$. from $60 \%$ to $80 \%$. The male of the species died within 24 hours after copulation even when provided with fresh flowers and pods. The male refused to mate the second time when offered freshly emerged virgins. The female on the other hand within 24 hours after copulation, becomes somewhat unseasy and extends and folds her wings alternately, rubbing her body with her legs. She finds a suitable place for egg laying 
either in the calyx cup or in a broken and bent depression on the pod. She exudes an almost transparent, sticky fluid from her genital opening and spreads it evenly on the surface of the calyx cup or of the depression by the tip of her abdomen. An egg is then slowly passed out by successive longitudinal movements of her abdomen and deposited in the fluid with its pointed end coming out first. It takes 20-30 seconds. to lay an egg, making a cluster of 4-15 eggs at a place. The process of egg laying is repeated with an interval of 10 minutes to 2 hours between two successive layings.

The observations on oviposition show that the number of eggs laid by copulated females varies from 6-29, each female laying eggs for $2-4$ days in succession after which she dies within 2-20 hours of having deposited its full quota of eggs.

The newly laid eggs are oval in shape and yellowish in colour. Each egg is rounded at the anterioi and pointed at the posterior end and slightly flattened below, measuring from $0-60 \mathrm{~mm}$ to $0.75 \mathrm{~mm}$ in length. The freshly laid egg is soft and transluscent but becomes hard on exposure to air.

The developing embryo inside the egg-shell becomes visible after 2 days when it lies with its ventral side up. The incubation period varies from 4-16 days under different conditions of temperature and humidity, the temperature having a significant effect. The incubation period goes upto 16 days during thecold months whereas it is as low as 4 days with the rise in temperature during the hot months.

The embryo shows movements inside the egg-shell before hatching. It takes a turn upside down and its prothoracic plate works against the inner surface of the egg-shell, producing ridges and grooves. The embryo then cuts a small circular hole in the egg shell by means of its strong mandibles and pushes its way out as a first instar larva, the process of eclosion taking about 2-5 hours and the larva coming out either in the early hours of the morning or late in the evening.

The first instar larva of $B$. angustifrons is yellow to light brown in colour except its head capsule, its mouth-parts and its prothoracic plate which are dark brown. Its body is cylindrical, broad anteriorly and tapering posteriorly. It measures from $0.50 \mathrm{~mm}$ to $0.65 \mathrm{~mm}$ in length and $0.15 \mathrm{~mm}$ to $0.20 \mathrm{~mm}$ in breadth, its surface beset with long and stiff setae. The head capsule is sclerotized and invaginated into the prothorax. The mandibles are strong, triangular and of the cutting type. The thorax comprises the pro, the meso and the metathoracic segments, each bearing a pair of rudimentary legs. The prothorax carries a well developed, strongly sclerotized, $\mathrm{H}$-shaped prothoracic plate, formed of 2 equal, tri-radiate, setose plates, each consisting of the posterior and the anterior arms united by a transverse bridge. The posterior arm of each half bears three teeth distally and a large, curved, posteriorly-directed tooth on its mesial aspect, and a triangular basal tooth meeting its fellow of the other half in a transverse bridge. The anterior arm is short and outwardly drawn out into a spine. The arrangement of teeth is shown as $1+1+3$ on either side. The prothoracic plate bears 5 pairs of setae on its surface. There are two pairs of additional setae, one pair on either side of the plate. The prothoracic plate helps the larva to produce ridges and grooves on the inner surface of the egg-shell to enable it to come out of the egg at eclosion. The abdomen is ten-segmented.

The first instar larva, after hatching, comes out of the egg, moves about on the surface of the pod and finally fixes itself at a suitable place. It then cuts a small circular hole in the surface of the pod by means of its mandibles. It takes $2-4$ hours to enter the pod carrying the powdered material with it, the entrance hole healing up behind. The first instar larva cuts through the soft coat of the seed, making a small hole to enter the seed and reaches the plumule. It moves further in between the cotyledons where it lies in a. 
shallow pit. It grows at the expense of the colyledons and after 4-5 days moults, discarding its exuvium along with its prothoracic plate to change into the second instar larva.

The second instar larva is light-yellow in colour, its body becoming thick and curved. It measures 1.00 to $1.25 \mathrm{~mm}$ in length and 0.35 to $0.45 \mathrm{~mm}$ in breadth. The head capsule is deeply invaginated into the prothorax. The thoracic segments bear each a pair of comparatively short, rudimentary legs. The larva moves deep into the seed and after 5-9 days moults again into the third instar larva.

The third instar larva is light -brown in colour and has grown to $1.50 \mathrm{~mm}$ to $2.20 \mathrm{~mm}$ in length and $0.85 \mathrm{~mm}$ to $1.00 \mathrm{~mm}$ in breadth. The legs are larger in size and 2-segmented. The abdominal segments are more distinctly marked. The larva moults again after 4-7 days into the fourth instar larva. The third instar larva and the early fourth instar larva are voracious eaters.

The fourth instar larva is C-shaped and brown in colour except the frons, the clypeus, the labrum and the mandibles which are dark brown. It measures from $2.00 \mathrm{~mm}$ to $2.75 \mathrm{~mm}$ in length and $1.20 \mathrm{~mm}$ to $1.40 \mathrm{~mm}$ in breadth. The head is hypognathous, a little longer than broad, deeply invaginated into the prothorax, with a well marked epicranial suture running down from the vertex and bifurcating to reach the antennary sockets, the short, two-segmented antennae, the undivided clypeus and the triangular mandibles. The thoracic segments bear each a pair of rudimentary, 3-segmented legs. The prothoracic tergum is undivided whereas the meso and metathorax are divided transversely, each into an anterior and a posterior part. The abdominal segments 1-7 are bi-annulate and segments 8-10 uniannulate. The late fourth instar larva stops feeding and becomes dark-brown. It smoothens the inside of the seed cavity by depositing its faecal matter and moistening the inside by its body secretions. The fourth instar takes 4-7 days to change into prepupa whose body straightens and darkens in colour with its head capsule protruded out of the prothorax. The prepupa stage lasts for 1-2 days after which it is transformed into the pupa.

The pupa is a dormant stage, lying motionless inside the seed. Its body is straight and yellow in colour. It measures $3.00 \mathrm{~mm}$ to $4.10 \mathrm{~mm}$ in length and $2.00 \mathrm{~mm}$ to $2.40 \mathrm{~mm}$ in breadth and is devoid of bristles. The head bears a pair of prominent horse-shoe-shaped eyes. The antennal sheaths físs laterally in front of the legs and lie below the elytral sheaths. The pro-, the meso-, and the metathoracic legs are folded back on themselves. The elytral sheathsare closely pressed against the body. The sheaths of the hind wings extend backward under the elytral sheaths. The abdomen shows six visible tergites, the seventh being the largest and forming the pygidium. The first two abdominal sternites are fused whereas the remaining are free.

The pupa darkens in colour before eclosion when its skin becomes loose.

The young adult inside gets separated and the pupal skin is ultimately ruptured by the vigorous movements of its legs. The adult takes 4.6 days to withdraw its body from the puparium. It then makes a circular hole in the wall of the seed and the covering pod by means of its mandibles to emerge as an adult within two days provided the environmental conditions outside are favourable. When, however, the environmental conditions outside are unfavourable as in the hot months of May and June or in the cold months of December and January, the emergence of the adults is delayed.

The period from the egg to the fully formed adult brushid varies from 28-47 days during the months of July to October depending upon the corresponding drying up of the pods containing the first instar larva and the subsequent stages. 
Biology and Life-history of Bruchidius tephrosiae Arora

(P1.25 figs. 181-186)

Bruchidius tephrosiae Arora attacks the pods and seeds of host plants Tephrosia purpurea Pers. and Tephrosia villos $a$ Pers. commonly growing as weeds in the country. Tephrosia perpurea starts flowering in the rainy season in the month of July and continues doing so till October, the pods becoming available for egg laying from August onward to January, maturing slowly during this period. The pods are flot and pubescent, measuring $4.25 \mathrm{~cm}$ to $5.00 \mathrm{~cm}$ in length and 4.00 to $5.00 \mathrm{~mm}$ in breadth. Each pod contains 5-7 oblong seeds.

The freshly emerged adults hide themselves in grass till the host plants flower when they are attracted by their fragrance. They do not feed on the pollen or any other part of the flowers but manage to hide themselves among them. The males in a population are more than thrice the number of females. They are aggressive from the very start. The male follows the female, touches her pygidium with his antennae and tries to ride her back. He ultimately succeeds when the female becomes receptive. He holds the female by means of his fore and middle legs, bends the tip of his abdomen to bring it in contact with the tip of the abdomen of his mate, trying to insert his extruded aedeagus into the female genital opening. The female widens her genital opening to facilitate the entry of the aedeagus, which is pushed forward to bring about complete coition. The exophallic valve continues to move rhythmically up and down to allow a rhythmic flow of the spermatophores from the male to the female. The average duration of copulation is 2.48 minutes at a temperature $22{ }^{\circ} \mathrm{C}$ to $26^{\circ} \mathrm{C}$ and $\mathrm{R} . \mathrm{H} .60 \%$ to $80 \%$. The copulating partners take 15-30 seconds to move apart, initiated by the vigorous backward strokes of the hind legs of the female and helped by a slow withdrawal by the male of its aedeagus.

The male after separation from his mate refuses to copulate the second time and ultimately dies within 8-24 hours after copulation. The copulated female, on the other hand, becomes somewhat uneasy prior to egg-laying, extends and folds her wings alternately and rubsits body with her legs. The preoviposition period lasts for 4-16 hours after which she stops at a selected place, exudes a transparent, sticky fluid from her genital opening and spreads it on the surface of the pod with the tip of her abdomen. An egg is then passed out and deposited on the sticky surface with the pointed end of the egg coming out first through the genital opening. It takes 3 minutes to lay an egg, the interval between two eggs laid in succession varying from ten minutes to six hours. As many as 7 eggs may be laid at each sutural margin of the pod and not more than 5 eggs are laid on either side of the pod against each developing seed within. Eggs are preferably laid during the early hours of the morning or late hours of the evening. The total number of eggs laid by a copulated female varies from 12-34, laying eggs for 2-3 days in succession, followed by its death within 8-24 hours after the full quota of eggs has been laid by her.

An egg of $B$. tephrosiae is light-yellow in colour with a broad and rounded anterior, and a narrow and pointed posterior end. The egg is convex above and flattened below. It measures 0.50 to 0.65 $\mathrm{mm}$ in length and 0.10 to $0.13 \mathrm{~mm}$ in diameter. The eggs are soft and transluscent when freshly laid but become tough on exposure to air.

The developing embryo inside the egg-shell can be properly made out within 5-6 days after it is laid with its ventral surface up and its head occupying the rounded end of the egg. The incubation period varies from 9-12 days in January in the laboratory when the average temperature is $14.95^{\circ} \mathrm{C}$ and average R.H. $70 \%$, and rises to $13-16$ days when the temperature is controlled at 240 to $26^{\circ} \mathrm{C}$ and R.H. $70 \%$. The 


\section{PLATE 25}
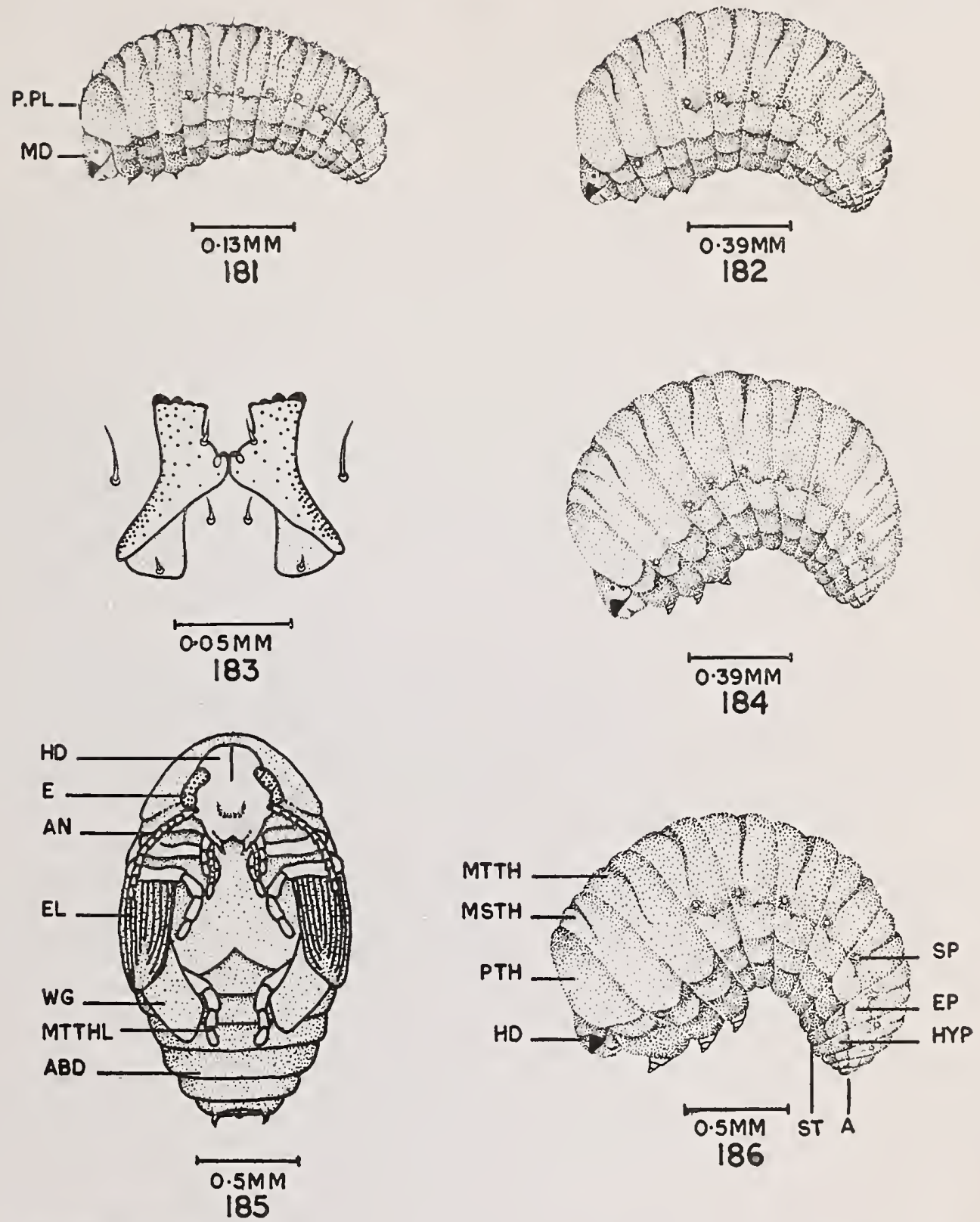

Bruchidius tephrosiae Arora

Figs. 181. First instar larva; 182. Second instar larva; 183. Prothoracic plate; :

184. Third instar larva; 185. Pupa; 186. Fourth instar larva. 
incubation period in the field in January, however, is longer, varying from 16-19 days (condition in the field being cooler than in the laboratory).

The fully-formed embryo inside the egg-shell shows movements and its prothoracic plate works forwards, downwards and backwards against the inner surface, producing grooves and ridges. The embryo takes a turn upside down and cuts a small hole in the region of grooves and ridges with the help of its mandibles, and hatches out as the first instar larva.

The first instar larva is light-yellow in colour except the head capsule and the prothoracic plate which are dark-brown. It measures $0.50-0.60 \mathrm{~mm}$ in length and 0.10 to $0.15 \mathrm{~mm}$ in breadth. The body is almost straight, bearing seate on its surface. The head capsule is invaginated into the prothorax. The mandibles are strong, triangular and of the cutting type. The thoracic segments bear each a pair of rudimentary legs, the prothorax also carrying the prothoracic plate.

The prothoracic plate is a sclerotized $\mathrm{H}$-shaped structure, formed of 2 equal, tri-radiate, setose plates, each consisting of the posterior and the anterior arms, united by a transverse bridge. The posterior arm, of each half bears 4-teeth distally and is produced inward into a single-toothed plate meeting its fellow of the other half in a bridge. The anteior arms are directed outward. The arrangement of teeth is represented as $1+4$. Associated with the plate are 4 pairs of setae, 2 pairs being on the surface, a pair in between the posterior arms and a seta each lying on either side.

The abdomen is ten-segmented.

The first instar larva cuts a small hole on the surface of the pod lying directly underneath and corresponding to the hole in the egg shell. The larva eats its way through the pod into the green developing seed within from the plumular end. The whole process from the time eclosion takes place till the entry of the larva into the seed takes 7-20 hours. The larva makes a shallow depression in between the cotyledons, grows in size at their expense and ultimately moults in 2-5 days, discarding its exuvium and the prothoracic shield and changing into the second instar larva.

The second instar larva becomes cream-colored with a thick and curved body, devoid of setae. It measures 0.75 to $1.00 \mathrm{~mm}$ in length, and 0.20 to $0.25 \mathrm{~mm}$ in breadth. The head is deeply invaginated into the prothorax. The thoracic segments bear each a pair of comparatively short legs. The terga of the meso- and meta-thorax are transversely divided into two. The abdomen is ten-segmented. The larva moves deep into the seed, grows in size, and moults after 10-15 days into the third instar larva.

The third instar larva is light-yellow in colour, except the frons, the clypeus and the mandibles which are dark-brown. The body becomes more curved, measuring $1.25-1.50 \mathrm{~mm}$ in length and 0.60 to 0.70 $\mathrm{mm}$ in breadth. The legs are 2-segmented. The third instar larva moults after 10-15 days forming the fourth instar larva. The third instar and the early fourth instar are voracious eaters.

The fourth instar larva is yellow in colour with dark-brown frons, clypeus and mandibles. The body is comma-shaped, measuring $1.50-2.00 \mathrm{~mm}$ in length and $0.75-1.25 \mathrm{~mm}$ in breadth. The head is hypognathous, pigmented and sclerotized around the mouth-parts. It is deeply invaginated into the prothorax, with a well-marked epicranial suture from the vertex and bifurcating further down. The antennae are two-segmented. The thoracic legs are 3 -segmeted. The abdominal segments $1-7$ are biannulate and segments 8-10 uniannulate. 
The late larva stops feeding. It smoothens the cavity of the seed wherein it lies by depositing its faeeal matter and moistening it by its secretions. The larva moults into the pre-pupa within 12-17 days.

The pre-pupa straightens up. The body is yellow in colour and measures 2.00 to $2.75 \mathrm{~mm}$ in length and 1.25 to $1.75 \mathrm{~mm}$ in breadth. The head is fully extended out and the legs bulging. The abdomen is blunt distally. This stage lasts for 1-2 days after which it is transformed into the pupa.

The pupa is a dormant stage inside the seed cavity. It is pale-yellow in colour, becoming darker later. It measures 3.00 to $3.50 \mathrm{~mm}$ in length and 1.75 to $2.25 \mathrm{~mm}$ in breadth. The head bears two prominent horse-shoe-shaped eyes. The antennal sheaths pass laterally in front of the fore-legs, lying below the elytral sheaths. The thoracic legs are folded back. The sheaths of the hind wings extend backward under the elytral sheaths. The abdomen shows six segments, followed by the large seventh one forming the pygidium. The first two abdominal stermites are fused whereas the sternites 3-7 are free.

The pupa darkens before eclosion. The pupal skin loosens and the adult inside gets separated after 12-18 days. The adult shows movements of legs and body which become vigorous, ultimately rupturing the pupal skin on the head, the thorax and some irregular ruptures on the legs. The adult then withdraws itself from the puparium. It then cuts a circular hole in the seed coat as well as in the pod covering it to finally emerge out in about 2-4 days in March and April.

The total life span from egg to adult varies from 64-83 days in January to April. A healthy seed harbours a single individual as a rule-but in case more than one larva enter the seed, only one reaches maturity. 


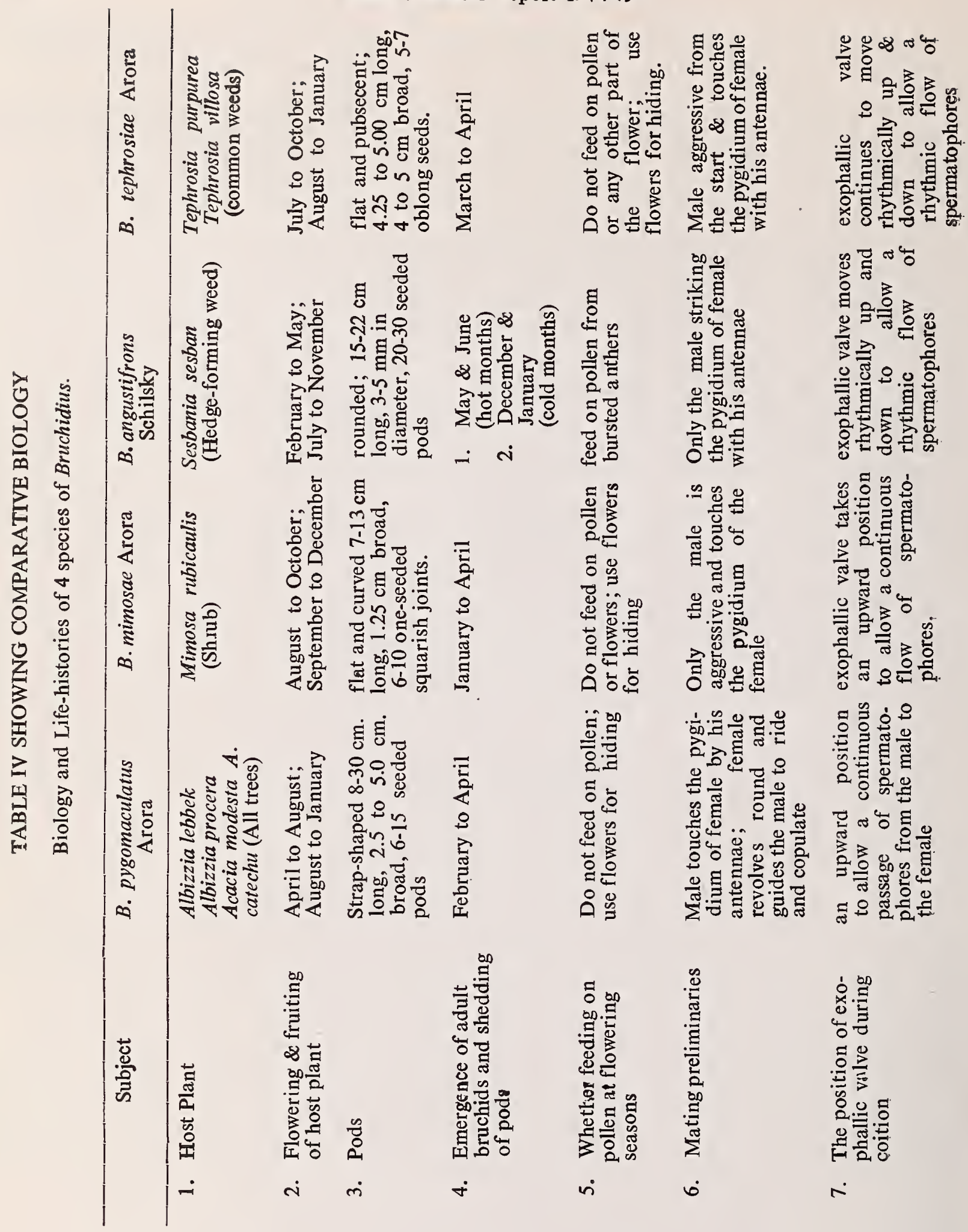




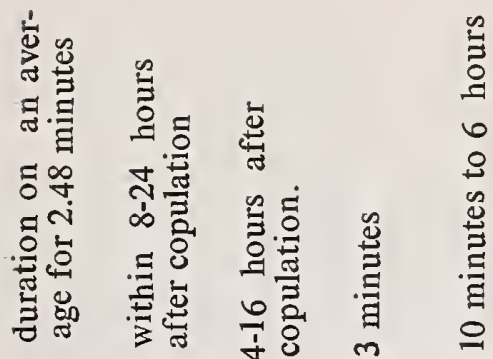

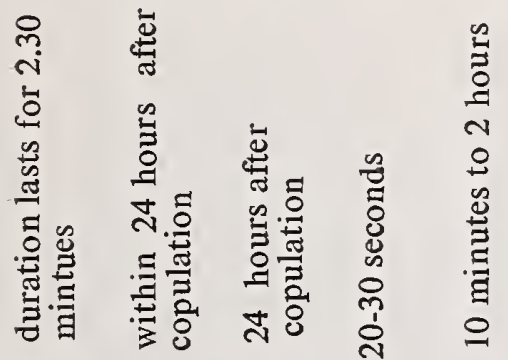

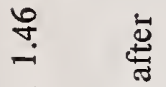

苞

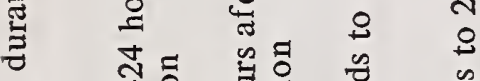

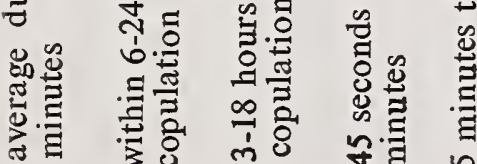

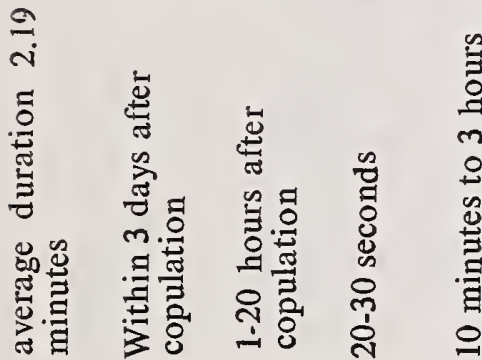

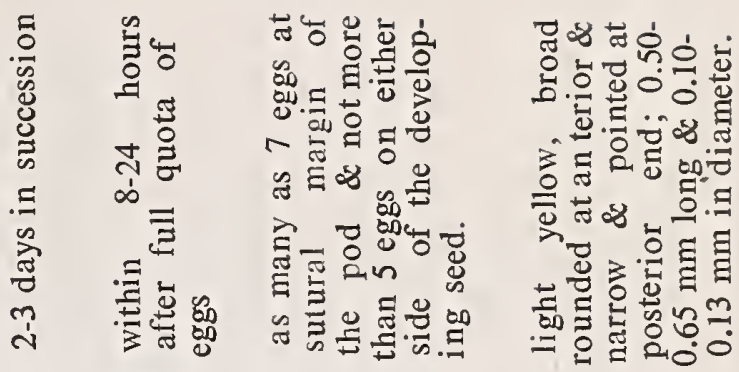

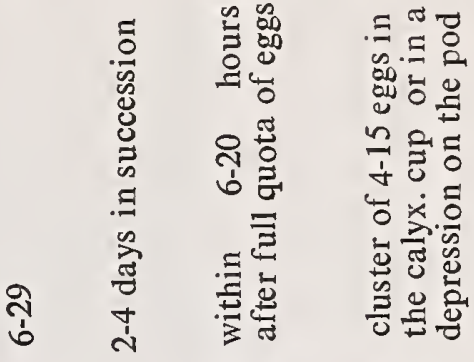

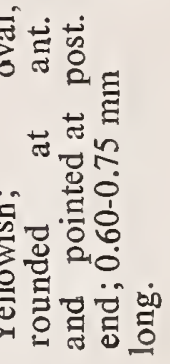

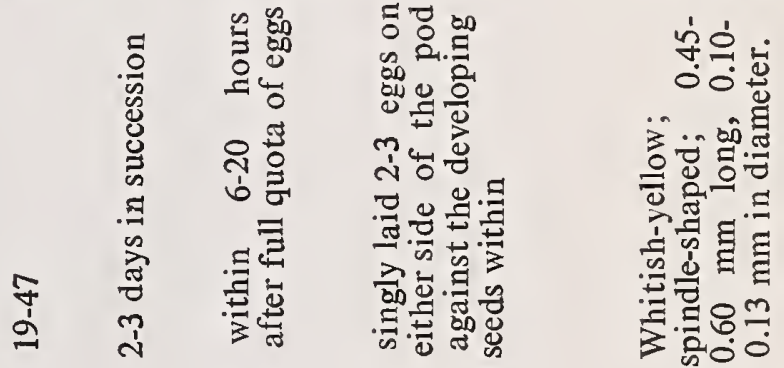

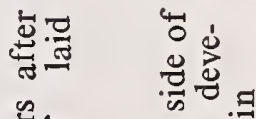

第。

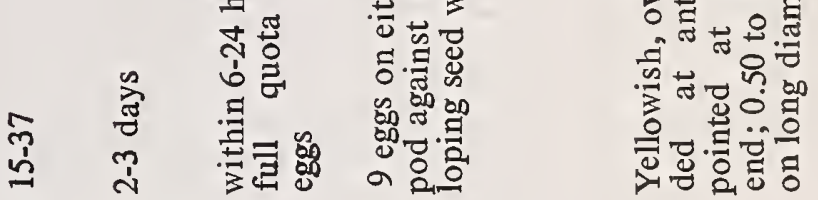

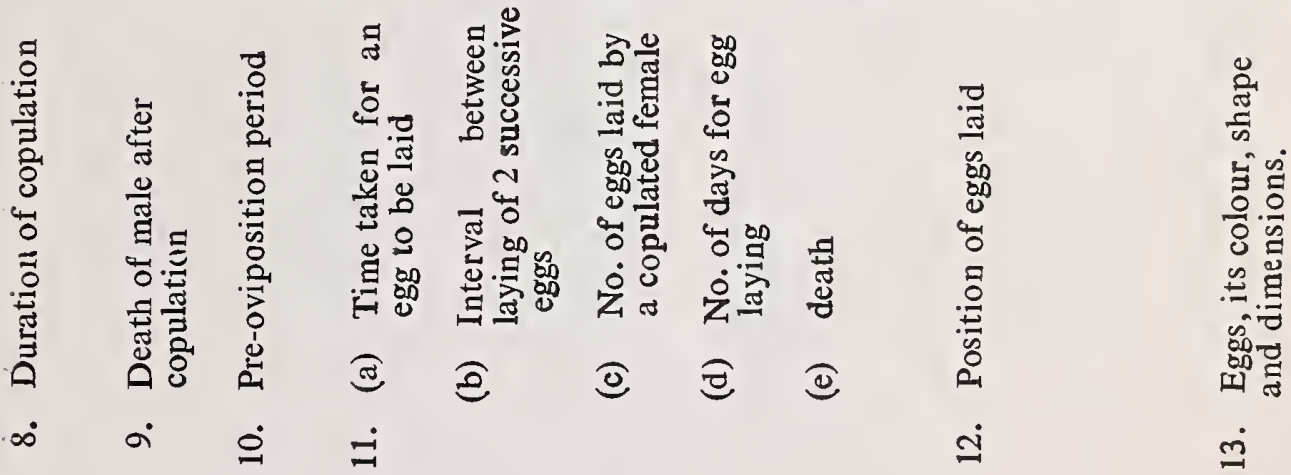




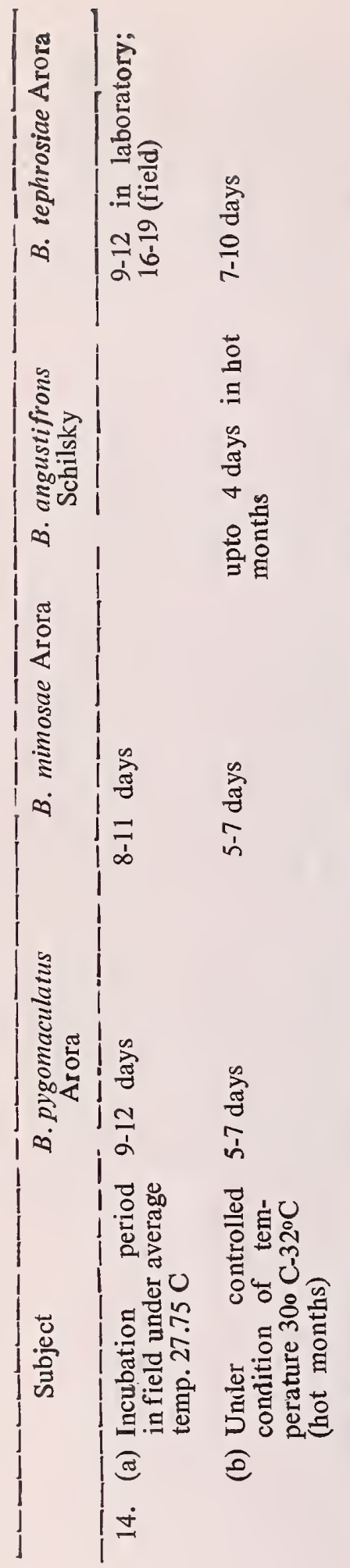

Final Technical Report 1974-79

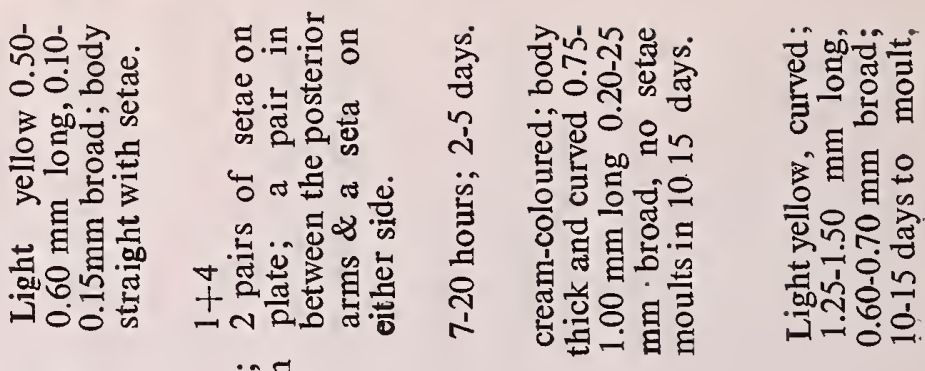

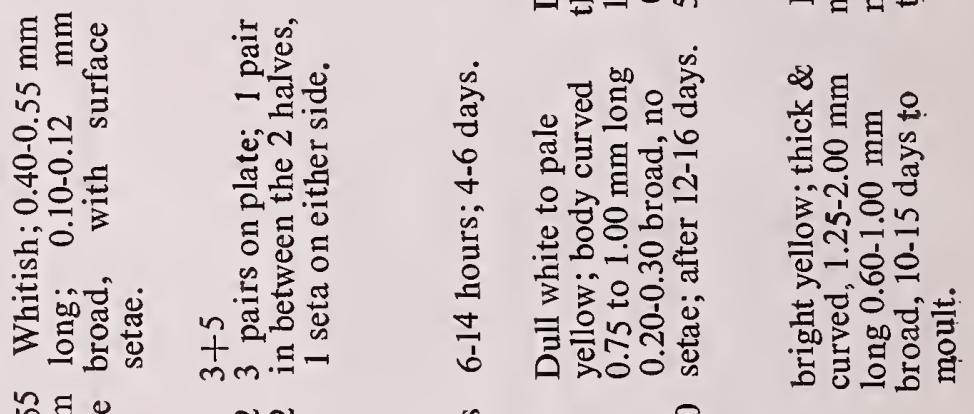

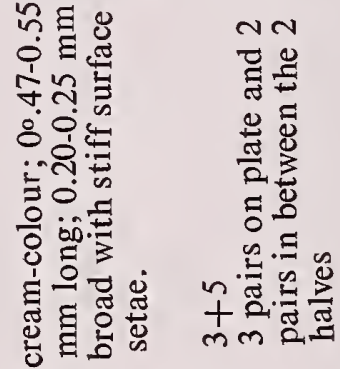

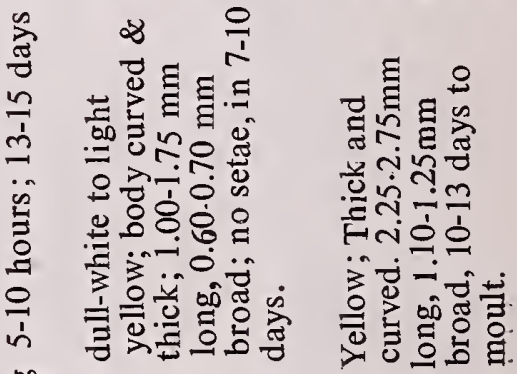

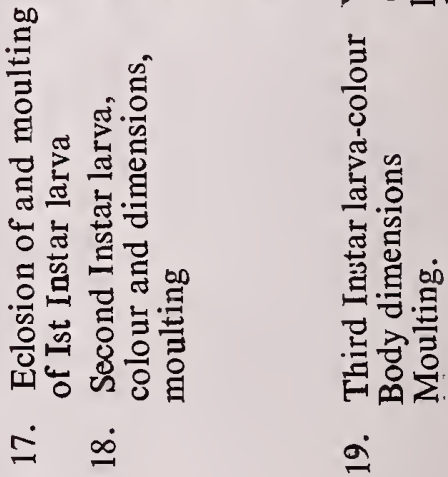


Arora : Biology and Taxonomy of Bruchidius

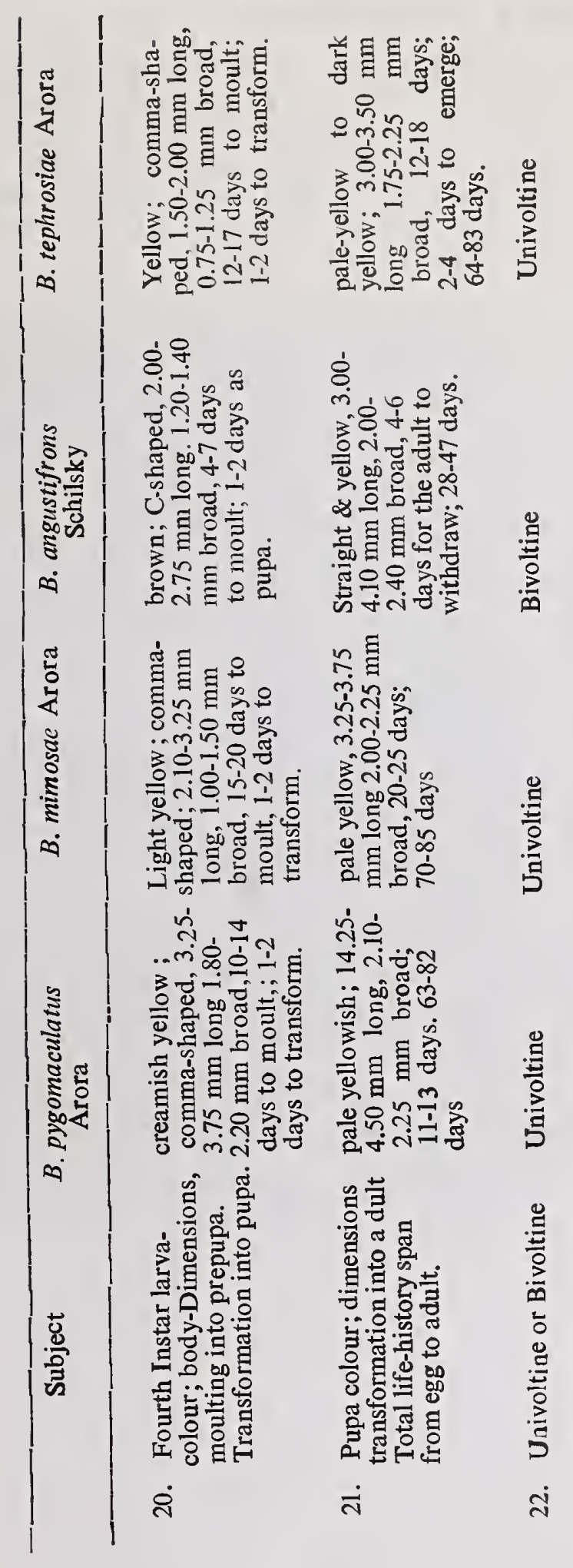




\section{DISCUSSION \& CONCLUSIONS}

The investigations \& observations recorded in the foregoing pages bring out the importance of the members of the Genus Burchidius. They are for one the destroyers of the edible, the common forest, medicinal and ornamental plants, leading to a heavy loss of our food stuffs and other valuable products. It is, therefore, our great concern to devise adequate measures to control such harmful pests. Secondly there are certain species which breed in the pods and seeds of the noxious weedy plants associated with our corps. They are, in fact, of considerable biological importance in keeping a check on the growth \& multiplication of the weeds and are of great practical significance.

Most of the species of Bruchidius are univoltine with a single generation in the year except $B$.angustifrons Schilsky which is bivoltine. The incidence and distribution of the species show that the population may je a dense one in certain States, medium in others and rare in still others. The dispersal of a species starts from a centre with dense population to centres with medium and rare populations.

As a result of our intensive surveys in the different States of India, it has been observed that the Genus Bruchidius is a well knit group of beetles with 44 species so far collected, of which 21 appear to be new. The collection and study of the weeds have brought to light that some of them may be the hostplants of species hitherto said to be with unknown host-plant. Quite a large number of species have been collected from grass or from among the flowers \& leaves of transitional host-plants to which they have flown after emergence. Buchidius vulgaris Arora, for example, has been collected from the common weed Alisycarpus monilifer in Punjab for the first time, known formerly to have been collected from the flowers and leaves of transitional host-plants e.g. Tagetes petula, Lantana indica, Escoscholtzia californica and Shorea robusta.

The studies on the biology and life-history of some common species of Bruchidius undertaken in the present project is a line in the right direction to investigate the behaviour of these insects at different levels. This is further helpful in determining the grouping of species.

\section{ACKNOWLEDGEMENT}

I heartily thank the Director, U.S. Department of Agriculture, American Embassy, New Delhi for providing adequate funds for completing the U.S. PL. 480 Research Project, and the Head and Chairman of the Department of Zoology, Panjab University, Chandigarh for making available necessary laboratory and office facilities. I am greatly indebited to Dr. John M. Kingsolver, Systematic Entomologist, U.S. Department of Agriculture, Washington for his valuable comments and suggestions throughout the period that the project ran at Chandigarh. My special thanks are due to my colleagues and assistants in the Project for rendering all possible technical help in our collection work in the different States of India, followed by experimental investigations in the laboratory. 
PHOTO I

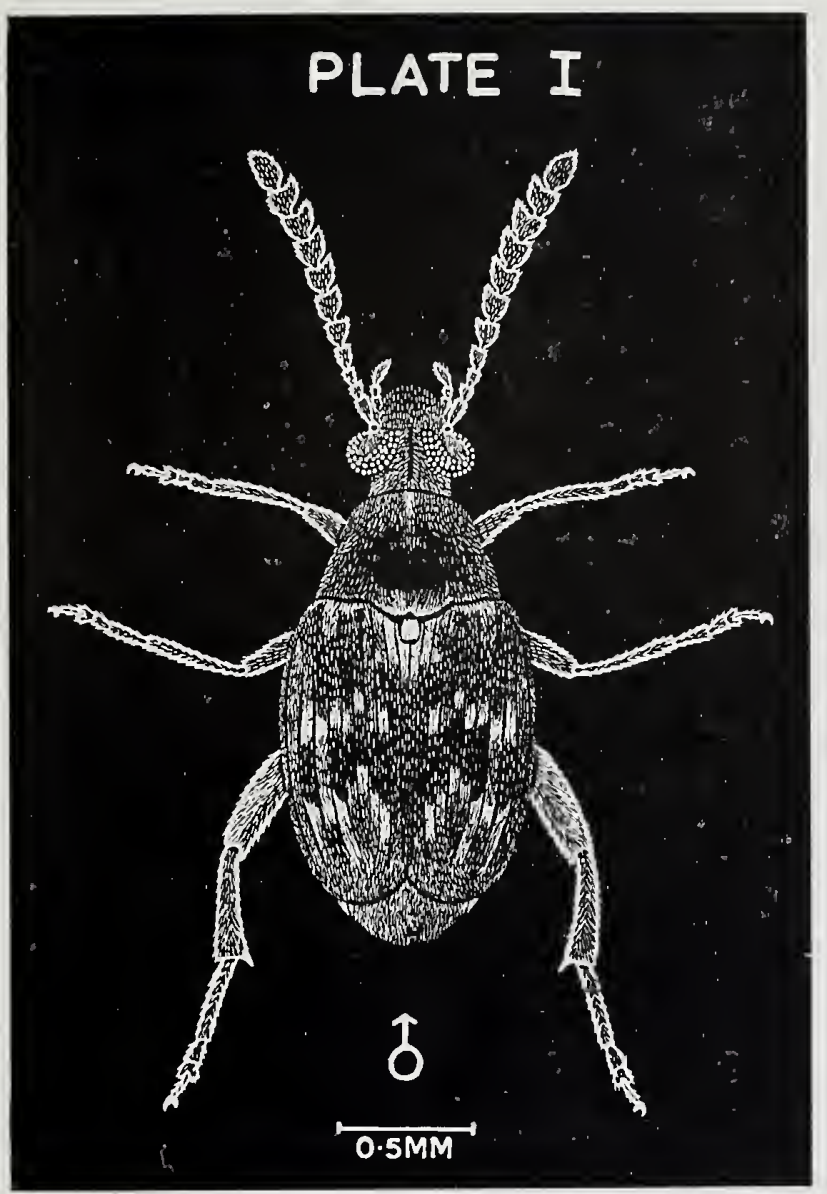

Bruchidius orientale sp. nov. (Male)
PHOTO II

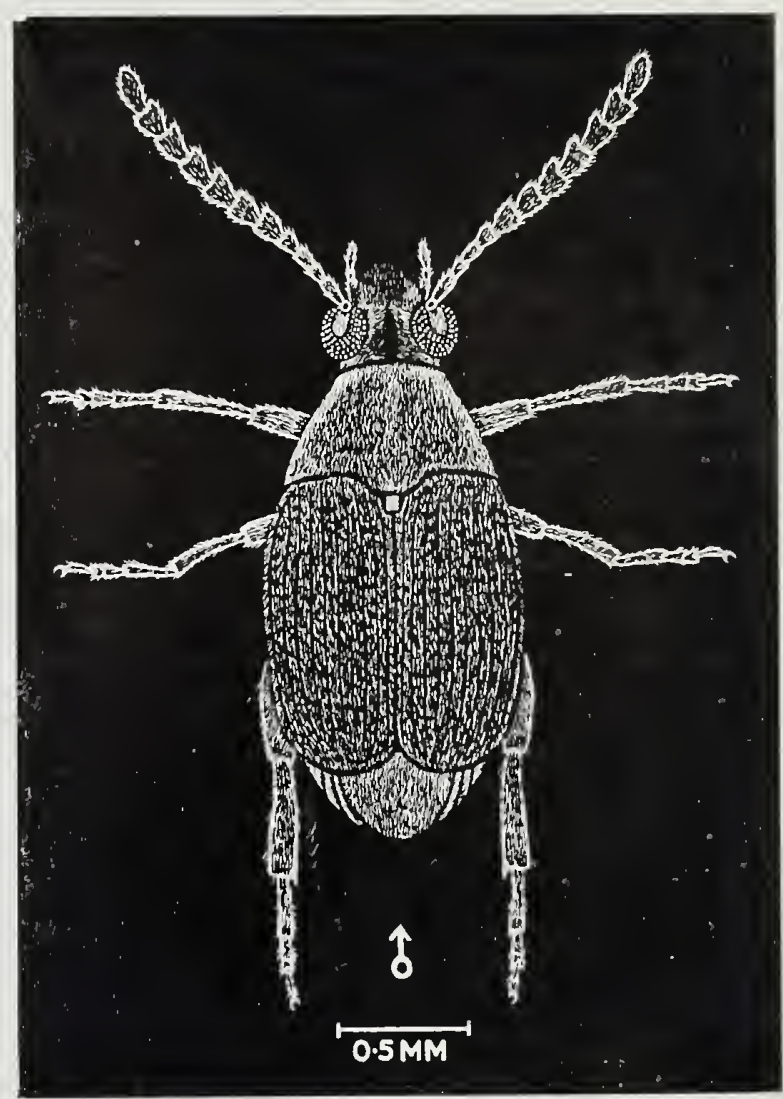

Bruchidius blemeris sp. nov. (Male) 
PHOTO III

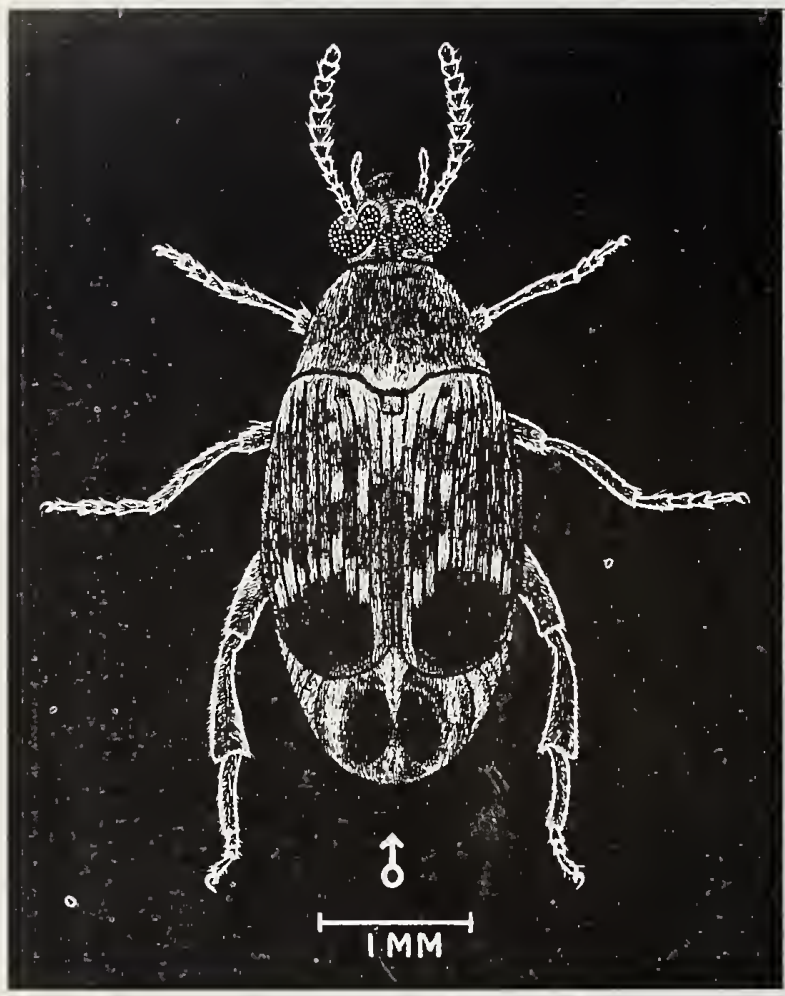

Bruchidius endotubercularis sp. nov. (Male)
PHOTO IV

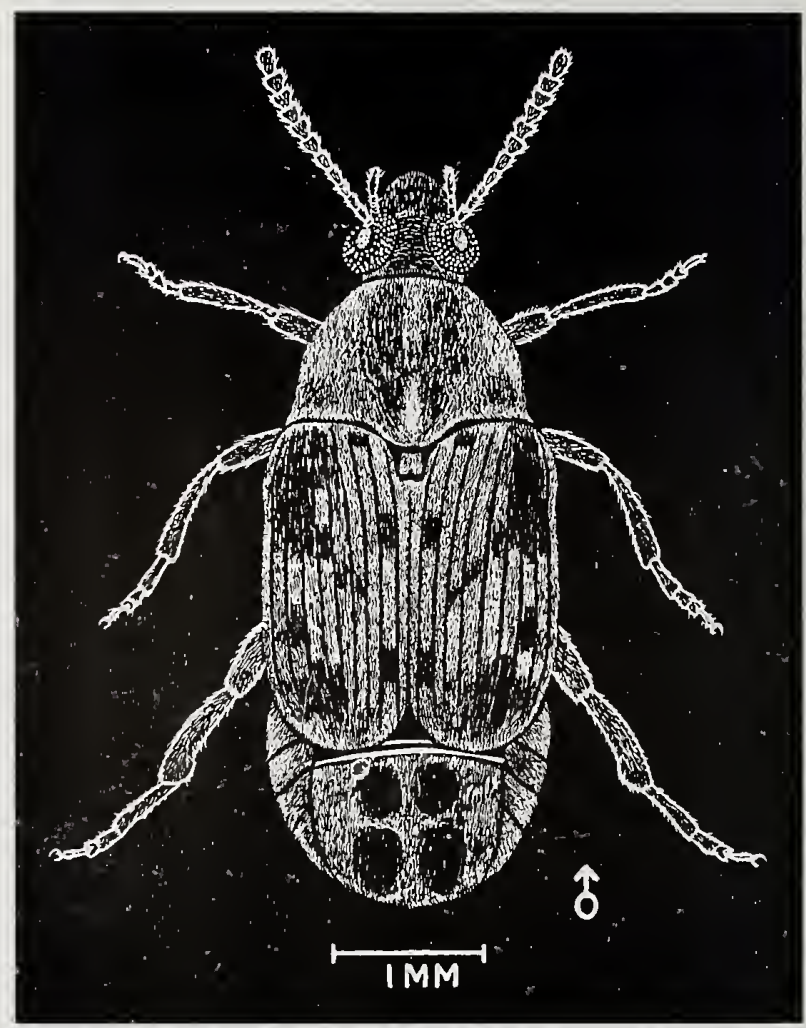

Bruchidius variegata sp. nov."(Male) 
PHOTO V

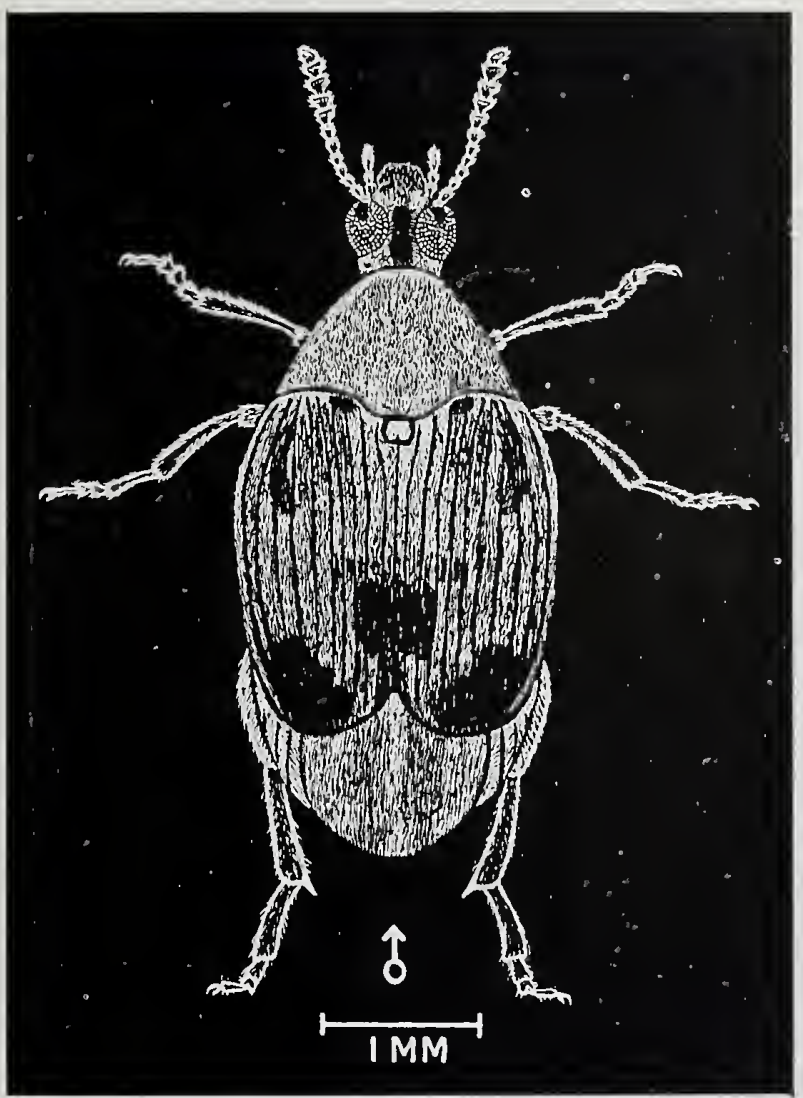

Bruchidius mathaii sp. nov. (Male)
PHOTO VI

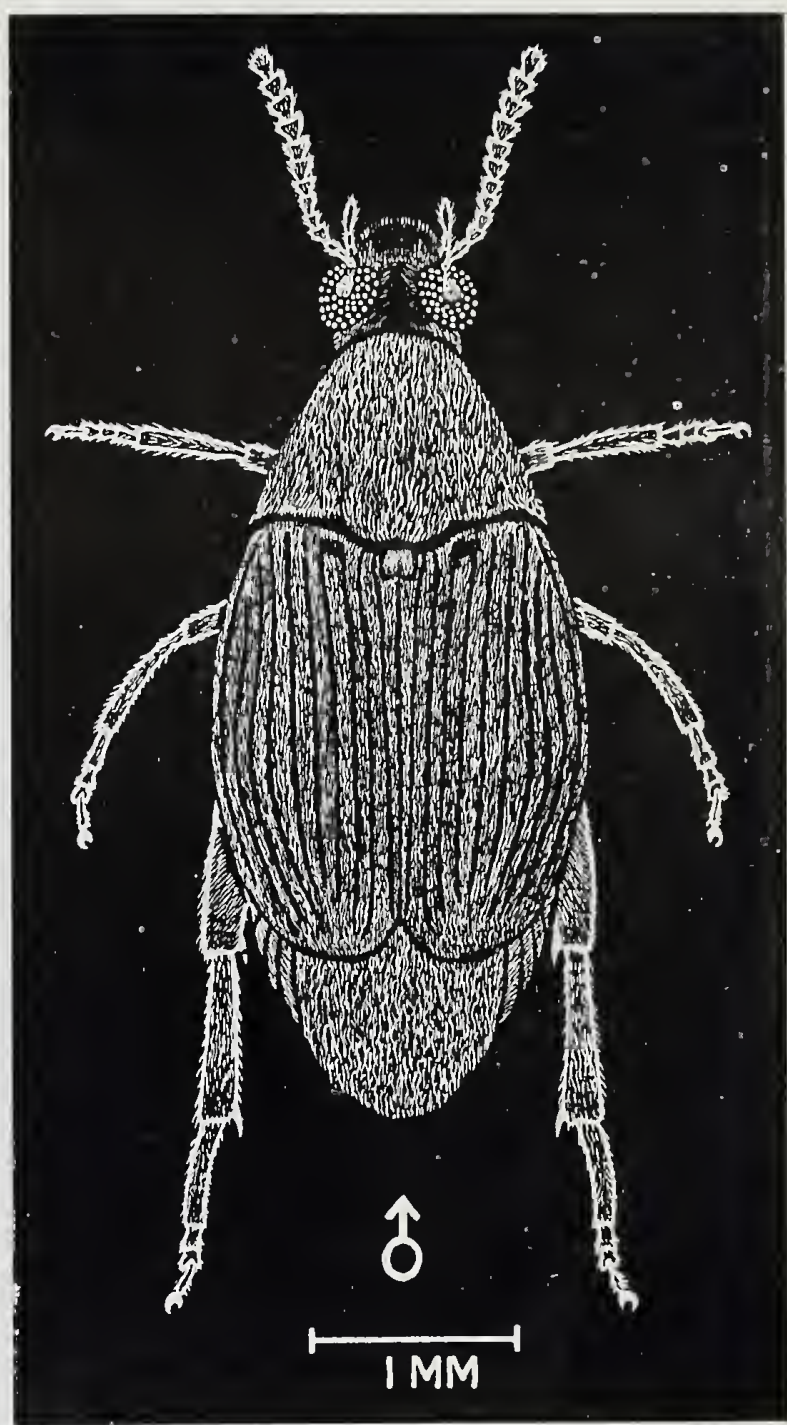

Bruchidius amarae sp. nov. (Male) 
PHOTO VII-A

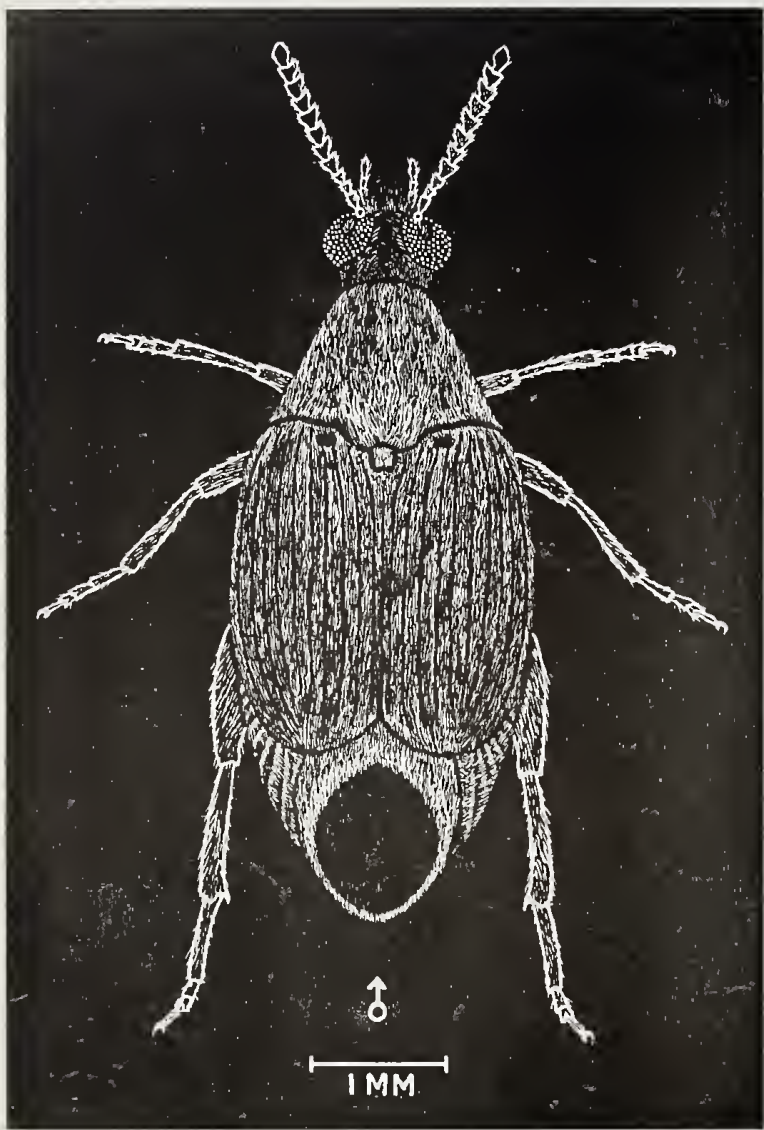

Bruchidius bangalorensis sp. nov. (Male)
PHOTO VII-B

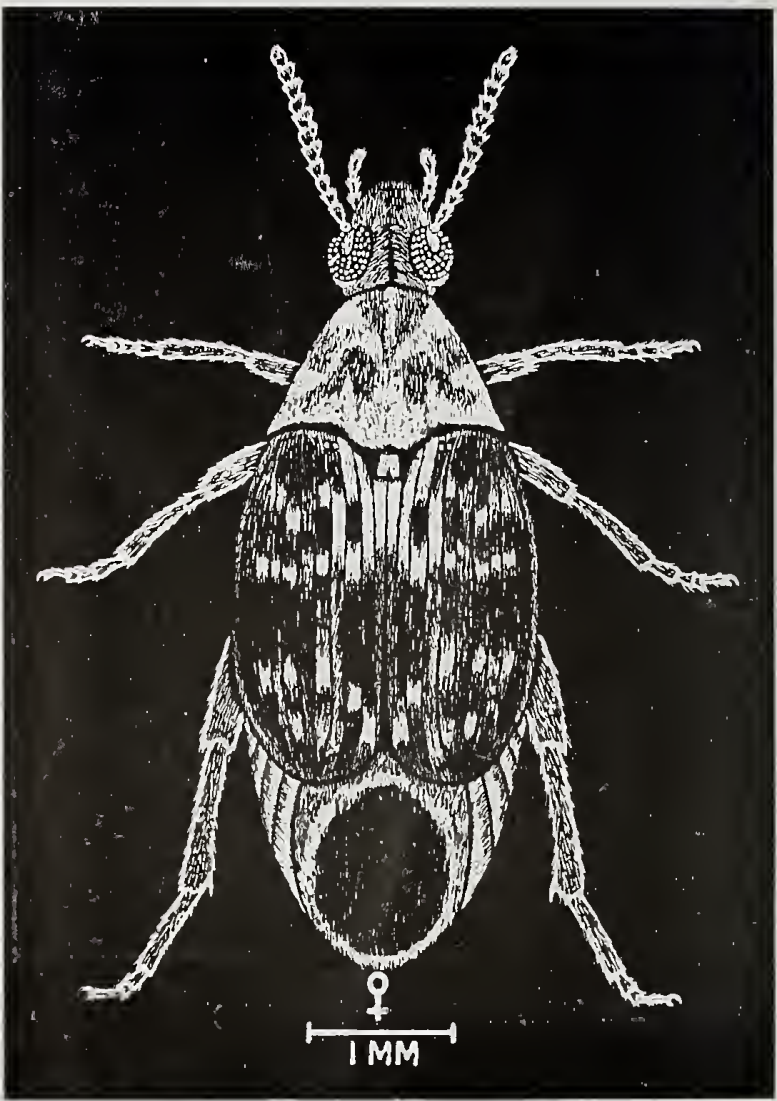

Bruchidius bangalorensis sp. nov. (Female 
PHOTO VIII

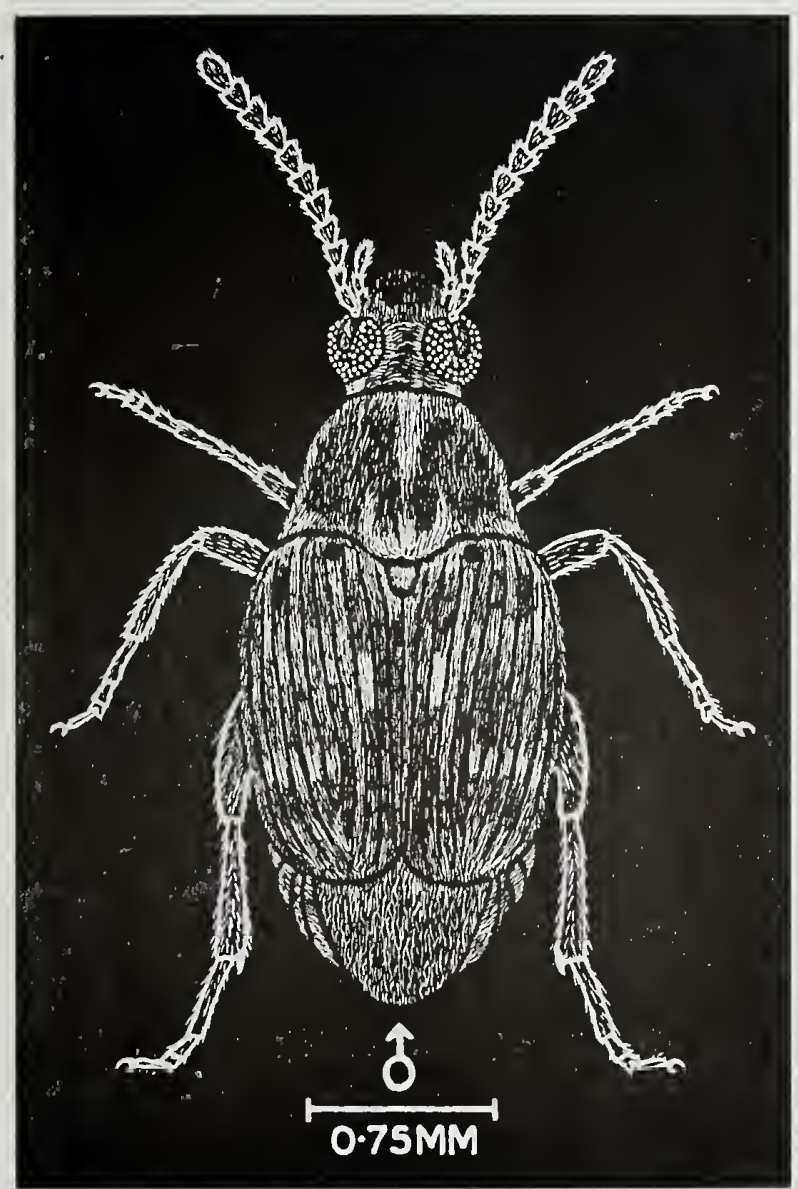

Bruchidius eupatoricus sp. nov. (Male)
PHOTO IX

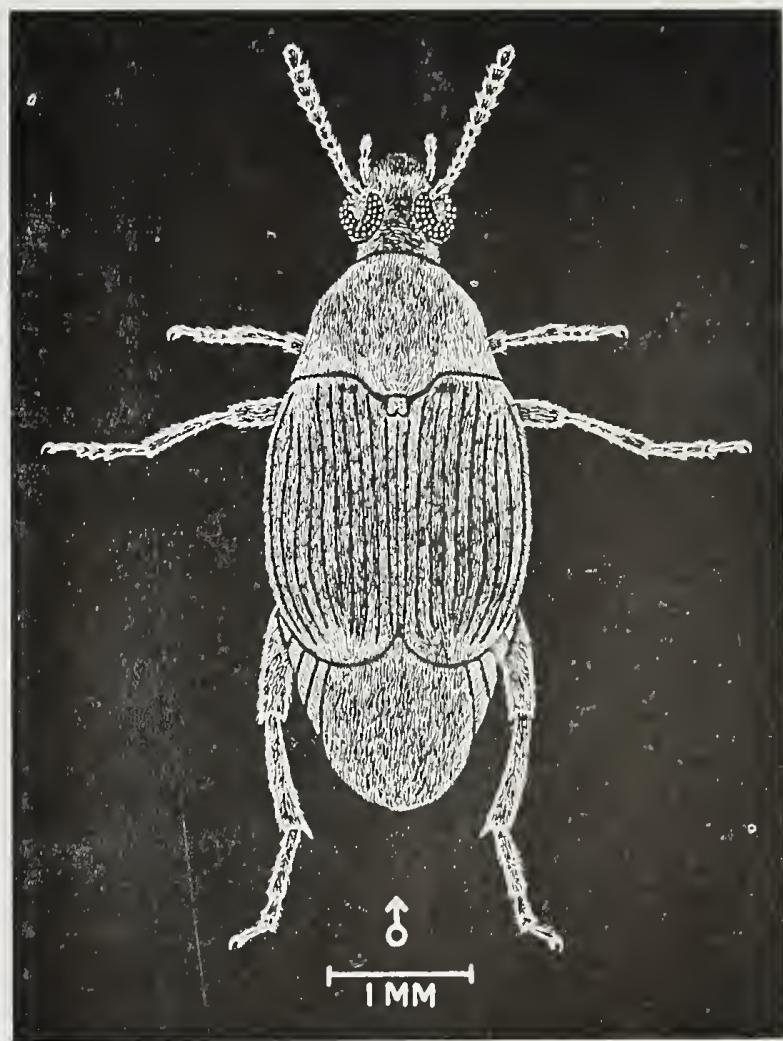

Bruchidius brunnetashii sp. nov. (Male) 


\section{$\therefore$ OTO X}
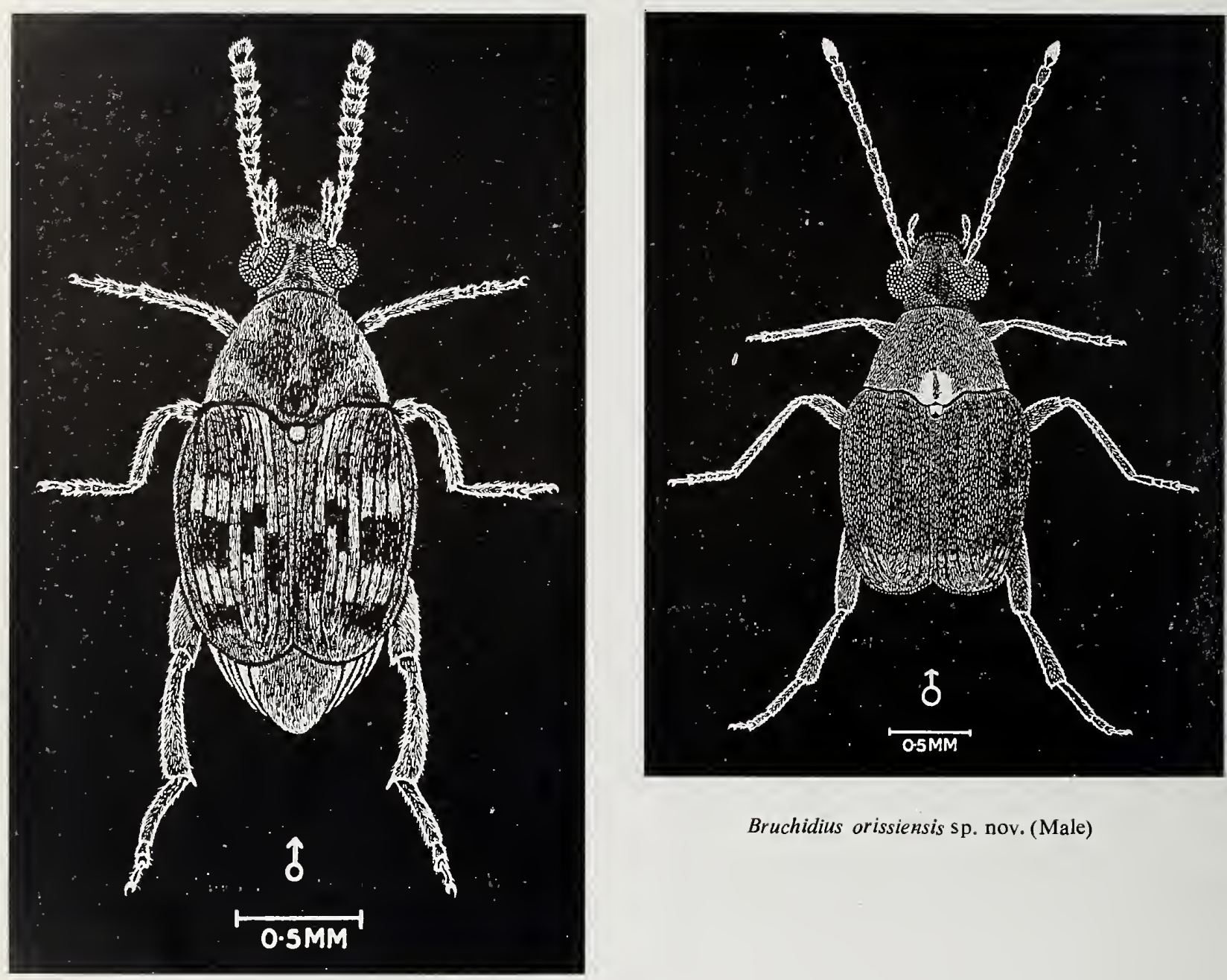

Bruchidius orissiensis sp. nov. (Male)

Bruchidius siwalikus sp. nov. (Male) 
PHOTO XII

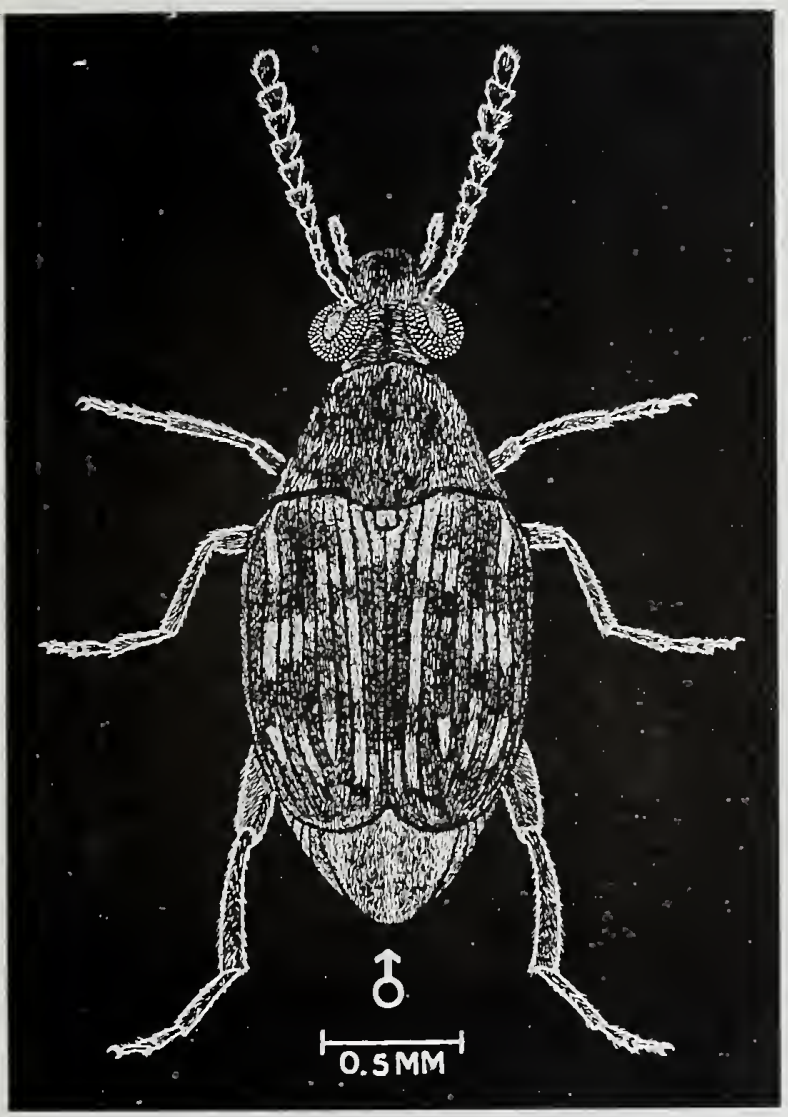

Bruchidius desmodei sp. nov. (Male)
PHOTO XIII-A

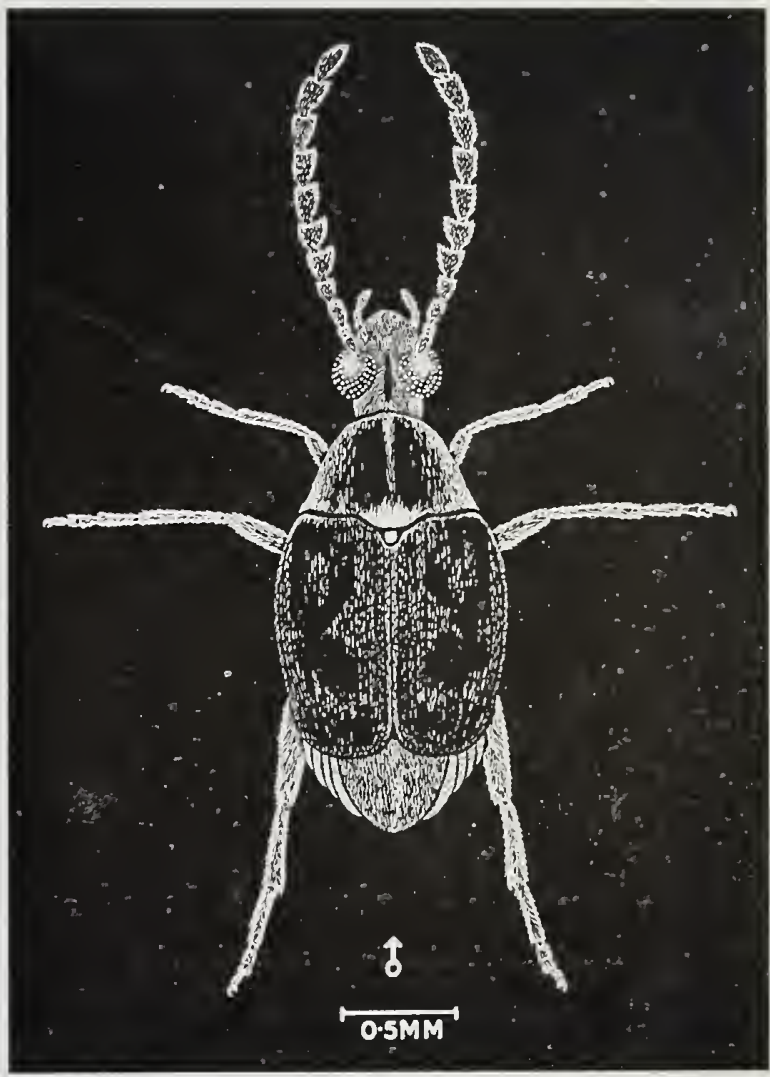

Bruchidius dorsivalvia sp. nov. (Male) 
PHOTO XIII-B

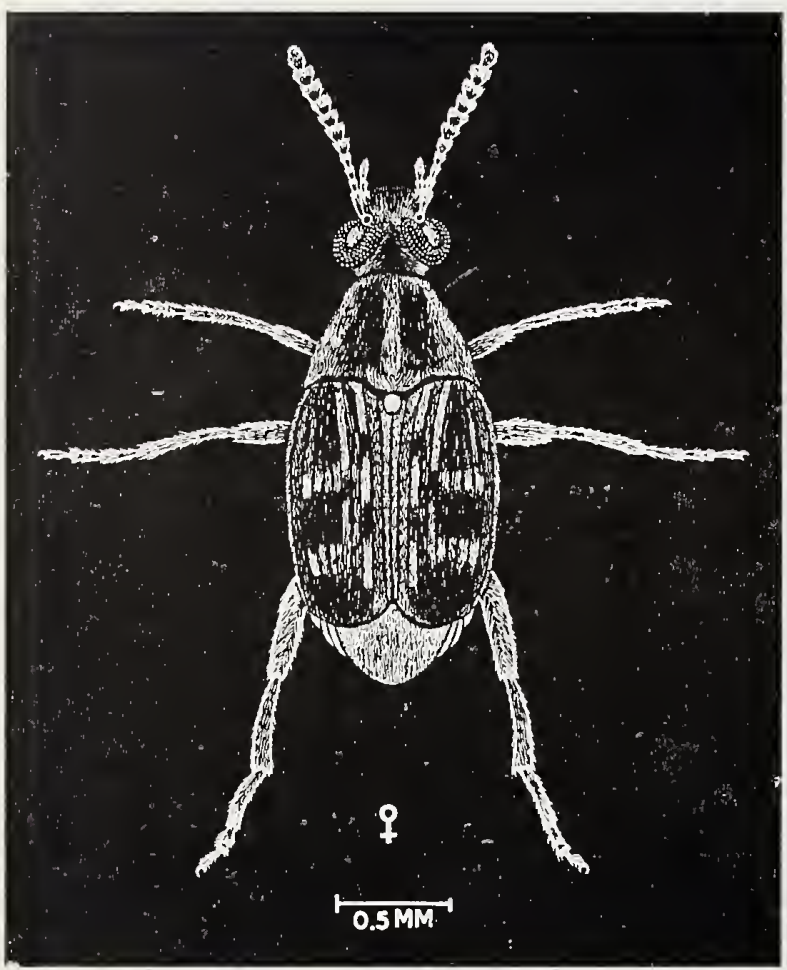

Bruchidius dorsivalvia sp. nov. (Female)
PHOTO XIV

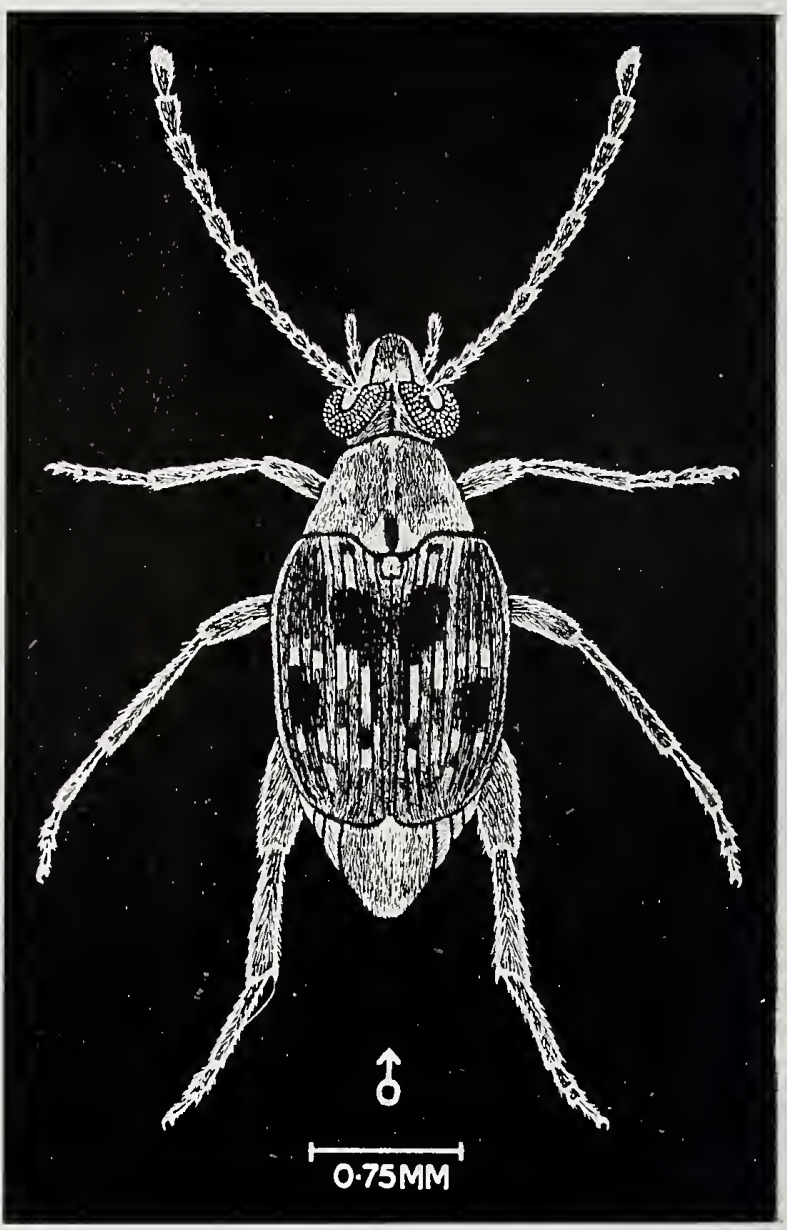

Bruchidius punctoterminalis sp. nov. (Male) 
PHOTO XV

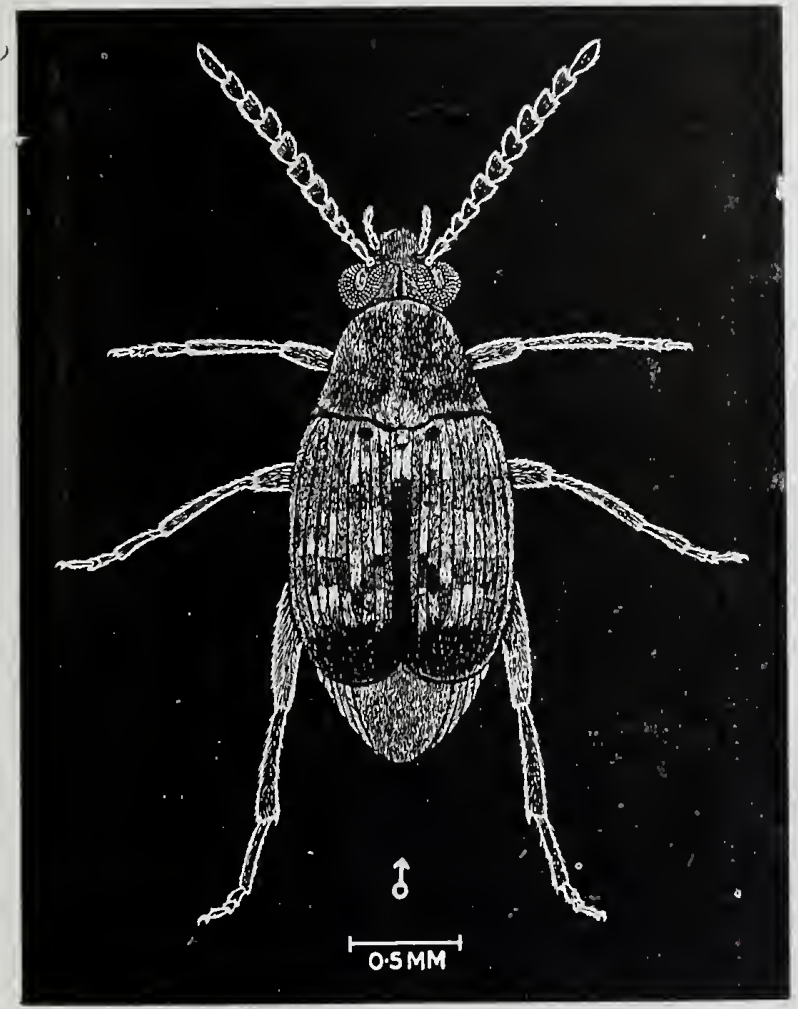

(Bruchidius kashmirensis s 3. nov. (Male)
PHOTO XVI

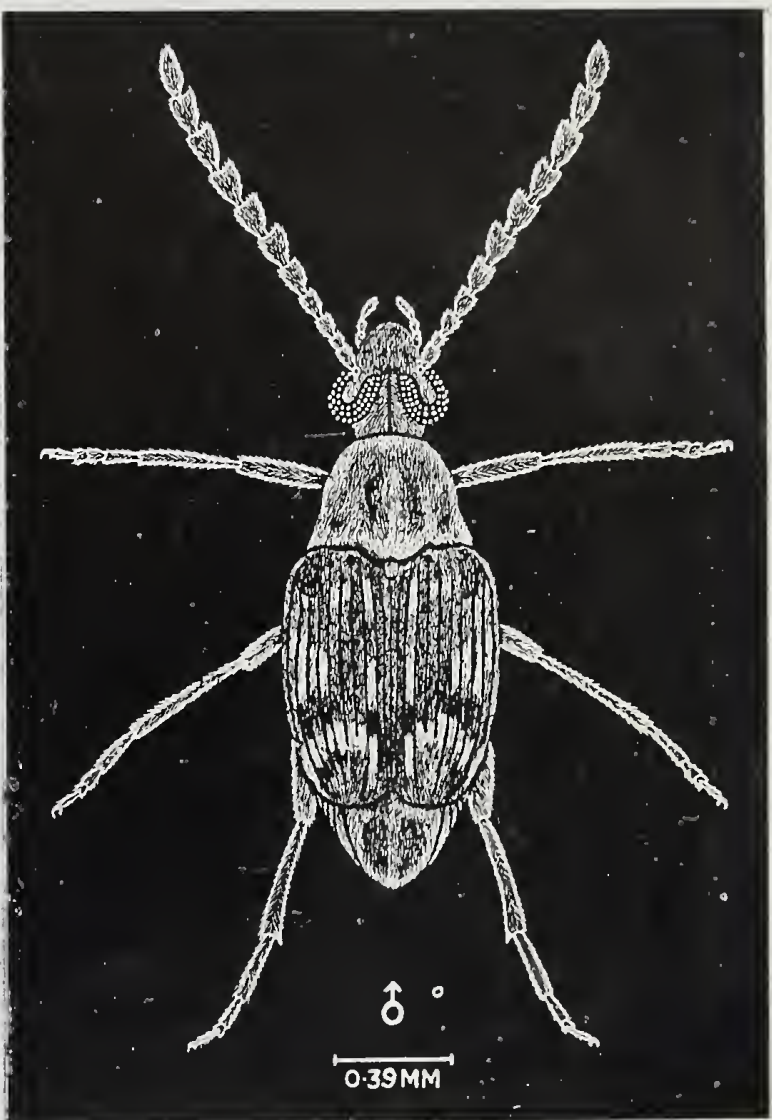

Bruchidius flapoparamerica sp. nov. (Male) 
PHOTO XVII

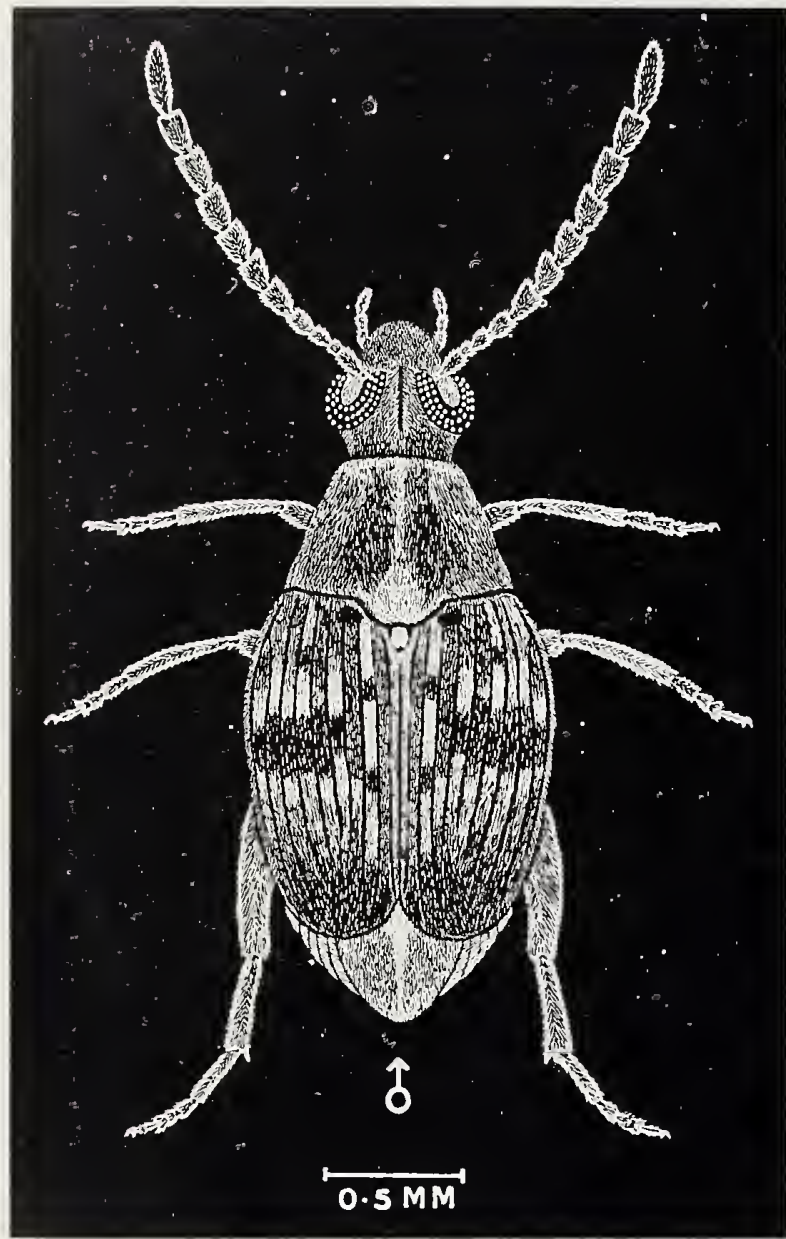

Bruchidius meibomiaca sp. nov. (Male)
PHOTO XVIII

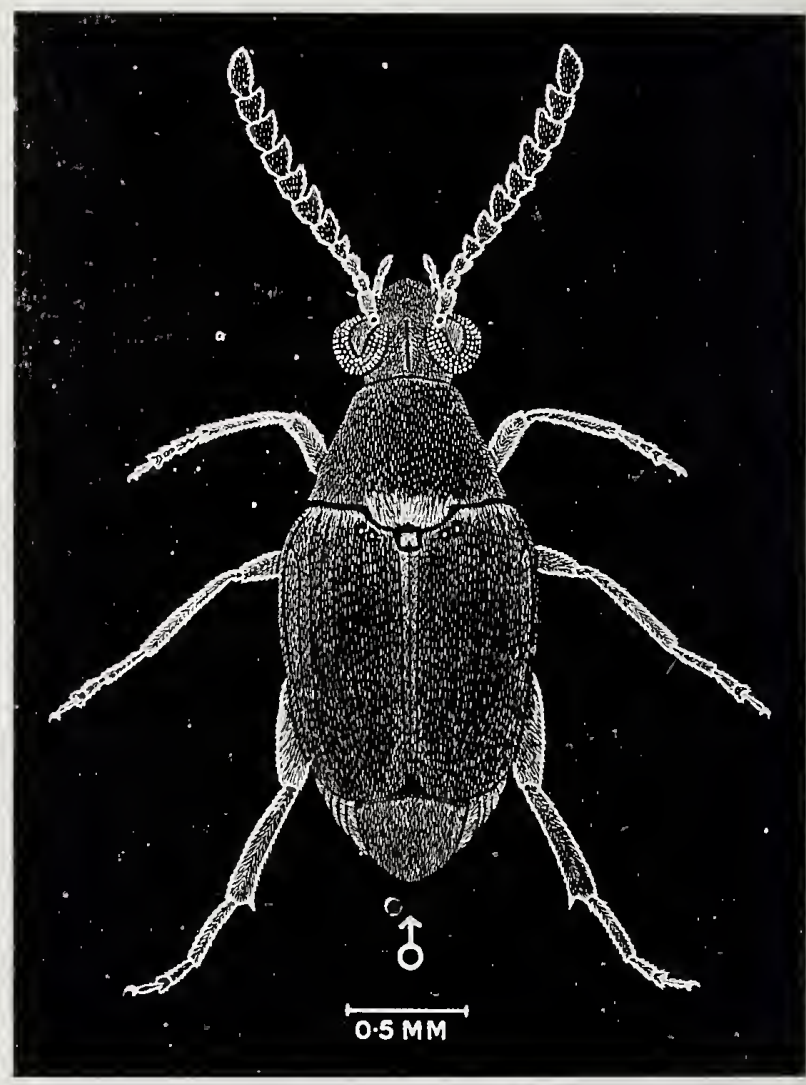

Bruchidius mussooriensis sp. nov. (Male) 
PHOTO XIX

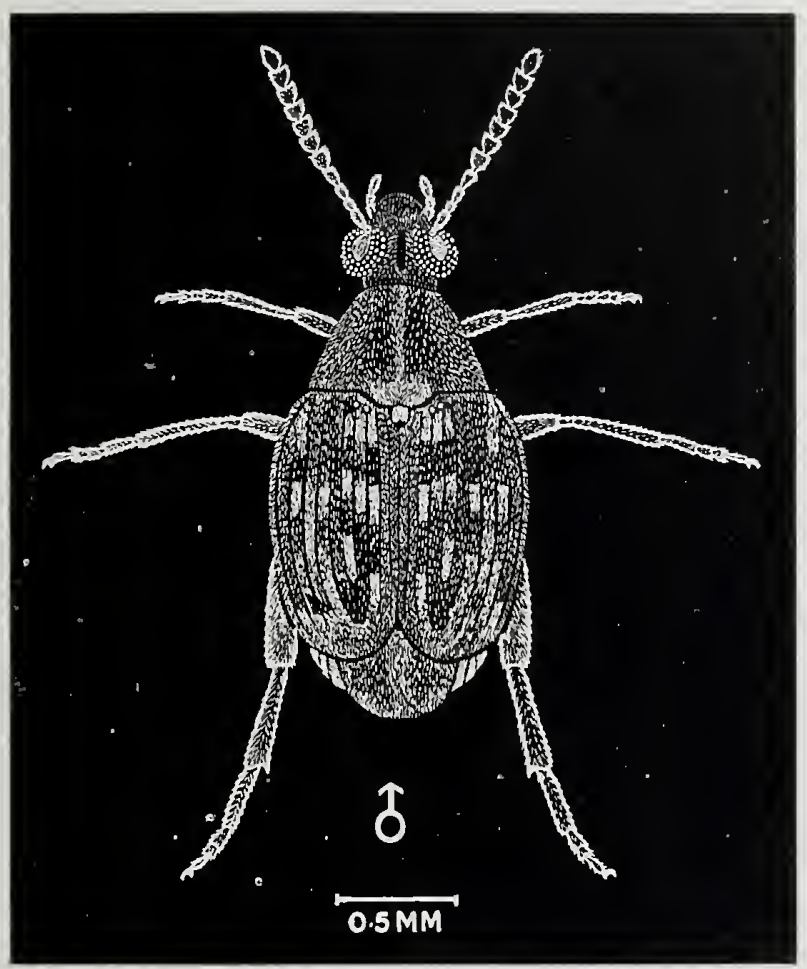

Bruchidius nangalensis sp. nov. (Male)
PHOTO XX

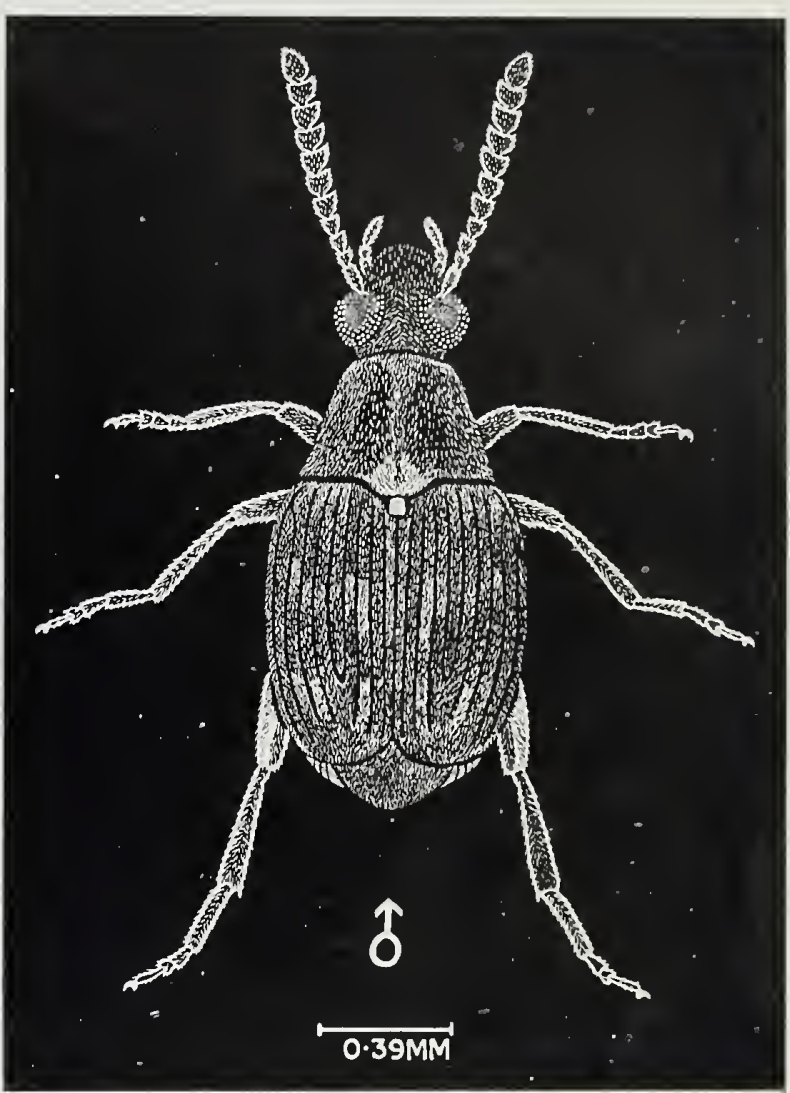

Bruchidius microminutus sp. nov. (Male) 
PHOTO XXI-A

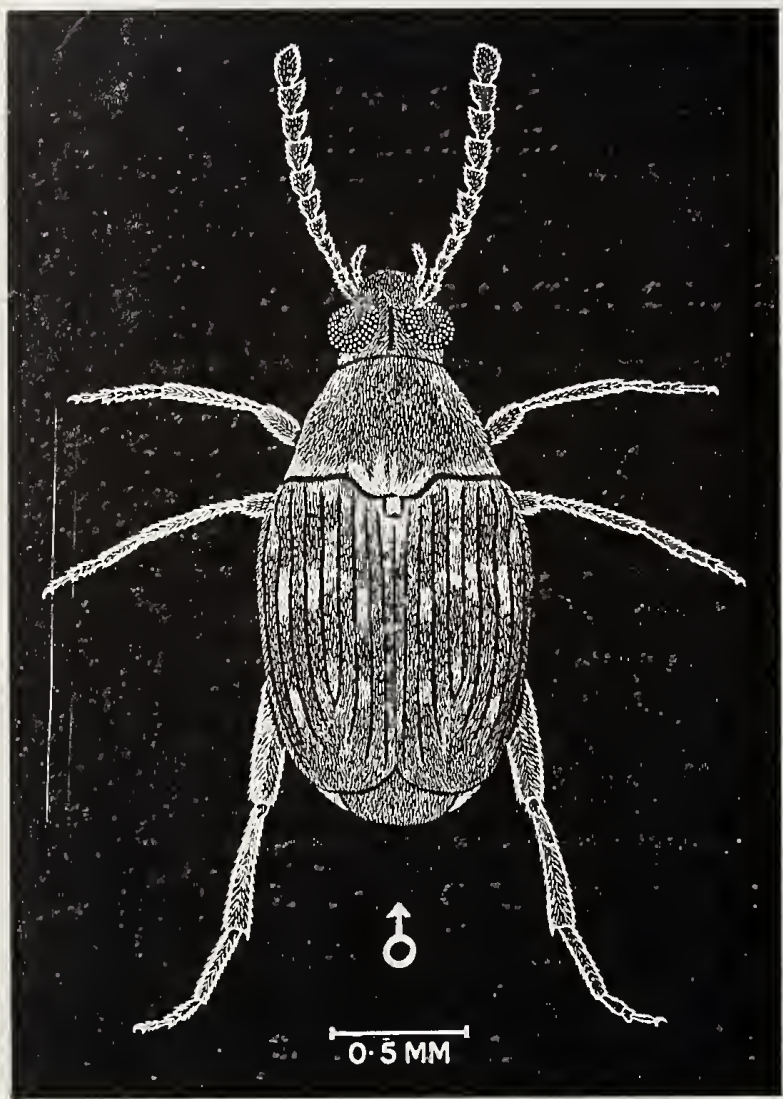

Bruchidius anusurindrii sp. nov. (Male)
PHOTO XXI-B

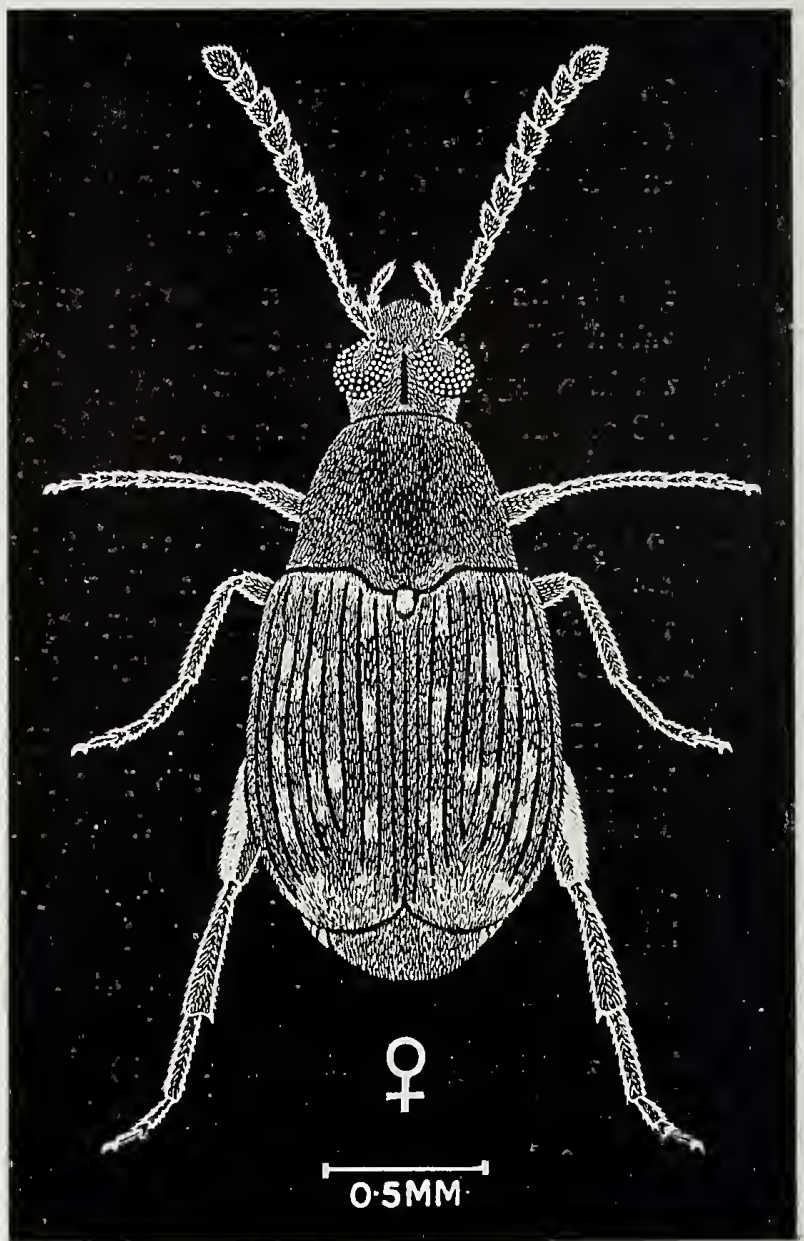

Bruchidius anusurindrii sp. nov. (Female) 


\section{REFERENCES}

Arora, G. L.

Champion, G. C.

El-Kifl, A. H. \&

Metawally, M. M.

Fabricius, J. C.

Gyllenhal, L.

Hafez. Mohmoud, \& Fawzy Hassan Osman

Huignard, J.

Jekel, $\mathrm{H}$.

Pic, M.

Schilsky, J.

Sharp, D.

Shommar, N. E. H.
1977 "Taxonomy of Bruchidae (Coleoptera) of Northwest India, Part I-Adults" Oriental Insects, Suppl. 7, 1977, 1-132.

1919 "Some Indian Coleoptera" Ent. Mon. Mag. $55,244-245$.

1974 "Biological and ecological studies on Bruchidius incarinatus Boh." Bull. Soc. Ent. Egypte, 55; 141-162.

1801 Systema Eleutheratorum, 2, Kiliae, 397403.

1833 In schonh. Gen. Curc. 1; 37-91.

1956 "Biological studies on Bruchidius trifolii (Motsch) and B.alfierii Pic. in Egypt (Coleoptera : Bruchidae)" Bull. Soc. ent. Egypte 40, 231-277.

1975 "Influence of some external stimulations due to mating in Acanthosceledes obtectuscopulation and spermatophores" Ann. Sci. Nat. Zool. Biol. Anim, 16(4); 361-435,

1855 Ins. Saund, 1, 6.

1932 "Nouveaux Bruchidae des Indes" Ann. Mag, Nat. Hist. London, 9 (10); 329-333.

1905 Die Kafer Europas Heft 41, Nurnberg, 100 leaves (Coleoptera).

1886 "On the Bruchidae of Japan." Ann. Nat. Hist. 18(5); 34-38.

1963 "A monographic revision of Bruchidae of Egypt (UAR)" Bul]. Soc. Ent. Egypte, 47; 141-196. 


\section{LIST OF PUBLICATIONS}

1. Arora, G. L., Singal, Shiv K.

2. Arora, G. L., Singal, Shiv K.

3. Arora G. L., Singal, Shiv K.

4. Arora, G. L., Singla, S. R. 1978
1977 Conicobruchus decellei-a new species from Chandigarh (Coleoptera: Bruchidae) Oriental Insects. V ol. II (2), p. 229-31.

1978 "Oryza sativa Linn. (Paddy) a new hostplant record of Caryedon serratus (Olivier) (Coleoptera : Bruchidae) from India". Ind. J. Ent. 40, 1, 1978, 86.

"Incidence and abundance of species of genus Bruchidius (Coleoptera : Bruchidae) from the Southern States of India" Oriental Insects 12(2), p. 205-10.

Observations on the copulation and ovipositional behaviour of Bruchtdius angustifrons Schilsky and B.pygomaculatus Arora (Coleoptera : Bruchidae). Indian Sc. Cong. 1978 (Abstract).

5. Arora, G. L., Singal, Shiv K.

1978 "Incidence \& distribution of the species of genus Bruchidius (Coleoptera : Bruchidae) in the States of Orissa, West Bengal \& Bihar in India" Ind. Sci. Cong. 1978 (Abstract).

6. Arora, G. L.

1977 "Taxonomy of the Bruchidae of NorthWest India "Part I Adults Oriental Insects, Suppl. 7, p. 1-132.

7. Arora, G. L.

1978 "Taxonomy of the Bruchidae of Northwest India" Part II-Larvae Oriental Insects, Suppl. 8, p. 1-48.

8. Arora, G.L.

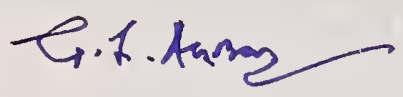

Signatures of Principal Investigator Incharge
Signatures of Chief Executive University Research Institute

PRINTIED BY : Panna Lal Khanna, Manager, Panjab University Press, Chandigarh.

$$
\text { P.U.P. (5632) }-500+8 / 17-4-80
$$


R0000 772291 
R0000 ??2591

NATIONAL AGRICULTURAL LIBRARY

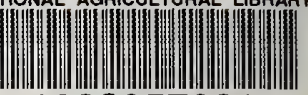

1022857921 